Florida International University FIU Digital Commons

$11-4-2015$

\title{
The Effect of Vitamin D Supplementation on Cardiovascular Risk Factors among Minorities with Type 2 Diabetes
}

Joel Exebio

Florida International University, jexebio@hotmail.com

DOI: $10.25148 /$ etd.FIDC000160

Follow this and additional works at: https:// digitalcommons.fiu.edu/etd

Part of the Dietetics and Clinical Nutrition Commons, Human and Clinical Nutrition Commons, and the International and Community Nutrition Commons

\section{Recommended Citation}

Exebio, Joel, "The Effect of Vitamin D Supplementation on Cardiovascular Risk Factors among Minorities with Type 2 Diabetes" (2015). FIU Electronic Theses and Dissertations. 2266.

https://digitalcommons.fiu.edu/etd/2266 


\section{FLORIDA INTERNATIONAL UNIVERSITY}

Miami, Florida

\section{THE EFFECT OF VITAMIN D SUPPLEMENTATION ON CARDIOVASCULAR}

RISK FACTORS AMONG MINORITIES WITH TYPE 2 DIABETES

A dissertation submitted in partial fulfillment of

the requirements for the degree of

DOCTOR OF PHILOSOPHY

in

DIETETICS AND NUTRITION

by

Joel Exebio

2015 
To: Interim Dean Mark Williams

R. Stempel College of Public Health and Social Work

This dissertation, written by Joel Exebio, and entitled The Effect of Vitamin D Supplementation on Cardiovascular Risk Factors among Minorities with Type 2 Diabetes, having been approved in respect to style and intellectual content, is referred to you for judgment.

We have read this dissertation and recommend that it be approved.

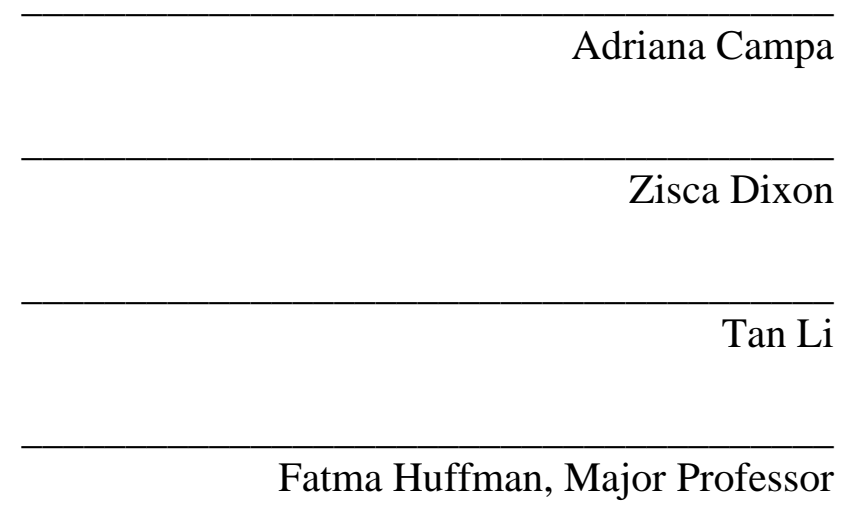

Date of Defense: November 4, 2015

The dissertation of Joel Exebio is approved.

Interim Dean Mark Williams

R. Stempel College of Public Health and Social Work

Dean Lakshmi N. Reddi

University Graduate School

Florida International University, 2015 


\section{DEDICATION}

I dedicate this dissertation to my parents, Cristobal and Isolina. Without their

support, love, sacrifices, and motivation, the completion of this work would not have been possible. 


\section{ACKNOWLEDGMENTS}

I would like to thank my dissertation committee members for their continue support and guidance during the preparation of this research and dissertation. Dr. Adriana Campa for her valuable comments and suggestions, Dr. Zisca Dixon for all her words of encouragement and suggestions, and Dr Tan Li for his expert statistical advice. I would like to thank my major professor Dr. Fatma Huffman. From the beginning of my tenure at FIU she was a role model, not only in the academic field, but also on a personal level. I also would like to thank MBRS program staff for financial support and guidance. 
ABSTRACT OF THE DISSERTATION

THE EFFECT OF VITAMIN D SUPPLEMENTATION ON CARDIOVASCULAR

RISK FACTORS AMONG MINORITIES WITH TYPE 2 DIABETES

\author{
by \\ Joel Exebio \\ Florida International University, 2015 \\ Miami, Florida \\ Professor Fatma Huffman, Major Professor
}

The aim of the present study was to determine the effect of vitamin D supplementation (4000 IU or $6000 \mathrm{IU}$ of cholecalciferol daily for 6 months) on fasting plasma glucose, fasting insulin, glycated hemoglobin, and lipid profile in a sample of African-Americans and Hispanics with T2D and vitamin D insufficiency. Seventy five participants were recruited by community outreach. Plasma glucose concentration was measured by hexokinase enzymatic method. Glycated hemoglobin was measured by the DCA2000+ system. Insulin in fasting blood was determined by radioimmunoassay. Plasma total cholesterol, triglycerides, low-density lipoprotein, and high-density lipoprotein cholesterol were assayed by enzymatic methods. Serum vitamin D concentrations were measured with an enzyme-immunoassay kit. Mixed model was used to compare treatment effects and Bonferroni multiple comparison tests was used to detect significant changes from baseline, 3 months, and 6 months on the outcome variables. Significant improvements in serum 25(OH)D levels were seen from baseline to 3 month and 6 months respectively in both treatments (from $22.25 \pm 7.19$ to $37.34 \pm 12.31$ and $37.99 \pm$ 13.22, $P<0.05$ in the 4000 IU group; from $23.74 \pm 5.09$ to $43.20 \pm 15.94$ and $40.62 \pm$ 
19.39, $P<0.05$ in the $6000 \mathrm{IU}$ group). No significant changes were observed for fasting plasma glucose, insulin or A1C between groups and within groups. A significant decrease in total cholesterol for the $6000 \mathrm{IU}$ group at 6 months (from $193.88 \pm 41.03$ to $183.48 \pm$ $47.53 \mathrm{mg} / \mathrm{dl}, \quad P=0.040$ ) was observed. Similarly, a significant change in serum triglycerides was observed at 6 months in the 6000 IU group (from $201.44 \pm 91.35$ to $172.92 \pm 76.87 \mathrm{mg} / \mathrm{dl}, \quad P=0.037)$. However, when the model was adjusted for confounders, significance was lost. Vitamin D supplementation did not improve glucose homeostasis in this sample. The positive effect of vitamin D supplementation on lipid profile may be mediated by other cofactors related to vitamin D metabolism. 


\section{TABLE OF CONTENTS}

CHAPTER

PAGE

CHAPTER I: INTRODUCTION ................................................................................

Type 2 Diabetes in the US Population and Mechanism of Action .........................1

Vitamin D in the US and Mechanism of Action...............................................2

Type 2 Diabetes and Vitamin D......................................................................

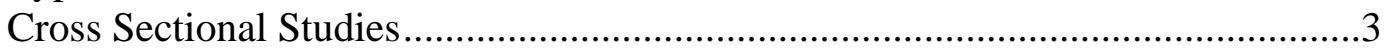

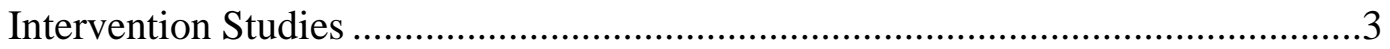

Type 2 Diabetes, Cardiovascular Disease and Vitamin D ...................................6

Vitamin D Repletion in Participants with Type 2 Diabetes...................................

Factors that Affect Vitamin D Insufficiency .....................................................8

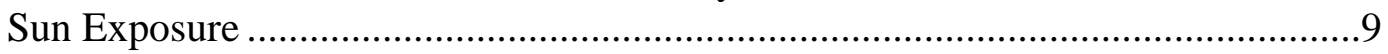

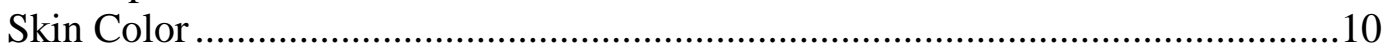

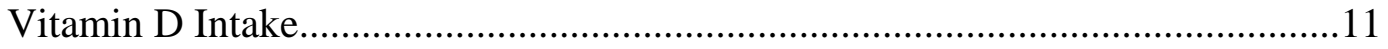

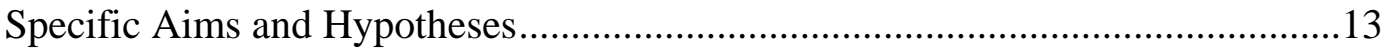

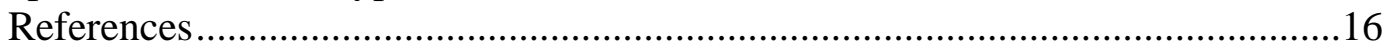

CHAPTER II: THE EFFECT OF VITAMIN D SUPPLEMENTATION ON BLOOD

LIPIDS IN MINORITIES WITH TYPE 2 DIABETES ..............................................22

CHAPTER III: THE EFFECT OF VITAMIN D SUPPLEMENTATION ON

GLUCOSE HOMEOSTASIS IN MINORITIES WITH TYPE 2 DIABETES ................40

CHAPTER IV: VITAMIN D REPLETION IN MINORITIES WITH TYPE 2

DIABETES AND COEXISTENT VITAMIN D INSUFFICIENCY .............................59

CHAPTER V: VALIDATION OF A SUN EXPOSURE QUESTIONNAIRE IN

PARTICIPANTS WITH TYPE 2 DIABETES RESIDING IN SOUTH FLORIDA ........76

CHAPTER VI: VALIDATION OF A SHORT FOOD FREQUENCY

QUESTIONNAIRE FOR THE ASSESSMENT OF VITAMIN D INTAKE IN

MINORITIES WITH TYPE 2 DIABETES.............................................................92

CHAPTER VII: SUMMARY AND CONCLUSIONS ............................................111

CHAPTER VIII: STRENGTHS AND LIMITATIONS ...........................................114

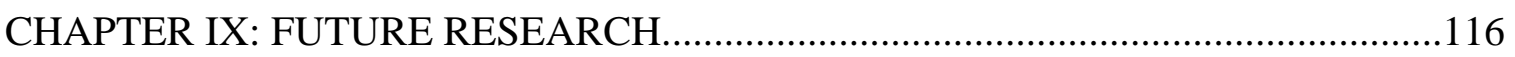

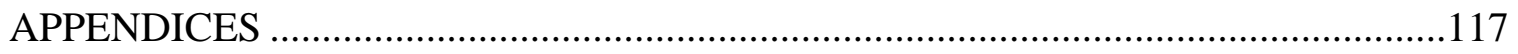

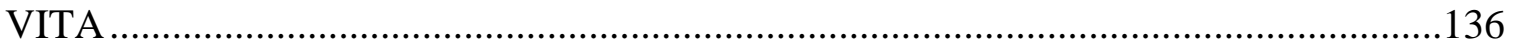




\section{LIST OF TABLES}

TABLE

PAGE

\section{CHAPTER II}

1. Baseline characteristics of participants prior to vitamin D repletion treatments...35

2. Group comparisons of metabolic parameters at different time points without adjusting for covariates..................................................

3. Group comparisons of metabolic parameters at different time points adjusting for covariates.

\section{CHAPTER III}

1. Baseline characteristics of participants prior to vitamin D repletion treatments...53

2. Group comparisons of metabolic parameters at different time points without adjusting for covariates............................................. 54

3. Group comparisons of metabolic parameters at different time points adjusting

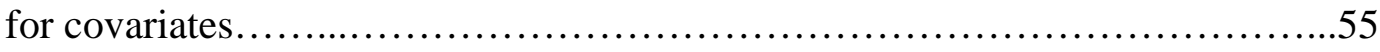

\section{CHAPTER IV}

1. Baseline characteristics of participants prior to vitamin D repletion treatments...71

2. Effect of vitamin D repletion treatments on serum vitamin D and parathyroid

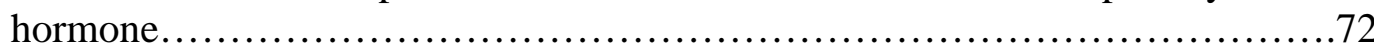

3. Relationship between change in parathyroid hormone, change in serum $25(\mathrm{OH}) \mathrm{D}$, and covariates at 3 months for the 4000 IU treatment.

4. Relationship between change in parathyroid hormone, change in serum $25(\mathrm{OH}) \mathrm{D}$, and covariates at 6 months for the $4000 \mathrm{IU}$ treatment.

\section{CHAPTER V}

1. Characteristics of the study participants at screening $(n=90) \ldots \ldots \ldots \ldots \ldots \ldots \ldots . \ldots 8$

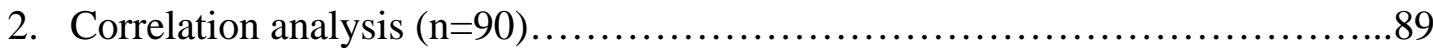

3. Relationship of serum $25(\mathrm{OH}) \mathrm{D}$ and covariates.......................... 89 


\section{CHAPTER VI}

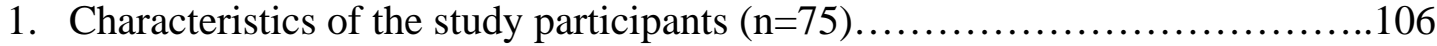

2. Dietary vitamin D intake derived from the long FFQ and short FFQ, and correlation between methods.............................................107

3. Cross-classification analysis to determine proportion of participants classified into the same, or same \pm 1quartile based on short FFQ and long FFQ intakes...107

4. Relationship of serum 25(OH)D, dietary vitamin D intake, and covariates......108 


\section{ABBREVIATIONS AND ACRONYMS}

T2D

Type 2 Diabetes

US United States

A1C Glycated Hemoglobin

NHANES National Health and Nutrition Examination Survey

$25(\mathrm{OH}) \mathrm{D} \quad$ Serum Vitamin D

VDR Vitamin D Receptor

IR Insulin Resistance

CVD Cardiovascular Disease

LDL Low Density Lipoprotein

UVB Ultra Violet B

FFQ Food Frequency Questionnaires

HIV Human Immunodeficiency Virus

IRB Institutional Review Board

FIU Florida International University

PTH Parathyroid Hormone

HDL High Density Lipoprotein

RPM Revolutions Per Minute

BMI Body Mass Index

SFFQ Short Food Frequency Questionnaire

RDA Recommended Dietary Allowance

FPG Fasting Plasma Glucose

VLDL Very Low Density Lipoprotein 


\section{CHAPTER I: INTRODUCTION}

\section{Type 2 Diabetes in the US Population and Mechanism of Action}

Type 2 diabetes (T2D), the most common form of diabetes (90-95\% of all cases) has increased dramatically in the United States (US) among adults 20 years of age and older from 9\% in 1988 to 12.3\% in 2012. Minorities, particularly African Americans and Hispanics, are disproportionately afflicted by T2D compared to non-Hispanics Whites. For instance, while the age-adjusted incidence of T2D in non-Hispanics Whites was 7.6\% in 2012, it was $13.2 \%$ for non-Hispanic blacks and $12.8 \%$ for Hispanics (1).

The food that we eat is digested and absorbed in the gastrointestinal tract. Glucose is one of the main byproducts of the digestive process. Glucose is transported in the blood to different organs where it is used as the main fuel source for cell functioning. Insulin produced by the beta cells of the pancreas is needed to activate the transporters and receptors that let glucose enter the cells. Type 2 diabetes is characterized by the diminished capacity of the beta cells to produce sufficient insulin and by the reduction in number of beta cells (2).

Many genetic and life style factors are associated with the onset of T2D. For instance, some individuals may have a decreased number of beta cells early in life predisposing them to the development of T2D. Smoking, obesity, lack of physical activity, a high calorie diet, stress, and other genetic and environmental factors lead to dyslipidemia, increased circulating leptin and cytokine levels which have a negative effect on beta cell function (2). 
Monitoring diabetes outcomes (fasting blood glucose, insulin and glycated hemoglobin (A1C) and cardiovascular disease risk factors (dyslipidaemia, obesity, and inflammation) is important for persons with diabetes. Poor diabetes outcomes can lead to complication such as heart disease, stroke, high blood pressure, blindness, kidney disease and nervous system disorders.

\section{Vitamin D in the US and Mechanism of Action}

Low levels of vitamin D are prevalent in the US. According to data from the National Health and Nutrition Examination Surveys (NHANES) in 2001-2006, 33\% of the general US population had serum 25(OH)D below $50 \mathrm{nmol} / \mathrm{L}$. In addition, low vitamin D levels are common among minorities. For instance, 41\% of African Americans and 33\% of Mexican Americans had serum 25(OH)D below $50 \mathrm{nmol} / \mathrm{L}$ compared to 18\% of non-Hispanic Whites (3).

Humans produce vitamin D in the skin by the action of ultraviolet light. Vitamin D can also be obtained from the diet from plant and animal sources. The plant form is vitamin $\mathrm{D}_{2}$ (ergocalciferol) and the animal form is vitamin $\mathrm{D}_{3}$ (cholecalciferol). Vitamin $\mathrm{D}_{3}$ needs to be activated by hydroxylation in the liver and kidney to form its metabolically active form: $1,25(\mathrm{OH})_{2} \mathrm{D}_{3}$. This metabolite produces some of its effects by activating the vitamin D receptor (VDR) in the cells (4).

With respect to diabetes, the VDRs have been found in pancreatic tissue (exclusively in the insulin-producing beta cells). Activated Vitamin $\mathrm{D}\left(1,25(\mathrm{OH})_{2} \mathrm{D}_{3}\right)$ binds to the VDR in the beta cells and modulates the transcription of genes signaling the production of insulin and other proteins important for beta cell function. Different VDR 
gene variances are present in different ethnicities and may predispose to the development of type 2 diabetes (5). These variances may explain, in part, the high incidence of type 2 diabetes among African Americans and Hispanic.

\section{Type 2 Diabetes and Vitamin D}

\section{Cross Sectional Studies}

Several associations between low vitamin D levels and incidence of metabolic disorders have been reported in recent years. For instance, poor vitamin D status has been found in persons at risk or with T2D, however, the nature of this relationship is not clear $(6,7)$. Similarly, a negative association between vitamin D levels and insulin resistance has been reported in a large sample representative of the US adult population and in participants at risk for T2D $(7,8)$. According to these results vitamin D levels are associated with insulin sensitivity and insulin resistance. The mechanism of action of vitamin D is not clear because most studies to date have been conducted in patients without diabetes.

\section{Intervention Studies}

Vitamin D supplementation in participants without diabetes had a positive effect on insulin secretion and insulin resistance (9). Similar results have been found in vitamin D deficient animals (10). Since patients with T2D not only have a high prevalence of vitamin D deficiency, but also, other cardiovascular risk factors that may interact with vitamin D homeostasis, it is difficult to extrapolate results from patients without diabetes. 
This scenario has increased the interest in the role that vitamin D may play in glucose homeostasis among patients with T2D, which includes insulin resistance and glycemic control. In fact, several interventional studies providing vitamin D to participants at risk or with T2D have been conducted that have found inconsistent results (11-15). Borissova et al (11) examined the effect of vitamin $\mathrm{D}_{3}$ supplementation on insulin resistance and insulin secretion in 10 patients with T2D. Seventeen age and gender-matched individuals without T2D served as controls. The intervention group received 1332 IU of cholecalciferol daily for 1 month. Fasting plasma insulin secretion increased significantly by 34.3\%, however, the decrease in insulin resistance was not significant. A small sample size and short duration of treatment are the major limitations of this study. In another study, however, vitamin D supplementation in men with T2D improved insulin secretion $(12,13)$. Inomata et al. (12) provided $2 u \mathrm{~g} / \mathrm{d}$ (80 IU/day) of alphacalcidiol versus placebo to 14 Japanese males with T2D, mean age 54.3 years for 3 weeks. The area under the oral glucose tolerance test curve was used as a measure of insulin secretion. Results showed improved insulin secretion. Limitations of this study are the lack of measure of plasma vitamin D concentrations and the small sample size. Similarly, Orwoll et al. (13) provided 1ug/d (40 IU/d) of 1,25(OH) 2 D versus placebo to 35 adults with recently diagnosed T2D (within 3 years) for 14 days, with mean age of 61 years. Insulin secretion was determined from the area under the glucose tolerance test after a meal challenge. A tendency for better insulin secretion was observed. Main limitations of this study were the short duration of the intervention and the lack of assessment of serum vitamin D post-intervention. Persons with T2D and low serum 25(OH)D had improvements in glycemic control with 3000 IU of vitamin $\mathrm{D}_{3}$ for 6 and 9 
months (14). In contrast, Jorde et al. (15) provided 40000 IU per week versus placebo to 32 participants with T2D for 6 months. No significant change on insulin, fasting plasma glucose or A1C was noted. Participants in this study were not vitamin D deficient, suggesting that vitamin D supplementation may have no effect on people who are not vitamin D deficient. Conflicting reports may be a consequence of different characteristics of the populations, inadequate dosages, different forms of vitamin D supplements used, short duration of the studies, different outcome variables, and lack of control of serum vitamin D levels pre and post intervention.

The vast majority of these studies have been conducted in non-Hispanic White populations. Prevalence of hypovitaminosis D however, is found to be higher in Blacks and Hispanics as compared to Whites (16-18). According to data from the Center for Disease Control and Prevention, 20\% of Mexican Americans and 46\% of African Americans had blood vitamin D levels lower than non-Hispanic Whites across age categories (19). Vitamin D levels decrease with increasing age. While vitamin D levels fall $1.6 \%$ from $60 \mathrm{nmol} / \mathrm{L}$ to $59 \mathrm{nmol} / \mathrm{L}$ for ages $6-59$ years for non-Hispanic Whites, it falls 34.7\% from $46 \mathrm{nmol} / \mathrm{L}$ to $30 \mathrm{nmol} / \mathrm{L}$ for African Americans and 20\% from 56 $\mathrm{nmol} / \mathrm{L}$ to $45 \mathrm{nmol} / \mathrm{L}$ for Mexican Americans in the same age range (19). While T2D is a multifactorial disease, evidence from observational studies and small clinical trials indicate possible improvements of T2D symptoms with vitamin D supplementation. Since minorities such as African Americans and Hispanics have higher risk of both T2D and vitamin D deficiency as compared to Caucasians (20), it is important to determine the effect of vitamin D supplementation in these high risk populations. 


\section{Type 2 Diabetes, Cardiovascular Disease and Vitamin D}

The literature indicates that patients with T2D and insulin resistance (IR) are more likely to develop arteriosclerosis and all of the complications related to this condition, such as myocardial infarction and stroke (21). In fact, vitamin D receptors are present in many cardio vascular target organs regulating cell differentiation, proliferation and function (22). Although patients with T2D usually have other risk factors for arteriosclerosis, associations among vitamin D levels and several risk factors for cardiovascular disease (CVD) have been documented. Martins et al. (23) demonstrated a strong association between hypovitaminosis $\mathrm{D}$ and cardio-vascular outcomes in a sample of 13,000 US adults using data from the Third National Health and Nutrition Examination Survey. After controlling for confounders, the prevalence of hypertension $(\mathrm{OR}=1.30)$, T2D $(\mathrm{OR}=1.98)$, obesity $(\mathrm{OR}=2.29)$, and high triglyceride levels $(\mathrm{OR}=1.47)$ was significantly higher in the first quartile compared to the fourth quartile of serum 25(OH)D levels $(P<0.001$ for all) demonstrating a high likelihood of association between vitamin D levels and several cardio vascular risk factors.

Similarly, Skaaby et al. (24), conducted a large prospective evaluation of serum vitamin D levels and blood lipids. They found a strong association between lower 25(OH)D level and elevated total cholesterol. The changes in lipid profile associated with a variation in vitamin D status, however, were small and without clinical significance. In addition, since obesity and ethnicity are risk factors for both vitamin D insufficiency and dyslipidemia, other confounding variables that may affect this relationship should not be excluded. 
Randomized clinical trials evaluating the effects of vitamin D repletion on lipid profile have reported conflicting results (25-27). Ponda et al. (25), assigned 151 vitamin D deficient adults at high risk of CVD to either 50,000 IU/week of vitamin $\mathrm{D}_{3}$ or placebo for 8 weeks. No improvements on lipid profile were noted. On the contrary, a significant increase in LDL cholesterol was reported. The authors remarked that vitamin D supplementation may be dangerous for participants at risk of CVD. In contrast, Alkharfy et al. (26), examined the effect of $2000 \mathrm{IU} /$ day vitamin $\mathrm{D}_{3}$ supplementation on 499 Saudi participants with type 2 diabetes on diet, insulin or oral hypoglycemic agents and compared them with a non-diabetic control group. Significant reductions in total cholesterol, triglycerides, and systolic blood pressure were found in the treatment groups receiving insulin and oral hypoglycemic agents. Similarly, Al-Daghri et al. (27), evaluated the effect of $2000 \mathrm{IU} /$ day vitamin $\mathrm{D}_{3}$ supplementation on participants with type 2 diabetes over a 12 month period. Significant decreases in total cholesterol and LDL were shown mainly in women.

Since finding new strategies to decrease diabetes complications and cardiovascular risk among patients with T2D is a major public health goal, testing the direct benefit of vitamin $\mathrm{D}$ repletion on cardio vascular risk factors is warranted.

\section{Vitamin D Repletion in Participants with Type 2 Diabetes}

Protocols for correction of vitamin D insufficiency in patients with cystic fibrosis, chronic kidney disease, hyperparathyroidism, osteoporosis and pregnancy have been published (28-32). There is no standard method that has been developed for the repletion of vitamin D insufficiency in subjects with T2D yet. 
Recently, the Endocrine Society announced new clinical practice guidelines of standard of care vitamin D supplementation for insufficient populations (1500-2000 IU daily for ages 19-70) to achieve sufficiency (25(OH)D $>75 \mathrm{nmol} / \mathrm{L}$ ) and recommended an upper limit of $4000 \mathrm{IU}$ as the threshold for safety in healthy individuals. In addition, all adults who are vitamin D deficient $(25(\mathrm{OH}) \mathrm{D}<50 \mathrm{nmol} / \mathrm{L}$ ) are recommended to supplement with $6000 \mathrm{IU} / \mathrm{d}$ of vitamin $\mathrm{D}_{3}$ until sufficiency is reached, followed by a maintenance therapy of $2000 \mathrm{IU} / \mathrm{d}$. In obese patients, and patients taking medications that interfere with vitamin D metabolism, the suggested therapy is to supplement with 6000$10000 \mathrm{IU} / \mathrm{d}$ of vitamin $\mathrm{D}_{3}$ until sufficiency is reached, followed by a maintenance therapy of 3000-6000 IU/d (33). The optimal vitamin D supplementation that is required to improve insulin resistance and glycemic control for special populations, including those with elevated insulin resistance, type 2 diabetes, and individuals with dark skin color with vitamin $\mathrm{D}$ insufficiency has not been determined. Therefore, it is important to test if the new standard of care has an impact on the glucose control of African Americans and Hispanics, or if higher dosages are needed. There is concern that vitamin D repletion regimens, however, may produce toxicity. Serum 25(OH)D levels $>150 \mathrm{ng} / \mathrm{ml}$ have been used as the threshold for toxicity (34).

\section{Factors that Affect Vitamin D Insufficiency}

Other factors that may contribute to the high prevalence of vitamin D insufficiency in persons with T2D are high melanin levels, lack of sun exposure, inadequate diet, obesity, and genetic predisposition to vitamin D insufficiency (35). 


\section{Sun Exposure}

In a tropical area such as South Florida, it is taken for granted that everybody will have enough sun exposure. Sun exposure, although, may vary depending on the profession/job performed, the presence of a disability condition that may keep individuals inside their homes, exercise habits, etc.

The sun is the main source of vitamin D. Ultraviolet B (UVB) radiation emitted by the sun is converted to vitamin $\mathrm{D}$ in the skin. The avoidance of sun exposure may explain in part the current vitamin D deficiency epidemic (36).

Research is still in progress to quantify vitamin D status in specific populations and its relation with several diseases. Therefore, the assessment of vitamin D status must take into consideration sun exposure behaviors through the use of validated tools.

Sun exposure questionnaires are commonly used to assess UVB exposure because they are easy to use and inexpensive. Observed sun exposure and dosimetry, an objective measure of UVB radiation, have been used for comparison (37-40), however, neither of them is considered a gold standard (41). The correlations among sun exposure questionnaires and observed exposure or dosimetry have been significant but relatively low, leaving a big percentage in the variation in UVB unexplained by sun exposure alone (37-40).

Similarly, when sun exposure questionnaires have been used in models to predict 25(OH)D (the universally accepted biomarker to determine vitamin D status) a large percentage of the variation was not explained by sun exposure, leading to a misclassification of vitamin D status if based on sun exposure alone (42-44). 
On the other hand, objective and reliable measures of change in skin color using scanners which allow in vivo quantification, have shown significantly high correlations with laboratory induced UVB exposure $\left(r_{\mathrm{s}}=0.99\right)(45)$. In addition, these devices offer high inter/intra rater reliability (46). They may be used as gold standard to validate sun exposure questionnaires. Therefore, it is necessary to validate sun exposure tools in order to accurately assess vitamin D status in minorities with T2D.

\section{Skin Color}

Even with similar levels of sun exposure, the skin color is a key determinant in vitamin D production. Each ethnic group has a different skin color: African Americans having the greatest amount of melanin compared to the majority of Whites who have the least amount of melanin and the fairest skin tone. African Americans are particularly at high risk for vitamin D deficiency because their darker skin color limits the amount of ultraviolet light that penetrates, thereby reducing cutaneous synthesis of vitamin $\mathrm{D}_{3}$ (47). Skin pigmentation can reduce the UVB from penetrating the skin by as much as $99 \%$ which has the same effect as applying sunscreen of factor 15 (48). Blood vitamin D levels in Blacks are lower than in Whites when exposed to the same levels of sun; and, Blacks are found to have lower serum 25(OH)D concentrations both in winter and in summer compared to their White counterparts $(49,50)$. Weaver et al. (51) estimated that Blacks need 1840-2480 IU/d of vitamin $\mathrm{D}_{3}$ supplementation, although, this assumption was based on a single study performed in White adults (52). It may not be a coincidence that darker-skinned Asian immigrants (who have a greater amount of melanin) have a four to five times higher prevalence of T2D than their British Caucasian counterparts; 
indicating that increased melanin may cause lower vitamin $\mathrm{D}$ status and potential to contribute to the development of diabetes $(53,54)$. Therefore, it is important to control for sun exposure when assessing serum vitamin D levels, not only through surveys, but also with objective measures of change in skin color.

\section{Vitamin D Intake}

Vitamin D level depends on several modifiable and non-modifiable factors. Skin color is the major non-modifiable factor and modifiable factors include sun exposure and vitamin D intake (55), however, there are no validated tools to assess vitamin D intake in participants with type 2 diabetes.

Nutrient intake can be estimated by multiple methods, each of them presenting their own advantages and disadvantages. Food records are usually considered the gold standard. They are administered over several days in order to represent usual intake, although, due to the burden of writing down every food and portion size, the period is limited (56). If the subject change his/her usual diet during this period, the data may be misleading. In addition, a tendency to underreport food intake by obese and overweight individuals have been reported (57). In contrast, food frequency questionnaires (FFQ) can assess food intake over a longer period of time (usually over a 1 year), can be administered by dietitians in situ or self-administered in a short period of time putting less burden on participants and may expose habits not evident on food records (58). Furthermore, FFQ should include ethnic specific foods and being validated in the specific population under study (58). 
Several vitamin D FFQs have been validated in different populations, however, to our knowledge; none have been validated in Hispanic and African American participants with T2D. Marshall et al. (56) validated the Iowa Study Targeted Nutrient SemiQuantitative Questionnaire and the Block Kids Food Questionnaire for estimating calcium and vitamin D intake among children using a 3-day food diary as reference. Correlations between the questionnaires and food diary for vitamin D were modest $(\mathrm{r}=0.487$ and $\mathrm{r}=0.512$, respectively). Pritchard et al. (59) validated a calcium, vitamin $\mathrm{D}$, and vitamin K FFQ that also included assessment of supplement intake in overweight and obese post-menopausal women against a 5-day diet record. A strong correlation between the FFQ and the diet record for vitamin D was reported ( $r=0.89)$. Taylor et al. (58) validated a FFQ for assessing calcium and vitamin D intake in adolescent girls with anorexia nervosa against a 4-day food record. Strong correlations among the two diet collection methods for vitamin $\mathrm{D}$ was observed $(\mathrm{r}=0.78)$. The analysis was adjusted for energy intake.

Nucci et al. (55) evaluated the effectiveness of a short FFQ in determining vitamin D intake against a previously validated long FFQ in a population of 6 to 14 year old children. Correlations among the questionnaires was modest at baseline and follow up $(r=0.35$ and $r=0.37$, respectively). The study took into consideration the sun exposure habits of the population. Blalock et al. (60) assessed the validity of a short calcium and vitamin D FFQ among 27 university employees against a 7 day food diary and a previously validated long FFQ. Vitamin D intakes from the food diary and short FFQ were significantly correlated $(\mathrm{r}=0.72)$. The positive predictive value for identifying participants with low vitamin D intake using a cutoff point of 200 IU/day was 100\%. 
It has been suggested that validation of nutrient intake should be conducted against a previously validated diet record but also against a biomarker of nutrient status (61). Vitamin D status is determined by serum 25(OH)D levels, however, since UVB light is the major contributor of vitamin D, validation studies should be conducted during winter where 25(OH)D will be mainly affected by intake and no sun exposure. Otherwise, sun exposure should be taken into consideration in the analysis of vitamin D intake and 25(OH)D.

In this regard, Wu et al. (61) validated a 37-item vitamin D FFQ among a multiethnic sample of Canadian adults during late winter against a 7-day food diary and 25(OH)D levels. Intakes were modestly correlated among dietary collection methods and 25(OH)D ( $r=0.529$ and $r=0.481$, respectively). After redefining the serving sizes and excluding fortified orange juice from the FFQ, the correlations improved (r=0.602 and $\mathrm{r}=0.520$, respectively).

Since studies suggested that vitamin D deficiency may have a role on insulin resistance and T2D progression, it is imperative to validate diet collection tools in this particular population.

\section{Specific Aims and Hypotheses}

\section{Specific Aim 1}

The aim of the present study was to determine the effect of supplemental vitamin D intake (4000 IU or 6000 IU of Cholecalciferol daily for 6 months) on fasting plasma glucose, fasting insulin, A1C, and blood lipids in a sample of African-Americans and 
Hispanics with T2D and vitamin D insufficiency $(25(\mathrm{OH}) \mathrm{D}<30 \mathrm{ng} / \mathrm{ml}), 30-70$ years of age, and living in South Florida.

\section{Hypothesis 1}

Vitamin D supplementation (4000 IU or 6000 IU of Cholecalciferol daily for 6 months) will improve fasting plasma glucose, fasting insulin, A1C, and blood lipids in a sample of African-Americans and Hispanics with T2D and vitamin D insufficiency (25(OH)D < 30 ng/ml), 30-70 years of age, living in South Florida.

\section{Specific Aim 2}

To evaluate the efficacy and safety of two vitamin D repletion regimens: 4000 IU and 6000 IU of Cholecalciferol daily for 6 months in a sample of African Americans and Hispanics with T2D and vitamin D insufficiency $(25(\mathrm{OH}) \mathrm{D}<30 \mathrm{ng} / \mathrm{ml}), 30-70$ years of age, and living in South Florida.

\section{Hypothesis 2}

Serum vitamin D will reach sufficient levels $(25(\mathrm{OH}) \mathrm{D} \geq 30 \mathrm{ng} / \mathrm{ml})$ in a sample of African Americans and Hispanics with T2D and vitamin D insufficiency, 30-70 years of age, living in South Florida; after 6 months of daily supplementation with 4000 IU and 6000 IU of Cholecalciferol with no reported adverse events .

\section{Specific Aim 3}

To validate a sun exposure questionnaire against objective measures of change in skin color and to assess its validity in predicting $25(\mathrm{OH}) \mathrm{D}$ status in a sample of African Americans and Hispanics with T2D. 


\section{Hypothesis 3}

The sun exposure questionnaire scores will correlate with the change in skin color scores due to sun exposure and will predict 25(OH)D status in a sample of African Americans and Hispanics with T2D.

\section{Specific Aim 4}

To expand the short FFQ developed by Blalock et al. (60) to include specific ethnic foods consumed by Hispanics and African Americans in South Florida and to examine the criterion validity of the short FFQ by comparing intakes with a previously validated long FFQ and serum 25(OH)D levels.

\section{Hypothesis 4}

The short FFQ questionnaire scores will correlate with a previously validated long FFQ scores and serum 25(OH)D levels. 


\section{References}

1. Centers for Disease Control and Prevention. National Diabetes Statistics Report, 2014. Accessed October 29, 2014. Available http://www.cdc.gov/diabetes/pubs/statsreport14/national-diabetes-report-web.pdf

2. Donath MY, Ehses JA, Maedler K, Schumann DM, Ellingsgaard H, Eppler E et al. Mechanism of B-cell death in type 2 diabetes. Diabetes. 2005;54(2):S108S113.

3. Centers for Disease Control and Prevention. Vitamin D Status: United States, 2001-2006. Accessed April 29, 2013. Available http://www.cdc.gov/nchs/data/databriefs/db59.pdf

4. Holick MF. Vitamin D: a millennium perspective. J Cell Biochem. 2003;88:296307.

5. Verstuyf A, Verlinden L, Van Etten E, Shi L, Wu Y, D’Halleweyn, et al. Biological activity of CD-ring modified 1alpha,25-dihydroxyvitamin D analogues: C-ring and five-membered D-ring analogues. J Bone Miner Res. 2000;15:237-252.

6. Baynes KCR, Boucher BJ, Feskens EJM, Kromhout D. Vitamin D, glucose tolerance and insulinaemia in elderly men. Diabetologia. 1997;40(3):344-347.

7. Scragg R, Sowers M, Bell C. Serun 25-hydroxyvitamin D, diabetes, and ethnicity in the Third National Health and Nutrition Examination Survey. Diabetes Care. 2004;27(12):2813-2818.

8. Kayaniyil S, Vieth R, Retnakaran R, Knight JA, Qi Y, Gerstein HC, et al. Association of vitamin $\mathrm{D}$ with insulin resistance and $\beta$-cell dysfunction in subjects at risk for type 2 diabetes. Diabetes Care. 2010;33(6):1379-1381.

9. Gedik O, Akahn S. Effects of vitamin D deficiency and repletion on insulin and glucagon secretion in man. Diabetologia. 1996;29(3):142-145.

10. Cade C, Norman AW. Vitamin D3 improves impaired glucose tolerance and insulin secretion in the vitamin D deficient rat in vivo. Endocrinology. 1986;119(1):84-90.

11. Borissova AM, Tankova T, Kirilov G, Dakovska L, Kovacheva R. The effect of vitamin D3 on insulin secretion and peripheral insulin sensitivity in type 2 diabetic patients. Int J Clin Pract. 2003;57(4):258-261. 
12. Inomata S, Kadowaki S, Yamatani T. Effect of $1 \alpha(\mathrm{OH})$-vitamin D3 on insulin secretion in diabetes mellitus. Bone and Mineral. 1986;1(3):187-192.

13. Orwoll E, Riddle M, Prince M. Effects of vitamin D on insulin and glucagon secretion in non-insulin-dependent diabetes mellitus. American Journal of Clinical Nutrition. 1994;59(5):1083-1087.

14. Schwalfenberg G. Vitamin D and diabetes: Improvement of glycemic control with vitamin D3 repletion. Canadian Family Physician. 2008;54:864-866.

15. Jorde R, Figenschau Y. Supplementation with cholecalciferol does not improve glycaemic control in diabetic subjects with normal serum 25-hydroxyvitamin D levels. European Journal of Nutrition. 2009;48(6):349-354.

16. Fiscella K, Pranks P. Vitamin D, race, and cardiovascular mortality: Findings from a national US sample. Annuals of Family Medicine. 2010;8(1):11-18.

17. Yanoff LB, Parikh SH, Spitalnik A, Denkinger B, Sebring NG, Slaughter P, McHugh T, Remaley AT, Yanovski JA. The prevalence of hypovitaminosis D and secondary hyperparathyroidism in obese Black Americans. Clin Endocrinol. 2006;64(5):523-529.

18. Zadshir A, Tareen N, Pan D, Norris K, Martins D. The prevalence of hypovitaminosis D among US adults: data from the NHANEIII. Ethn Dis. 2005;15(Suppl 5):S5-97-1010

19. Centers for Disease Control and Prevention. Fat-soluble vitamins \& micronutrients: Vitamin D. National report on Biochemical Indicators of Diet and Nutrition in the U.S. Population 1999-2002. Accessed April 24, 2013. Available http://www.cdc.gov/nutritionreport/99-02/part_2b.html

20. Centers for Disease Control and Prevention. National diabetes fact sheet: general information and national estimates on diabetes in the United States, 2007. Atlanta, GA: U.S. Department of Health and Human Services, Centers for Disease Control and Prevention, 2008. Accessed April 24, 2013. Available online: http://www.cdc.gov/diabetes/pubs/pdf/ndfs_2007.pdf

21. Ginsberg HN. Insulin resistance and cardiovascular disease. J Clin Invest. 2000;106:453-458.

22. Muller D, Kleinewietfeld M, Kvakan H. Vitamin D review. Journal of ReninAngiotensin-Aldosterone System. 2011;12:125-128.

23. Martins D, Wolf M, Pan D, Zadshir A, Tareen N, Thadhani R, et al. Prevalence of cardiovascular risk factors and the serum levels of 25-hydroxyvitamin $\mathrm{D}$ in the 
United States: Data from the Third National Health and Nutrition Examination Survey. Arch Intern Med. 2007;167:1159-1165.

24. Skaaby T, Husemoen LLN, Pisinger C, Jorgensen T, Thuesen BH, Fenger M, et al. Vitamin D status and changes in cardiovascular risk factors: A prospective study of a general population. Cardiology. 2012;123:62-70.

25. Ponda MP, Dowd K, Finkielstein D, Holt PR, Breslow JL. The short term effects of vitamin D repletion on cholesterol: A randomized, placebo-controlled trial. Arterioscler Thromb Vasc Biol. 2012;32:2510-2515.

26. Alkharfy KM, Al-Daghri NM, Sabico SB, Al-Othman A, Moharram O, Alokail MS, et al. Vitamin D supplementation in patients with diabetes mellitus type 2 on different therapeutic regimens: a one-year prospective study. Cardiovascular Diabetology. 2013;12:113-123.

27. Al-Daghri NM, Alkharfy KM, El-Kholie E, Yousef M, Al-Othman A, Al-Saleh Y, et al. Vitamin D supplementation as an adjuvant therapy for Saudi patients with DMT2: an 18-month interventional study. Cardiovasc Diabetol. 2012;11:85.

28. Aris RM, Merkel PA, Bachrach LK, Borowitz DS, Boyle MP, Elkin SL, et al. Guide to bone health and disease in cystic fibrosis. J Clin Endocrinol Metab. 2005;90:1888-1896.

29. National Kidney Foundation. K/DOQI clinical practice guidelines for bone metabolism and disease in chronic kidney disease. Am J kidney Dis. 2003;42(4 suppl 3):S1-S201.

30. Grey A, Lucas J, Horne A, Gamble G, Davidson JS, Reid IR. Vitamin D repletion in patients with primary hyperparathyroidism and coexistent vitamin D insufficiency. J Clin Endocrinol Metab. 2005;90:2122-2126.

31. AACE Osteoporosis Task Force. American Association of Clinical Endocrinologist medical guidelines for clinical practice for the prevention and treatment of post-menopausal osteoporosis: 2001 edition, with selected updates for 2003. Endocr Pract. 2003;9:544-564.

32. Basile LA, Taylor SN, Wagner CL, Horst RL, Hollis BW. The effect of high-dose vitamin D supplementation on serum vitamin D levels and milk calcium concentration in lactating women and their infants. Breasfeed Med. 2006;1:27-35.

33. Endocrine Society. Evaluation, treatment, and prevention of vitamin D deficiency: an Endocrine Society Clinical Practice Guideline. J Clin Endocrinol Metab. 2011;96:1911-1930. 
34. Pepper KJ, Judd SE, Nanes MS, Tangpricha V. Evaluation of vitamin D repletion regimens to correct vitamin D status in adults. Endocr Pract. 2009;15(2):95-103.

35. Penckofer S, Kouba J, Emanuele W, Emanuele M. Vitamin D and diabetes: Let the sun shine in. The Diabetes Educator. 2008;34(6):939-954. doi:10.1177/0145721708326764

36. Holick MF. Vitamin D deficiency. N Engl J Med 2007;357:266-281.

37. Vishvakarman D, Wong JCF, Boreham BW. Annual occupational exposure to ultraviolet radiation in central Queensland. Health Phys 2001;81:536-544.

38. O'Riodan DL, Lunde KB, Steffen AD, Maddock JE. Validity of beach-goers' self-report of their sun habits. Arch Dermatol 2006;142:1304-1311.

39. Diffey BL, Saunders PJ. Behavior outdoors and its effect on personal ultraviolet exposure rate measured using an ambulatory data logging dosimeter. Photochem Photobiol 1995;61:615-618.

40. Dwyer T, Blizzard L, Gies PH, Ashbolt R, Roy C. Assessment of habitual sun exposure in adolescents via questionnaire-a comparison with objective measurement using polysulphone badges. Melanoma Res 1996;6:231-239.

41. McCarty CA. Sunlight exposure assessment: can we accurately assess vitamin D exposure from sunlight questionnaires? Am J Clin Nutr 2008;87:1097S-1101S.

42. Van der Maei IAF, Blizzard L, Ponsonby AL, Dwyer T. Validity and reliability of adult recall of past sun exposure in a case-control study of multiple sclerosis. Cancer Epidemiol Biomarkers Prev 2006;15:1538-1544.

43. Brot C, Vestergaard P, Kolthoff N, Gram J, Hermann AP, Sorensen OH. Vitamin $\mathrm{D}$ status and its adequacy in healthy Danish perimenopausal women: relationships to dietary intake, sun exposure, and serum parathyroid hormone. Br J Nutr 2001;86:S97-S103.

44. Pasco JA, Henry MJ, Nicholson GC, et al. Vitamin D status of women in the Geelong Osteoporosis Study: association with diet and casual exposure to sunlight. Med J Aust 2001;175:401-405.

45. Andersen PH, Bjerring P. Spectral reflectance of human skin in vivo. Photodermatol Photoimmunol Photomed 1990;7:5-12.

46. Glanz K, Mayer JA. Reducing ultraviolet radiation exposure to prevent skin cancer methodology and measurement. American Journal of Preventive Medicine 2005;29:131-142. 
47. Aloia JF. African Americans, 25-hydroxyvitamin D, and osteoporosis: a paradox. Am J Clin Nutr. 2008;88:545S-50S.

48. Holick M.F. Resurrection of vitamin D deficiency and rickets. Journal of Clinical Investigation. 2006;116:2062-2072.

49. Harris SS, Soteriades E, Coolidge JA, Mudgal S, Dawson-Hughes B. Vitamin D insufficiency and hyperparathyroidism in a low income, multiracial, elderly population. Journal of Clinical Endocrinology and Metabolism. 2000;85(11):4125-4130.

50. Harris SS, Dawson-Hughes B. Seasonal changes in plasma 25-hydroxyvitaminD concentrations of young American black and white women. American Journal of Clinical Nutrition. 1998;67(6):1232-1266.

51. Weaver C, Fleet J. Vitamin D requirements: current and future. American Journal of Clinical Nutrition. 2004;80 (suppl):1735S-1739S.

52. Heaney RP, Davies KM, Chen TC, Holick MF, Barger-Lux MJ. Human serum 25 hydroxycholecalciferol response to extended oral dosing with cholecalciferol. American Journal of Clinical Nutrition. 2003;77:204-210.

53. Zitterman A. Vitamin D in preventative medicine: are we ignoring the evidence? British Journal of Nutrition. 2003;89:552-572.

54. McKeigue PM, Pierpoint T, Ferrie JE, Marmot MG. Relationship of glucose intolerance and hyperinsulinemia to body fat pattern in south Asians and Europeans. Diabetologica. 1992;35:785-791.

55. Nucci AM, Russell CS, Luo R, Ganji V, Olabopo F, Hopkins B, et al. The effectiveness of a short food frequency questionnaire in determining vitamin $\mathrm{D}$ intake in children. Dermato-Endocrinology. 2013;5(1):205-210.

56. Marshall TA, Eichenberger Gilmore JM, Broffitt B, Stumbo PJ, Levy SM. Realtive validity of the Iowa Fluoride Study Targeted Nutrient Semi-Quantitative Questionnaire and the Block Kids' Food Questionnaire for estimating beverage, calcium, and vitamin D intakes by children. J Am Diet Assoc. 2008;108:465-472.

57. Kaaks R, Ferrari P, Ciampi A, Plummer M, Riboli E, Part H. Uses and limitations of statistical accounting for random error correlations, in the validation of dietary questionnaire assessments. Public Health Nutr. 2002;5(6A):969-976.

58. Taylor C, Lamparello B, Kruczek K, Anderson E, Hubbard J, Misra M. Validation of a food frequency questionnaire for determining calcium and vitamin 
D intake by adolescents girls with anorexia nervosa. J Am Diet Assoc. 2009;109:479-485.

59. Pritchard JM, Seechurn T, and Atkinson SA. A food frequency questionnaire for the assessment of calcium, vitamin $\mathrm{D}$, and vitamin $\mathrm{K}$ : a pilot validation study. Nutrients. 2010,2:805-819.

60. Blalock SJ, Norton LL, Patel RA, Cabral K, Thomas CL. Development and assessment of a short instrument for assessing dietary intakes of calcium and vitamin D. J Am Pharm Assoc. 2003;43:685-693.

61. Wu H, Gozdzik A, Barta JL, Wagner D, Cole DE, Vieth R, et al. The development and evaluation of a food frequency questionnaire used in assessing vitamin D intake in a sample of healthy young Canadian adults of diverse ancestry. Nutrition Research. 2009;29:255-261. 


\section{CHAPTER II: THE EFFECT OF VITAMIN D SUPPLEMENTATION ON BLOOD LIPIDS IN MINORITIES WITH TYPE 2 DIABETES}

\section{Introduction}

Low levels of vitamin D are prevalent in the US. According to data from the National Health and Nutrition Examination Surveys (NHANES) in 2001-2006, 33\% of the general US population had serum 25(OH)D below $50 \mathrm{nmol} / \mathrm{L}$. In addition, low vitamin D levels are common among minorities. For instance, 41\% of African Americans and 33\% of Mexican Americans had serum 25(OH)D below $50 \mathrm{nmol} / \mathrm{L}$ compared to 18\% of non-Hispanic Whites (1).

Vitamin D is produced in the skin by the action of ultraviolet light. Vitamin D can also be obtained from the diet with consumption of vegetable and animal products. Vitamin D needs to be activated by hydroxylation in the liver and kidney to form its metabolically active form: $1,25(\mathrm{OH})_{2} \mathrm{D}_{3}$. This metabolite produces its effects by activating the vitamin D receptor (VDR) in the cells (2).

The VDR is present in vascular and myocardial cells which suggest an involvement of vitamin D mediated effects in the development of cardiovascular disease (CVD) (3). Cardiovascular risk factors such as type 2 diabetes and dyslipidemia are the major causes of death in the US, especially among minorities (4). Therefore, it is of crucial importance to determine the role of vitamin D supplementation on the prevention of CVD.

Associations among vitamin D insufficiency and lower high density lipoprotein (HDL), higher triglycerides, and hypercholesterolemia have been reported (5-7). Skaaby et al. (7), conducted a large prospective evaluation of serum vitamin D level and blood 
lipids. They found a strong association between lower serum 25(OH)D level and elevated total cholesterol. The changes in lipid profile associated with a variation in vitamin D status, however, were small and without clinical significance. In addition, since obesity and ethnicity are risk factors for both vitamin D insufficiency and dyslipidemia, confounding for these variables should not be excluded.

Randomized clinical trials evaluating the effects of vitamin D repletion on lipid panel have reported conflicting results (8-10). Ponda et al. (8), assigned 151 vitamin D deficient adults at high risk of CVD to either 50,000 IU/week of vitamin D3 or placebo for 8 weeks. No improvements on lipid panel were noted. On the contrary, a significant increase in low density lipoprotein (LDL) cholesterol was reported. The authors remarked that vitamin D supplementation may be dangerous for participants at risk of CVD. In contrast, Alkharfy et al. (9), examined the effect of 2000 IU/day vitamin $\mathrm{D}_{3}$ supplementation on 499 Saudi participants with type 2 diabetes on diet, insulin or oral hypoglycemic agents and compared them with a non-diabetic control group. Significant reductions in total cholesterol, triglycerides, and systolic blood pressure were found in the insulin and oral hypoglycemic groups. Similarly, Al-Daghri et al. (10), evaluated the effect of 2000 IU/day vitamin $\mathrm{D}_{3}$ supplementation on participants with type 2 diabetes over a 12 month period. Significant decreases in total cholesterol and LDL were shown mainly in women.

Patients with type 2 diabetes are more likely to develop hypertension, dyslipidemia, arteriosclerosis and all of the complications related to myocardial infarction and stroke (11). Since finding new strategies to decrease diabetes complications and cardiovascular risk among patients with type 2 diabetes is a major public health goal, 
testing the direct benefit of vitamin D repletion on blood lipids is warranted. In addition, most of the current studies have been conducted in Caucasian populations. Since African Americans and Hispanics are more prone to both vitamin D insufficiency and type 2 diabetes compared to Caucasians, it is important to test the effect of vitamin D repletion on these high risk populations.

The aim of the present study was to determine the effect of supplemental vitamin D intake (4000 IU/day or $6000 \mathrm{IU} /$ day of vitamin $\mathrm{D}_{3}$ over a 6 month period) on blood lipids in a sample of African Americans and Hispanics with type 2 diabetes and vitamin D insufficiency $(25(\mathrm{OH}) \mathrm{D}<30 \mathrm{ng} / \mathrm{ml})$ living in South Florida.

\section{Methods}

\section{Subject Recruitment}

An intervention study to assess the effects of vitamin D supplementation (4000 IU/day and 6000 IU/day) over six months on cardiovascular disease markers among a sample of African Americans and Hispanics with T2D was conducted. The present study analyzed the data collected at screening (serum 25(OH)D), baseline (blood lipids), 3 months (serum 25(OH)D and blood lipids), and 6 months (serum 25(OH)D and blood lipids).

The study consisted of two phases: phase one included the screening of individuals, phase two included the recruitment of individuals who met inclusion criteria and beginning of the vitamin D intervention trial. Inclusion criteria were vitamin D insufficiency $(25(\mathrm{OH}) \mathrm{D}<30 \mathrm{ng} / \mathrm{ml})$, 30-70 years of age, African American or Hispanic with confirmed T2D. Exclusion criteria were taking vitamin D supplements other than 
standard daily multivitamin formula, being pregnant or lactating, having thyroid, hepatic, renal dysfunction, cancer, HIV, or major psychiatric disorders.

Flyers explaining the purpose of the study, inclusion/exclusion criteria and the investigators' emails and phone numbers were distributed in highly visited community areas such as churches, supermarkets, and clinics. Two clinics were visited every week for recruitment purposes: Borinquen Health Care Center and Clinical Care Medical Center. When volunteer participants called the investigators back, purposes of the study were explained and specific questions were asked to assure compliance with inclusion criteria. All qualified participants were invited to take part in a morning session at the Human Nutrition Laboratory at Florida International University (FIU) for fasting blood sampling to screen for vitamin D insufficiency. The study was approved by IRB at FIU. All participants were asked to sign an informed consent form previous to screening data collection. Only participants with confirmed T2D diagnosis by a physician were eligible for the study. All participants were screened for vitamin D insufficiency in phase one. They were contacted either to continue in the study or to inform them that they were disqualified based on their vitamin D levels.

Participants in both groups were required to take either 4000 IU or $6000 \mathrm{IU}$ of vitamin D (Cholecalciferol) per day given in the form of a pill in a single daily dose. Compliance was determined by returned pill count at follow ups. When less than $80 \%$ of the pills were taken, the subject was classified as non-compliant. Adverse events were recorded at each visit. Each participant was seen 4 times; at screening, baseline, 3 months, and 6 months. Serum 25(OH)D was measured at screening, 3 months, and 6 
months. Blood lipids were measured at baseline, 3 months, and 6 months. The time spam between screening and baseline was one week.

Total study lasted for 25 weeks for each participant from screening to final assessment. The study started in June 2011 and was completed on September 2013. Ninety two participants were screened. Seventy five qualified for the intervention $(n=50$ for $4000 \mathrm{IU} /$ day treatment and $\mathrm{n}=25$ for $6000 \mathrm{IU} /$ day treatment). Three participants qualified for the study based on their vitamin D status but did not attend the 3 month and 6 month follow ups (all in the 4000 IU group). Eight participants attended the 3 month but not the 6 month follow up (5 in the $4000 \mathrm{IU}$ and 3 in the $6000 \mathrm{IU}$ group, respectively). Five participants completed the study but were non-compliant (3 in the 4000 IU and 2 in the 6000 IU treatment, respectively). Since an intent to treat approach was followed, all 75 participants were included in the present study.

\section{Blood Collection}

Venous blood (15 ml) was collected from each subject by a certified phlebotomist using standard laboratory methods at each study point. After coagulation, blood was centrifuged at 2500 RPM for 30 minutes. Plasma total cholesterol, triglycerides, LDL, and HDL cholesterol were assayed by enzymatic methods (Cobas Mira, Roche Diagnostics, Indianapolis, IN). Serum vitamin D concentrations were measured with an enzyme-immunoassay kit by absorbance (Immunodiagnostic Systems Scottsdale, AZ). Vitamin D values were tested at screening, 3 month and 6 month visits. Total cholesterol, triglycerides, LDL, and HDL cholesterol were tested at baseline, 3 month, and 6 month visits. 


\section{Socio-demographic Questionnaire}

Participants were asked to complete the standard questionnaire on site. Trained bilingual interviewers (English and Spanish) administered the questionnaires in the language of preference of the participant. Data were collected using a socio-demographic questionnaire which included questions related to gender, age, education level, years with diabetes, smoking, and medication use.

\section{Anthropometric Measurements}

Height and weight were measured using a SECA clinical balance scale (Seca Corp, Columbia, MD). Body mass index (BMI) was calculated as weight in $\mathrm{kg} / \mathrm{height}$ in $\mathrm{m}^{2}$. BMI was calculated at baseline, 3 month, and at 6 month visits. Only baseline values were used for the analysis due to the lack of significant changes in BMI at 3 months and 6 months.

\section{Sun Exposure Questionnaire}

The sun exposure questionnaire developed by Hanwell et al. (12) was applied following the original rubric. Time spent outdoors during the previous week $(0 \leq 5$ minutes, $1=5-30$ minutes and $2 \geq 30$ min) was self-reported. Four options for skin exposed while outdoors were offered (1=face and hands, 2=face, hands and arms, 3=face, hands and legs and 4=bathing suit). The daily sun exposure score for each day was calculated by multiplying the time spent outdoors score times the skin exposed while outdoors score. The scale for each day ranged from 0 to 8 . The weekly sun exposure was calculated by adding the daily scores $(\min =0, \max =56)$. The questionnaire was 
administered at baseline, 3 months, and 6 months, but because it did not change significantly, only baseline values were used in the analysis. Since the sun is the main source of vitamin D, baseline sun exposure may have an effect on our final outcomes. Therefore, analysis was adjusted for sun exposure.

\section{Skin Color}

In order to have an objective measure of sun exposure, skin color was determined by reflectance colorimetry using the SmartProbe 400 (IMS Inc. USA). This instrument uses the International Commission on Illumination Scale which ranges from 0 (black) to 100 (white) for skin color. Two readings at each measurement site for each participant were taken: two on the dorsal aspect of the wrist of the right hand (area most exposed to sun), two on the inside of the right upper arm (area less exposed to the sun). The mean values of the two readings at each measurement site were used for analysis. Data were collected at baseline, 3 months, and 6 months, but because it did not change significantly, only baseline values were used in the present analysis. Since participants with darker skin color tend to have lower levels of serum 25(OH)D, skin color may have an effect on lipid profile. Therefore, analysis of the effect of vitamin D supplementation on lipid panel was adjusted for skin color.

\section{Assessment of Dietary Intake}

Dietary intake was determined using the long food frequency questionnaire (FFQ) developed by Walter Willett (13). This FFQ has been validated in different ethnic groups and, also, specifically in Cuban-Americans in South Florida (14). Participants self- 
reported the average consumption of specific amount of foods over the past 12 months. Frequencies ranged from "never" to "six or more servings per day". The FFQ also assessed the frequency use of multivitamin/mineral supplements, salt, sugar, alcohol and vitamin D intake. The questionnaire was administered at baseline.

\section{Statistical analysis}

Descriptive statistics were used for baseline characteristics. Numerical normally distributed data and categorical data were compared using independent t-test and ChiSquared test, respectively. Intent to treat analysis was used to analyze the effect of vitamin $\mathrm{D}$ on the outcome variables.

Main variables of the study were: plasma total cholesterol, triglycerides, LDL, and HDL cholesterol. All variables were input as continuous in the analysis. Control variables included: BMI, gender, age, smoking, years with diabetes, sun exposure score, vitamin D intake, fasting plasma glucose, lipid lowering medication use, and skin color. Mixed model was used to compare treatment effects (4000 IU vs. $6000 \mathrm{IU}$ ) on the outcome variables. Bonferroni multiple comparison test was used to detect significant changes from baseline, 3 months, and 6 months on the outcome variables with and without adjustment for age, gender, years with diabetes, smoking, BMI, vitamin D intake, sun exposure score, upper arm skin color, forearm skin color, fasting plasma glucose, and lipid lowering medication use. Significance was set at $\mathrm{p}<0.05$ and all analyses were two sided. Statistical analysis was conducted using SPSS 18.0 (Chicago). 


\section{Results}

Groups were different at baseline on BMI $\left(34.72 \pm 6.98 \mathrm{~kg} / \mathrm{m}^{2}\right.$ vs. $30.74 \pm 4.93$ $\mathrm{kg} / \mathrm{m}^{2}, P=0.013$ for $4000 \mathrm{IU}$ and $6000 \mathrm{IU}$; respectively) and HDL cholesterol (50.64 \pm $12.20 \mathrm{mg} / \mathrm{dl}$ vs. $42.44 \pm 10.40 \mathrm{mg} / \mathrm{dl}, P=0.004$ for $4000 \mathrm{IU}$ and $6000 \mathrm{IU}$; respectively) (Table 1).

There was no significant difference between groups regarding serum 25(OH)D $(P=0.225)$. However, significant improvements in serum 25(OH)D levels were seen from baseline to 3 month and 6 months, respectively in both treatments (from $22.25 \pm 7.19$ to $37.34 \pm 12.31$ and $37.99 \pm 13.22, P<0.05$ in the 4000 IU group; from $23.74 \pm 5.09$ to $43.20 \pm 15.94$ and $40.62 \pm 19.39, P<0.05$ in the 6000 IU group) (Table 2).

Differences between 3 months and 6 months levels for serum 25(OH)D were not significant in both treatments $(P>0.05)$. In the 6000 IU group, the value showed a nonsignificant decline at 6 months compared to the 3 months follow up.

In the unadjusted model, the difference between and within groups was significant for total cholesterol ( $P=0.027$ and $P=0.044$, respectively). However, the interaction between time and treatment was not significant $(P=0.653)$ (Table 2). The multiple comparisons analysis showed a borderline not significant decrease in total cholesterol for the $4000 \mathrm{IU}$ group at 6 months (from $213.08 \pm 42.30$ to $199.84 \pm 32.79 \mathrm{mg} / \mathrm{dl}, P=0.052$ ) and a significant decrease for the $6000 \mathrm{IU}$ group at 6 months (from $193.88 \pm 41.03$ to $180.48 \pm 27.53 \mathrm{mg} / \mathrm{dl}, P=0.040$ ). However, when the model was adjusted for confounders, significance was lost (Table 3). 
Similarly, in the unadjusted model (Table 2), a significant change for triglycerides was observed at 6 months in the $6000 \mathrm{IU}$ group (from $201.44 \pm 91.35$ to $172.92 \pm 76.87$ $\mathrm{mg} / \mathrm{dl}, P=0.037$ ). The significance was lost after adjusting for confounders (Table 3).

In the adjusted model, only serum 25(OH)D changed significantly over time (Table 3). Adherence defined as consumption of more than $80 \%$ of supplied vitamin D pills was $94 \%$ for the 4000 IU group and 92\% for the 6000 IU group without any differences between groups. No adverse events were reported during the course of the study.

Three participants stopped taking lipid lowering medication during the course of the study due to lack of money to buy the refills ( 2 in the 4000 IU group and 1 in the 6000 IU group).

\section{Discussion}

In the current study, vitamin $\mathrm{D}_{3}$ supplementation at $6000 \mathrm{IU} /$ day significantly reduced total cholesterol, and triglycerides in a sample of Hispanics and African Americans with type 2 diabetes and vitamin D insufficiency. However, the significance was lost after adjusting for confounders.

In fact, vitamin D insufficiency is related to other cardiovascular risk factors such as obesity, smoking, and unhealthy diet $(15,16)$. Regarding the strong association between obesity and vitamin D insufficiency, it has been hypothesized that vitamin $\mathrm{D}$ is stored in the fat tissue and is not bioavailable in obese participants resulting in low levels of serum vitamin D despite sufficient intake (15). In this context, if obesity is corrected we may see improvements in both serum vitamin D levels and lipid profile. 
Our results support this hypothesis. The participants were obese based on BMI classification. The positive effect of vitamin D supplementation on total cholesterol and triglycerides observed in the 6000 IU/day group disappeared when the model was adjusted for covariates such as smoking, age, gender, skin color, sun exposure, lipid lowering medication, years with diabetes, and BMI. Therefore, our results suggest that the association between vitamin D insufficiency and dyslipidemia may be mediated by other cardiovascular risk factors.

Recent clinical trials examining the effect of vitamin D supplementation on lipid profile among individuals with and without type 2 diabetes and vitamin D insufficiency have been inconsistent $(8,9,17)$. Some studies have found significant improvements in lipid profile after vitamin D supplementation. However, none of them adjusted for covariates in the analysis. Alkharfy et al. (9), randomly assigned 499 participants with type 2 diabetes to 8 groups: control $(n=151)$, rosiglitazone alone $(n=49)$, diet $(n=15)$, insulin alone $(n=55)$, insulin + orals $(n=12)$, metformin alone $(n=121)$, oral agents combination ( $n=37)$, and sulphonylurea alone (n=59). Participants received 2000 IU/day of vitamin $\mathrm{D}_{3}$ for 12 months. In the insulin alone group, total cholesterol decreased significantly in women. In the insulin + orals group, triglycerides and total cholesterol decreased significantly after 12 month. This study provides a view of how vitamin D supplementation can interact with certain drugs commonly used in patients with type 2 diabetes regarding lipid lowering benefits. In contrast, Ponda et al. (8), randomly assigned 151 vitamin D deficient participants at high risk for CVD to either 50000 IU of vitamin $\mathrm{D}_{3}$ weekly or placebo. Vitamin D failed to improve lipid profile. In addition, a significant increase in LDL was noted which significantly correlated with a decrease in 
parathyroid hormone (PTH) levels. Similarly, Salehpour et al. (17), randomly distributed 77 healthy premenopausal overweight and obese women to either $25 \mu$ g/day of vitamin D3 or placebo for 12 weeks. Significant increases in total cholesterol, LDL and HDL were reported. This study excluded participants taking any antihypertensive and lipid lowering medication. Since it is difficult to evaluate the effect of vitamin D supplementation on lipid profile when participants are already taking lipid lowering medication, this study provided a new insight into the raw metabolic effects of vitamin D. Authors from the last two studies warned that vitamin D may have both positive and negative effects on different cholesterol particles. Therefore, it should be monitored and used with caution among participants at risk of CVD. Conflicting results may be a consequence of different dosages used, different populations, different duration of treatment, and lack of control for obesity, physical activity, sun exposure, vitamin D intake, and medication usage.

Regarding lipid metabolism, studies have shown that vitamin D can reduce hepatic triglyceride synthesis and increase uptake by peripheral tissues due to increased intestinal calcium absorption $(18,19)$. Similarly, vitamin D promotes the formation of large HDL particles due to an increase in apolipoprotein A1, which increases reverse cholesterol transport (20). Vitamin D also increases the lipolytic activity of heparin and reduces VLDL-cholesterol synthesis (18).

In our study, the positive effect of vitamin D supplementation on total cholesterol and triglycerides was observed only in the 6000 IU group despite both groups reaching similar serum vitamin D levels. It may be that sufficient vitamin D status was achieved sooner in the $6000 \mathrm{IU} /$ group. Therefore, participants were exposed to sufficient vitamin D 
for a longer period of time. The half-life of vitamin $\mathrm{D}_{3}$ is about 2 months. Therefore, maintaining a plateau of sufficient 25(OH)D levels for more than 20 weeks is needed in order to see improvements on tissues not related to calcium metabolism (21).

Our study has several strengths. First, to our knowledge this is the first study that analysed vitamin D supplementation effects on Hispanics and African Americans with T2D. Second, the dosages used were large enough to raise serum vitamin D to normal levels in a population that was insufficient at baseline. Third, analysis was adjusted for a wide range of covariates related to vitamin D metabolism. Lastly, compliance in our study was high with $94 \%$ for the 4000 IU group and 92\% for the 6000 IU group without any differences between groups. No adverse events were reported during the course of the study.

Limitations of our study included. First, participants were not randomly distributed among groups. Second, there was an imbalance in baseline characteristics for BMI and HDL-cholesterol. Third, there was a difference in sample size between groups which may have decreased the statistical power. Fourth, a longer duration of treatment may be needed to see more drastic effects on lipid profile. Fifth, the number of African American participants was not large enough to analyze data by ethnicity. Lastly, 64\% and $68 \%$ of participants were taking lipid lowering medication in the $4000 \mathrm{IU}$ and $6000 \mathrm{IU}$ groups, respectively. Medication use may mask the effect of vitamin D supplementation. We tried to control for it by advising participants to keep their medication use constant during the study. However, this panorama reflects common clinical practice among patients with type 2 diabetes. 
Finally, our results suggest that the positive effect of vitamin D supplementation on lipid profile may be mediated by other cofactors related to vitamin D metabolism among Hispanic and African American participants with type 2 diabetes. Longer, well designed randomized clinical trials are needed to confirm these results.

Table 1. Baseline characteristics of participants prior to vitamin D repletion treatments

\begin{tabular}{lccc}
\hline Characteristic & \multicolumn{2}{c}{ Treatment } & \\
\cline { 2 - 3 } & $4000 \mathrm{IU}(\mathrm{n}=50)$ & $6000 \mathrm{IU}(\mathrm{n}=25)$ & \\
\hline & & & \\
25(OH)D $(\mathrm{ng} / \mathrm{ml})$ & $22.25 \pm 7.19$ & $23.74 \pm 5.09$ & 0.302 \\
FGP (mg/dl) & $188.76 \pm 87.19$ & $168.16 \pm 55.94$ & 0.220 \\
Age (years) & $54.76 \pm 8.56$ & $54.17 \pm 10.99$ & 0.999 \\
Gender (Female \%) & $48 \%$ & $52 \%$ & 0.809 \\
Years with T2D & $6.48 \pm 5.18$ & $5.48 \pm 5.93$ & 0.478 \\
Smoking (yes \%) & $10 \%$ & $28 \%$ & 0.091 \\
BMI (kg/m $\left.{ }^{2}\right)$ & $34.72 \pm 6.98$ & $30.74 \pm 4.93$ & 0.013 \\
Total Cholesterol (mg/dl) & $213.08 \pm 42.30$ & $193.88 \pm 41.03$ & 0.065 \\
Triglycerides (mg/dl) & $182.98 \pm 110.11$ & $201.44 \pm 91.35$ & 0.445 \\
LDL cholesterol (mg/dl) & $128.34 \pm 40.54$ & $115.56 \pm 34.53$ & 0.160 \\
HDL cholesterol (mg/dl) & $50.64 \pm 12.20$ & $42.44 \pm 10.40$ & 0.004 \\
Vitamin D intake (IU/day) & $316.82 \pm 251.70$ & $301.97 \pm 225.49$ & 0.797 \\
Sun exposure score & $20.06 \pm 14.92$ & $18.68 \pm 15.52$ & 0.715 \\
Upper arm skin color & $58.67 \pm 9.54$ & $62.09 \pm 5.65$ & 0.056 \\
Forearm skin color & $54.82 \pm 8.51$ & $54.37 \pm 4.37$ & 0.099 \\
Lipid lowering meds & $64 \%$ & $68 \%$ & 0.215 \\
\hline
\end{tabular}

Continues variables are presented as mean \pm SD and categorical variables as $\%$. 25(OH)D: serum vitamin D, FPG: fasting plasma glucose, T2D: type 2 diabetes, BMI: body mass index, LDL: low density lipoprotein, HDL: high density lipoprotein. 
Table 2. Group comparisons of metabolic parameters at different time points without adjusting for covariates

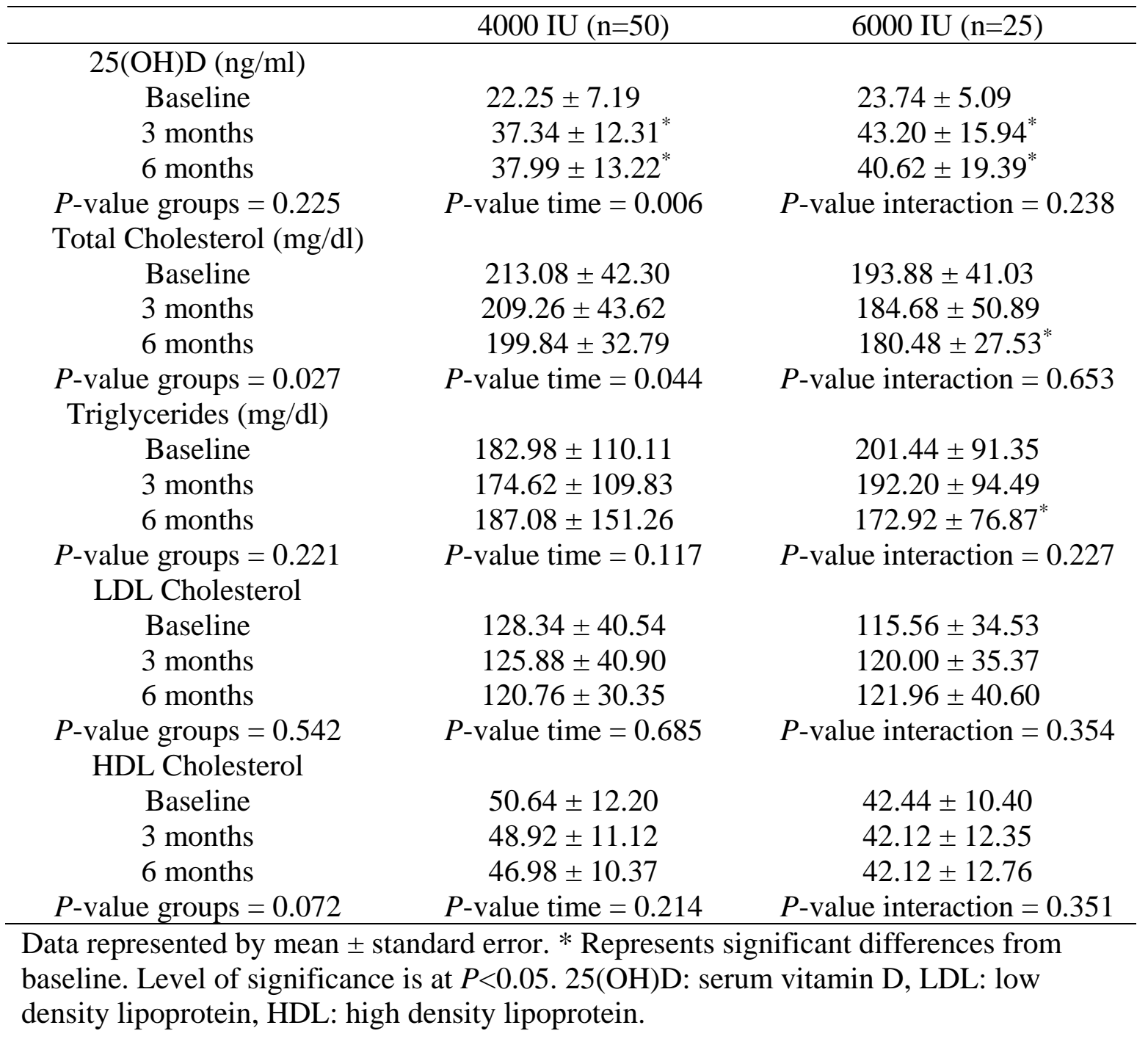


Table 3. Group comparisons of metabolic parameters at different time points adjusting for covariates

\begin{tabular}{|c|c|c|}
\hline & $4000 \mathrm{IU}(\mathrm{n}=50)$ & $6000 \mathrm{IU}(\mathrm{n}=25)$ \\
\hline \multicolumn{3}{|l|}{ 25(OH)D (ng/ml) } \\
\hline Baseline & $22.25 \pm 7.19$ & $23.74 \pm 5.09$ \\
\hline 3 months & $37.34 \pm 12.31^{*}$ & $43.20 \pm 15.94^{*}$ \\
\hline 6 months & $37.99 \pm 13.22^{*}$ & $40.62 \pm 19.39^{*}$ \\
\hline$P$-value groups $=0.232$ & $P$-value time $=0.019$ & $P$-value interaction $=0.352$ \\
\hline \multicolumn{3}{|l|}{ Total Cholesterol (mg/dl) } \\
\hline Baseline & $213.08 \pm 42.30$ & $193.88 \pm 41.03$ \\
\hline 3 months & $209.26 \pm 43.62$ & $184.68 \pm 50.89$ \\
\hline 6 months & $199.84 \pm 32.79$ & $180.48 \pm 27.53$ \\
\hline$P$-value groups $=0.204$ & $P$-value time $=0.954$ & $P$-value interaction $=0.605$ \\
\hline \multicolumn{3}{|l|}{ Triglycerides (mg/dl) } \\
\hline Baseline & $182.98 \pm 110.11$ & $201.44 \pm 91.35$ \\
\hline 3 months & $174.62 \pm 109.83$ & $192.20 \pm 94.49$ \\
\hline 6 months & $187.08 \pm 151.26$ & $172.92 \pm 76.87$ \\
\hline$P$-value groups $=0.962$ & $P$-value time $=0.250$ & $P$-value interaction $=0.167$ \\
\hline \multicolumn{3}{|l|}{ LDL Cholesterol } \\
\hline Baseline & $128.34 \pm 40.54$ & $115.56 \pm 34.53$ \\
\hline 3 months & $125.88 \pm 40.90$ & $120.00 \pm 35.37$ \\
\hline 6 months & $120.76 \pm 30.35$ & $121.96 \pm 40.60$ \\
\hline$P$-value groups $=0.969$ & $P$-value time $=0.872$ & $P$-value interaction $=0.423$ \\
\hline \multicolumn{3}{|l|}{ HDL Cholesterol } \\
\hline Baseline & $50.64 \pm 12.20$ & $42.44 \pm 10.40$ \\
\hline 3 months & $48.92 \pm 11.12$ & $42.12 \pm 12.35$ \\
\hline 6 months & $46.98 \pm 10.37$ & $42.12 \pm 12.76$ \\
\hline$P$-value groups $=0.088$ & $P$-value time $=0.188$ & $P$-value interaction $=0.118$ \\
\hline \multicolumn{3}{|c|}{$\begin{array}{l}\text { Data represented by mean } \pm \text { standard error. * Represents significant differences from } \\
\text { baseline. Level of significance is at } P<0.05 .25(\mathrm{OH}) \mathrm{D} \text { : serum vitamin } \mathrm{D}, \mathrm{LDL} \text { : low } \\
\text { density lipoprotein, HDL: high density lipoprotein. Analysis was adjusted for age, } \\
\text { gender, years with diabetes, smoking, BMI, vitamin D intake, sun exposure score, fasting } \\
\text { plasma glucose, upper arm skin color, forearm skin color, and lipid lowering medication } \\
\text { use. }\end{array}$} \\
\hline
\end{tabular}




\section{References}

1. Centers for Disease Control and Prevention. Vitamin D Status: United States, 20012006. Accessed April 29, 2013. Available http://www.cdc.gov/nchs/data/databriefs/db59.pdf

2. Holick MF. Vitamin D: a millennium perspective. J Cell Biochem. 2003;88:296-307.

3. Muller D, Kleinewietfeld M, Kvakan H. Vitamin D review. Journal of ReninAngiotensin-Aldosterone System. 2011;12:125-128.

4. Organization, W.H. World Health Statistics 2012; World Health Organization: Geneva, Switzerland, 2012.

5. Jorde R, Grimnes G. Vitamin D and metabolic health with especial reference to the effect of vitamin D on serum lipids. Prog Lipid Res. 2011;50:303-312.

6. Jaimungal S, Wehmeier K, Mooradian AD, Haas MJ. The emerging evidence for vitamin D-mediated regulation of apolipoprotein A1 synthesis. Nutr Res. 2011;31:805-812.

7. Skaaby T, Husemoen LLN, Pisinger C, Jorgensen T, Thuesen BH, Fenger M, et al. Vitamin D status and changes in cardiovascular risk factors: A prospective study of a general population. Cardiology. 2012;123:62-70.

8. Ponda MP, Dowd K, Finkielstein D, Holt PR, Breslow JL. The short term effects of vitamin D repletion on cholesterol: A randomized, placebo-controlled trial. Arterioscler Thromb Vasc Biol. 2012;32:2510-2515.

9. Alkharfy KM, Al-Daghri NM, Sabico SB, Al-Othman A, Moharram O, Alokail MS, et al. Vitamin D supplementation in patients with diabetes mellitus type 2 on different therapeutic regimens: a one-year prospective study. Cardiovascular Diabetology. 2013;12:113-123.

10. Al-Daghri NM, Alkharfy KM, El-Kholie E, Yousef M, Al-Othman A, Al-Saleh Y, et al. Vitamin D supplementation as an adjuvant therapy for Saudi patients with DMT2: an 18-month interventional study. Cardiovasc Diabetol. 2012;11(85):1-7.

11. Ginsberg HN. Insulin resistance and cardiovascular disease. J Clin Invest. 2000;106:453-458. 
12. Hanwell HE, Vieth R, Cole DE, Scillitani A, Modoni S, Frusciante V, et al. Sun exposure questionnaire predicts circulating 25-hydroxyvitamin D concentrations in Caucasian hospital workers in southern Italy. J Steroid Biochem Mol Biol. 2010;121(1-2):334-337.

13. Willet WC, Sampson L, Stampfer MJ, Rosner B, Bain C, Witschi J, et al. Reproducibility and validity of a semiquantitative food frequency questionnaire. Am J Epidemiol. 1985;122(1):51-65.

14. Nath SD, Huffman FG. Validation of a semi quantitative food frequency questionnaire to assess energy and macronutrient intakes of Cuban Americans. International Journal of Food Science and Nutrition. 2005;56(5):309-314.

15. Thuesen B, Husemoen L, Fenger M, Jakobsen J, Schwarz P, Toft U, et al. Determinants of vitamin D status in a general population of Danish adults. Bone. 2012;50:605-610.

16. Borges MC, Martini LA, Rogero MM. Current perspectives on vitamin D, immune system, and chronic diseases. Nutrition. 2011;27:399-404.

17. Salehpour A, Shidfar F, Hosseinpanah F, Vafa M, Razaghi M, Hoshiarrad A, et al. Vitamin $\mathrm{D}_{3}$ and the risk of CVD in overweight and obese women: A randomized controlled trial. Br J Nutr. 2012;108:1866-1873.

18. Khajehdehi P, Taheri S. Effect of oral calcitriol pulse therapy on the lipid, calcium, and glucose homeostasis of hemodialysis patients: its safety in a combination with oral calcium carbonate. J Ren Nutr. 2003;13:78-83.

19. Lacour B, Basile C, Drueke T, Funck-Brentano JL. Parathyroid function and lipid metabolism in the rat. 1982;7:157-165.

20. Ogata T, Miyauchi T, Sakai S, Irukiyama-Tomobe Y, Goto K, Yamaguchi L. Stimulation of peroxisome-proliferator-activated receptor alpha (PPAR alpha) attenuates cardiac fibrosis and endothelin-1 production in pressure-overloaded rat hearts. Clin Sci (Lond). 2002;103:284S-288S.

21. Jones G. Pharmacokinetics of vitamin D toxicity. Am J Clin Nutr. 2008;88:582S586S. 


\section{CHAPTER III: THE EFFECT OF VITAMIN D SUPPLEMENTATION ON GLUCOSE HOMEOSTASIS IN MINORITIES WITH TYPE 2 DIABETES}

\section{Introduction}

Low levels of vitamin D are prevalent in the US. According to data from the National Health and Nutrition Examination Surveys (NHANES) in 2001-2006, 33\% of the general US population had serum 25(OH)D below $50 \mathrm{nmol} / \mathrm{L}$. In addition, low vitamin D levels are common among minorities. For instance, 41\% of African Americans and 33\% of Mexican Americans had serum 25(OH)D below 50 nmol/L compared to 18\% of non-Hispanic Whites (1).

Vitamin D is produced in the skin by the action of ultraviolet light. Vitamin D can also be obtained from the diet with consumption of vegetable and animal products. Vitamin $\mathrm{D}_{3}$ needs to be activated by hydroxylation in the liver and kidney to form its metabolically active form: $1,25(\mathrm{OH})_{2} \mathrm{D}_{3}$. This metabolite produces its effects by activating the vitamin D receptor (VDR) in the cells (2).

With respect to diabetes, the VDRs are found in genes encoding proteins important for beta cell function which may have some effect on glucose homeostasis. For instance, vitamin D increases the calcium concentration in the cell which may translate into better glucose uptake. Similarly, vitamin D has anti-inflammatory properties that may reduce the chronic inflammation seen in T2D (3). Therefore, providing vitamin D to individuals with T2D may have an effect on glucose homeostasis. 
In fact, several interventional studies providing vitamin D to participants at risk or with T2D have been conducted with inconsistent results. Borissova et al (4) examined the effect of vitamin $\mathrm{D}_{3}$ supplementation on insulin resistance and insulin secretion in 10 patients with T2D. Seventeen age and gender-matched individuals without T2D served as controls. The intervention group received 1332 IU of cholecalciferol daily for 1 month. Fasting plasma insulin secretion increased significantly by $34.3 \%$, however, the decrease in insulin resistance was not significant. The small sample size and short duration of treatment were the major limitations of this study. In similar studies, vitamin D supplementation in men with T2D improved insulin secretion (5, 6). Inomata et al. (5) provided 2ug/d (80 IU/day) of alphacalcidiol versus placebo to 14 Japanese males with T2D, with mean age of $54.3 \pm 6.4$ years for 3 weeks. The area under the oral glucose tolerance test curve was used as a measure of insulin secretion. Results showed improved insulin secretion. Limitations of this study were lack of measure of plasma vitamin D concentrations and the small sample size. Similarly, Orwoll et al. (6) provided 1ug/d (40 $\mathrm{IU} / \mathrm{d}$ ) of 1,25(OH) 2 D versus placebo to 35 adults recently diagnosed with T2D (within 3 years) for 14 days, with mean age of $61 \pm 4.3$ years. Insulin secretion was determined from the area under the curve for the glucose tolerance test after a meal challenge. A tendency for better insulin secretion was observed. The main limitations of this study were the short duration of the intervention and the lack of assessment of serum vitamin D post-intervention.

In contrast, Jorde et al. (7) provided 40,000 IU per week versus placebo to 32 participants with T2D for 6 months. No significant change on insulin, fasting plasma glucose or A1C was noted. Participants in this study were not vitamin D insufficient, 
suggesting that vitamin D supplementation may have no effect on participants that are not vitamin D insufficient. Conflicting reports may be a consequence of different characteristics of the populations, inadequate dosages, different forms of vitamin D supplements used, short duration of the studies, different outcome variables, and lack of control of serum vitamin D levels pre and post intervention.

The vast majority of these studies have been conducted in non-Hispanic White populations. Prevalence of hypovitaminosis D however, is found to be higher in Blacks and Hispanics as compared to Whites (8-10). Since minorities such as African Americans and Hispanics have higher risk of both T2D and vitamin D deficiency as compared to Caucasians (11), it is important to determine the effect of vitamin D supplementation in this high risk population.

The aim of the present study was to determine the effect of supplemental vitamin D intake (4000 IU or 6000 IU of Cholecalciferol daily for 6 months) on fasting plasma glucose, fasting insulin, and A1C in a sample of African-Americans and Hispanics with T2D and vitamin D insufficiency $(25(\mathrm{OH}) \mathrm{D}<30 \mathrm{ng} / \mathrm{ml}), 30-70$ years of age, and living in South Florida.

\section{Methods}

\section{Subject Recruitment}

An intervention study to assess the effects of vitamin D supplementation (4000 IU/day and 6000 IU/day) over six months on cardiovascular disease markers among a sample of African Americans and Hispanics with T2D was conducted. The present study analyzed the data collected at screening (serum 25(OH)D), baseline (fasting plasma 
glucose, fasting insulin, and A1C), 3 months (serum 25(OH)D, fasting plasma glucose, fasting insulin, and $\mathrm{A} 1 \mathrm{C}$ ), and 6 months (serum 25(OH)D, fasting plasma glucose, fasting insulin, and A1C).

The study consisted of two phases: phase one included the screening of individuals, phase two included the recruitment of individuals who met inclusion criteria and beginning of the vitamin D intervention trial. Inclusion criteria were vitamin D insufficiency (25(OH)D $<30 \mathrm{ng} / \mathrm{ml}), 30-70$ years of age, African American or Hispanic with confirmed T2D. Exclusion criteria were taking vitamin D supplements other than standard daily multivitamin formula, being pregnant or lactating, having thyroid, hepatic, renal dysfunction, cancer, HIV, or major psychiatric disorders.

Flyers explaining the purpose of the study, inclusion/exclusion criteria and the investigators' emails and phone numbers were distributed in highly visited community areas such as churches, supermarkets, and clinics. Two clinics were visited every week for recruitment purposes: Borinquen Health Care Center and Clinical Care Medical Center. When volunteer participants called the investigators back, purposes of the study were explained and specific questions were asked to assure compliance with inclusion criteria. All qualified participants were invited to take part in a morning session at the Human Nutrition Laboratory at Florida International University (FIU) for fasting blood sampling to screen for vitamin D insufficiency. The study was approved by IRB at FIU. All participants were asked to sign an informed consent form previous to screening data collection. Only participants with confirmed T2D diagnosis by a physician were eligible for the study. All participants were screened for vitamin D insufficiency in phase one. 
They were contacted either to continue in the study or to inform them that they were disqualified based on their vitamin D levels.

Participants in both groups were required to take either 4000 IU or $6000 \mathrm{IU}$ of vitamin $\mathrm{D}$ (Cholecalciferol) per day given in the form of a pill in a single daily dose. Compliance was determined by returned pill count at follow ups. When less than $80 \%$ of the pills were taken, the subject was classified as non-compliant. Adverse events were recorded at each visit. Each participant was seen 4 times; at screening, baseline, 3 months, and 6 months. Serum 25(OH)D was measured at screening, 3 months, and 6 months. Fasting plasma glucose, fasting insulin, and A1C were measured at baseline, 3 months, and 6 months visits. The time spam between screening and baseline was one week.

Total study lasted for 25 weeks for each participant from screening to final assessment. The study started in June 2011 and was completed on September 2013. Ninety two participants were screened. Seventy five qualified for the intervention ( $\mathrm{n}=50$ for $4000 \mathrm{IU} /$ day treatment and n=25 for $6000 \mathrm{IU} /$ day treatment). Three participants qualified for the study based on their vitamin D status but did not attend the 3 month and 6 month follow ups (all in the 4000 IU group). Eight participants attended the 3 month but not the 6 month follow up (5 in the 4000 IU and 3 in the 6000 IU group, respectively). Five participants completed the study but were non-compliant (3 in the $4000 \mathrm{IU}$ and 2 in the $6000 \mathrm{IU}$ treatment, respectively). Since an intent to treat approach was followed, all 75 participants were included in the present study.

\section{Blood Collection}


Venous blood (15 ml) was collected from each subject by a certified phlebotomist using standard laboratory methods at each study point. After coagulation, blood was centrifuged at 2500 RPM for 30 minutes. The plasma glucose concentration was measured by hexokinase enzymatic method. A1C was measured by the DCA2000+ system (Bayer Corporation, Diagnostics Division, N.Y.) using the monoclonal antibody method. Insulin in fasting blood was determined by radioimmunoassay using an insulinspecific kit (Linco Research Inc., St. Charles, MO). Serum vitamin D concentrations were measured with an enzyme-immunoassay kit by absorbance (Immunodiagnostic Systems Scottsdale, AZ). Vitamin D values were tested at screening, 3 month and 6 month visits. Fasting plasma glucose, fasting insulin, and A1C were tested at baseline, 3 month, and 6 month visits.

\section{Socio-demographic Questionnaire}

Participants were asked to fill out standard questionnaires on site. Trained interviewers bilingual in English and Spanish administered the questionnaires in the language of preference of the participants. Data were collected using a sociodemographic questionnaire which includes questions related to gender, age, education, years with diabetes, smoking, and medications at baseline.

\section{Anthropometric Measurements}

Height and weight were measured using a SECA clinical balance scale (Seca Corp, Columbia, MD). Body mass index (BMI) was calculated as weight in $\mathrm{kg} / \mathrm{height}$ in $\mathrm{m}^{2}$. BMI was calculated for baseline, 3 month, and 6 month visits. Only baseline values 
were used for the analysis due to the lack of significant changes in BMI at 3 months and 6 months.

\section{Sun Exposure Questionnaire}

The sun exposure questionnaire developed by Hanwell et al. (12) was applied following the original rubric. Time spent outdoors during the previous week $(0 \leq 5$ minutes, $1=5-30$ minutes and 2= >30 min) was self-reported. Four options for skin exposed while outdoors were offered (1=face and hands, 2=face, hands and arms, 3=face, hands and legs and 4=bathing suit). The daily sun exposure score for each day was calculated by multiplying the time spent outdoors score times the skin exposed while outdoors score. The scale for each day ranged from 0 to 8 . The weekly sun exposure was calculated by adding the daily scores $(\min =0, \max =56)$. The questionnaire was administered at baseline, 3 months, and 6 months, but because it did not change significantly, only baseline values were used in the analysis. Since the sun is the main source of vitamin $\mathrm{D}$, baseline sun exposure may have an effect on our final outcomes. Therefore, analysis was adjusted for sun exposure.

\section{Skin Color}

In order to have an objective measure of sun exposure, skin color was determined by reflectance colorimetry using the SmartProbe 400 (IMS Inc. USA). This instrument uses the International Commission on Illumination Scale which ranges from 0 (black) to 100 (white) for skin color. Two readings at each measurement site for each participant 
were taken: two on the dorsal aspect of the wrist of the right hand (area most exposed to sun), two on the inside of the right upper arm (area less exposed to the sun). The mean values of the two readings at each measurement site were used for analysis. Data were collected at baseline, 3 months, and 6 months, but because it did not change significantly, only baseline values were used in the present analysis. Since participants with darker skin color tend to have lower levels of serum $25(\mathrm{OH}) \mathrm{D}$, skin color may have an effect on glucose homeostasis. Therefore, analysis of the effect of vitamin D supplementation on lipid panel was adjusted for skin color.

\section{Assessment of Dietary Intake}

Dietary intake was determined using the long food frequency questionnaire (FFQ) developed by Walter Willett (13). This FFQ has been validated in different ethnic groups and, also, specifically in Cuban-Americans in South Florida (14). Participants selfreported the average consumption of specific amount of foods over the past 12 months. Frequencies ranged from “never” to "six or more servings per day”. The FFQ also assessed the frequency use of multivitamin/mineral supplements, salt, sugar, alcohol and vitamin $\mathrm{D}$ intake. The questionnaire was administered at baseline.

\section{Statistical analysis}

Descriptive statistics were used for baseline characteristics. Numerical normally distributed data and categorical data were compared using independent t-test and ChiSquared test, respectively. Intent to treat analyses was used to analyze the effect of vitamin $\mathrm{D}$ on the outcome variables. 
Main variables of the study were: fasting plasma glucose, A1C, and fasting insulin. All the variables were input as continuous in the analysis. Control variables included: BMI, gender, age, smoking, years with diabetes, sun exposure score, vitamin D intake, and skin color.

Mixed model was used to compare treatment effects (4000 IU vs. $6000 \mathrm{IU}$ ) on the outcome variables. Bonferroni multiple comparison tests was used to detect significant changes from baseline, 3 months, and 6 months on the outcome variables with and without adjusting for age, gender, years with diabetes, smoking, BMI, vitamin D intake, sun exposure score, upper arm skin color, and forearm skin color. Significance was set at $\mathrm{p}<0.05$ and all analyses were two sided. Statistical analysis was conducted using SPSS 18.0 (Chicago).

\section{Results}

Groups were similar in all baseline characteristics except for BMI (34.72 \pm 6.98 $\mathrm{kg} / \mathrm{m}^{2}$ vs. $30.74 \pm 4.93 \mathrm{~kg} / \mathrm{m}^{2}, P=0.013$ for $4000 \mathrm{IU}$ and $6000 \mathrm{IU}$; respectively) (Table 1). There was no significant difference between groups regarding serum 25(OH)D $(P=0.225)$. However, significant improvements in serum 25(OH)D levels were seen from baseline to 3 month and 6 months, respectively in both treatments (from $22.25 \pm 7.19$ to $37.34 \pm 12.31$ and $37.99 \pm 13.22, P<0.05$ in the 4000 IU group; from $23.74 \pm 5.09$ to $43.20 \pm 15.94$ and $40.62 \pm 19.39, P<0.05$ in the 6000 IU group) (Table 2).

Differences between 3 months and 6 months levels for serum 25(OH)D were not significant in both treatments $(P>0.05)$. In the 6000 IU group, the value showed a nonsignificant decline at 6 months compare to the 3 months follow up. 
A decreasing trend was observed for fasting plasma glucose in the 4000 IU group and for A1C in the 6000 IU group. However, no significant changes were observed for fasting plasma glucose, insulin or A1C between groups and within groups both in the unadjusted and adjusted models (Table 2 and Table 3). Similarly, interaction values were not-significant (Table 2 and Table 3).

Adherence defined as consumption of more than $80 \%$ of supplied vitamin D pills was $94 \%$ for the $4000 \mathrm{IU}$ group and $92 \%$ for the $6000 \mathrm{IU}$ group without any differences between groups. No adverse events were reported during the course of the study.

\section{Discussion}

Low serum vitamin D levels are common among participants with type 2 diabetes. However, it is still uncertain if there is a cause and effect association between these two conditions or if low vitamin D levels are just a marker of worse health status. Impaired $\beta$ cell function and insulin resistance are the two factors that lead to development of type 2 diabetes. Vitamin D deficiency decreased the ability of $\beta$ cells to secrete insulin, while vitamin D repletion restored insulin secretion in vitro studies (15). The direct effect of vitamin $D$ in $\beta$ cells may be caused by the binding of the active metabolite 1,25 dihydroxyvitamin $\mathrm{D}$ to the vitamin D receptor site on these cells (16). The indirect effect of vitamin D in insulin secretion may be due the regulation of calcium, since insulin secretion is a calcium-dependent process (17). Insulin sensitivity may also be improved in peripheral cells by increasing the expression of insulin receptors and by increasing the calcium concentration (3). In order to prevent type 2 diabetes, interventions that preserve $\beta$ cell function are desired. 
Studies regarding the effect of vitamin D supplementation for participants at risk or with type 2 diabetes had provided conflicting results. Some intervention studies conducted in small samples and for short duration have shown improvements in insulin secretion, but not insulin sensitivity $(3,18)$. Studies with positive results were conducted in participants with a recent diagnosis of type 2 diabetes ( $<3$ years) or at risk of type 2 diabetes. Pittas et al. (18), found that $700 \mathrm{IU} /$ day of vitamin $\mathrm{D}_{3}$ combined with calcium improved insulin resistance in participants with impaired glucose tolerance. Mitri et al. (3), found that $2000 \mathrm{IU} /$ day of vitamin $\mathrm{D}_{3}$ for 16 weeks improved the disposition index and insulin secretion in participants at risk of type 2 diabetes. In addition, even though, no significant change was seen in A1C levels, there was a trend toward and attenuation on the rise of this marker, which occurs over time in the natural history of pre-diabetes. Intervention studies conducted with participants with established type 2 diabetes (> 3 years) had found negative results. Jorde et al (7) provided 40,000 IU per week versus placebo to 32 participants with T2D for 6 months. No significant change in insulin, fasting plasma glucose or A1C was noted. A meta-analysis of 15 randomized clinical trials reported that a reduction in fasting plasma glucose and insulin resistance was observed only in participants with impaired glucose tolerance, but no effect was observed in participants with type 2 diabetes after vitamin D supplementation (19).

Our results did not support the hypothesis that vitamin D supplementation may improve glucose homeostasis in patients with established type 2 diabetes. Our participants had $6.48 \pm 5.18$ and $5.48 \pm 5.93$ years with type 2 diabetes for the $4000 \mathrm{IU}$ and $6000 \mathrm{IU}$ groups, respectively. This may indicate that vitamin D supplementation have 
no effect on glucose homeostasis once beta cell function have passed a certain point of deterioration.

In fact, Alkharfy et al. (20), conducted a study to determine the effect of 2000 IU/day of Cholecalciferol supplementation for 12 months among participants on diet, insulin, or oral hypoglycemic agents compared with a healthy control group. No improvements on glucose homeostasis were found in any of the groups. However, significant reduction in triglycerides and total cholesterol were observed in the insulin + vitamin D and oral hypoglycemic agents + vitamin D groups. According to a similar study, vitamin D seems to have a better effect on lipid panel and not on markers of glycemic control in patients with type 2 diabetes (21).

Our study had sufficient power to find changes in fasting plasma glucose, fasting insulin, and A1C. The vitamin D supplement dosages provided were high enough to achieve serum 25(OH)D>30 ng/ml which is the level recommended for optimum health (22). However, this recommendation (serum $25(\mathrm{OH}) \mathrm{D}>30 \mathrm{ng} / \mathrm{ml}$ ) was based on observational studies and evidence from intervention studies about the optimum vitamin D level for adequate glucose homeostasis is lacking. Another strong point of our study was that individuals did not change medication, vitamin D intake, BMI, smoking or sun exposure habits during the course of the study and analysis was adjusted for those variables. In addition, compliance in our study was high with $94 \%$ for the 4000 IU group and 92\% for the 6000 IU group without any differences between groups. No adverse events were reported during the course of the study.

In contrast, a factor that may explain the negative results in our study may be that our sample was categorized as obese according to their BMI. Since vitamin D is 
sequestered in the fat tissue and not metabolically active in obese patients (23), it may be possible that a higher dosage or a longer duration of treatment is needed to see changes in glucose homeostasis markers in obese participants with type 2 diabetes.

Similarly, all our participants were vitamin D deficient at baseline. Therefore, it may be possible that after vitamin $\mathrm{D}$ repletion, other functions related to vitamin $\mathrm{D}$ are improved first and $\beta$ cell restoration was not the priority. Since our sample did not have enough variability regarding baseline vitamin D levels, a post hoc analysis adjusting for baseline vitamin D levels to see if the ones who started with higher serum vitamin D levels improved the most did not find any significant results either.

A trend for a decline in fasting plasma glucose was observed in the $4000 \mathrm{IU}$ group. However, since no improvement was observed in A1C, a marker of long term glycemic control, changes in fasting plasma glucose are of limited significance in this population with established type 2 diabetes.

Limitations of our study include the use of a convenience sample without randomization, thus our results are not generalizable, the small number of African American participants which did not allow us to analyze the data by ethnicity, and the inclusion of only participants with vitamin D deficiency which decreased the external validity of the study.

In conclusion, improvements in glucose homeostasis were not observed after 6 months of vitamin $\mathrm{D}_{3}$ supplementation among Hispanics and African American participants with type 2 diabetes. The main objective of glycemic control in patients with type 2 diabetes is to prevent microvascular and macrovascular complications. The use of surrogate measures like fasting plasma glucose, insulin resistance, and A1C are of 
practical clinical significance but not ideal for research purposes. Longer and larger studies supplementing vitamin $\mathrm{D}$ to participants with type 2 diabetes that focus on microvascular and macrovascular complications, instead of surrogate measures, are needed to confirm our results.

Table 1. Baseline characteristics of participants prior to vitamin D repletion treatments

\begin{tabular}{lccc}
\hline Characteristic & \multicolumn{2}{c}{ Treatment } & \\
\cline { 2 - 3 } & $4000 \mathrm{IU}(\mathrm{n}=50)$ & $6000 \mathrm{IU}(\mathrm{n}=25)$ & \\
\hline & & & \\
25(OH)D (ng/me & \\
FGP (mg/dl) & $22.25 \pm 7.19$ & $23.74 \pm 5.09$ & 0.302 \\
Age (years) & $188.76 \pm 87.19$ & $168.16 \pm 55.94$ & 0.220 \\
Gender (Female \%) & $54.76 \pm 8.56$ & $54.17 \pm 10.99$ & 0.999 \\
Years with T2D & $48 \%$ & $52 \%$ & 0.809 \\
Smoking (yes \%) & $6.48 \pm 5.18$ & $5.48 \pm 5.93$ & 0.478 \\
BMI $\left(\mathrm{kg} / \mathrm{m}^{2}\right)$ & $10 \%$ & $28 \%$ & 0.091 \\
A1C $(\%)$ & $34.72 \pm 6.98$ & $30.74 \pm 4.93$ & 0.013 \\
Insulin $(\mu \mathrm{U} / \mathrm{ml})$ & $8.25 \pm 2.40$ & $8.26 \pm 1.92$ & 0.981 \\
Vitamin D intake (IU/day) & $12.86 \pm 12.82$ & $12.13 \pm 7.08$ & 0.753 \\
Sun exposure score & $20.06 \pm 251.70$ & $301.97 \pm 225.49$ & 0.797 \\
Upper arm skin color & $58.67 \pm 9.54$ & $18.68 \pm 15.52$ & 0.715 \\
Forearm skin color & $54.82 \pm 8.51$ & $62.09 \pm 5.65$ & 0.056 \\
\hline Conn & $54.37 \pm 4.37$ & 0.099 \\
\hline
\end{tabular}

Continues variables are presented as mean \pm SD and categorical variables as $\%$. 25(OH)D: serum vitamin D, FPG: fasting plasma glucose, T2D: type 2 diabetes, BMI: body mass index, A1C: glycated hemoglobin. 
Table 2. Group comparisons of metabolic parameters at different time points without adjusting for covariates

\begin{tabular}{ccc}
\hline & $4000 \mathrm{IU}(\mathrm{n}=50)$ & $6000 \mathrm{IU}(\mathrm{n}=25)$ \\
\hline 25(OH)D $(\mathrm{ng} / \mathrm{ml})$ & $22.25 \pm 7.19$ & $23.74 \pm 5.09$ \\
Baseline & $37.34 \pm 12.31^{*}$ & $43.20 \pm 15.94^{*}$ \\
3 months & $37.99 \pm 13.22^{*}$ & $40.62 \pm 19.39^{*}$ \\
6 months & $P$-value time $=0.006$ & $P$-value interaction $=0.238$ \\
$P$-value groups $=0.225$ & $188.76 \pm 87.19$ & $168.16 \pm 55.94$ \\
FPG $(\mathrm{mg} / \mathrm{dl})$ & $182.14 \pm 73.34$ & $176.56 \pm 59.68$ \\
Baseline & $173.16 \pm 73.54$ & $160.96 \pm 63.64$ \\
3 months & $P$-value time $=0.265$ & $P$-value interaction $=0.814$ \\
6 months & $12.86 \pm 12.82$ & $12.13 \pm 7.08$ \\
$P$-value groups $=0.321$ & $11.08 \pm 7.47$ & $13.08 \pm 7.25$ \\
Insulin $(\mu U / m l)$ & $11.53 \pm 7.84$ & $12.20 \pm 7.33$ \\
Baseline & $P$-value time $=0.390$ & $P$-value interaction $=0.412$ \\
3 months & & \\
6 months & $8.25 \pm 2.40$ & $8.26 \pm 1.92$ \\
$P$-value groups $=0.748$ & $8.32 \pm 2.17$ & $8.08 \pm 1.63$ \\
A1C $(\%)$ & $8.25 \pm 2.14$ & $8.05 \pm 1.80$ \\
Baseline & $P$-value time $=0.402$ & $P$-value interaction $=0.306$ \\
3 months & & \\
6 months & & \\
$P$-value groups $=0.198$ & & \\
& &
\end{tabular}

Data represented by mean \pm standard error. $*$ Represents significant differences from baseline. Level of significance is at $P<0.05$. 25(OH)D: serum vitamin D, FPG: fasting plasma glucose, A1C: glycated hemoglobin. 
Table 3. Group comparisons of metabolic parameters at different time points adjusting for covariates

\begin{tabular}{ccc}
\hline & $4000 \mathrm{IU}(\mathrm{n}=50)$ & $6000 \mathrm{IU}(\mathrm{n}=25)$ \\
\hline 25(OH)D $(\mathrm{ng} / \mathrm{ml})$ & $22.25 \pm 7.19$ & $23.74 \pm 5.09$ \\
Baseline & $37.34 \pm 12.31^{*}$ & $43.20 \pm 15.94^{*}$ \\
3 months & $37.99 \pm 13.22^{*}$ & $40.62 \pm 19.39^{*}$ \\
6 months & $P$-value time $=0.019$ & $P$-value interaction $=0.352$ \\
$P$-value groups $=0.232$ & & \\
FPG $(\mathrm{mg} / \mathrm{dl})$ & $188.76 \pm 87.19$ & $168.16 \pm 55.94$ \\
Baseline & $182.14 \pm 73.34$ & $176.56 \pm 59.68$ \\
3 months & $173.16 \pm 73.54$ & $160.96 \pm 63.64$ \\
6 months & $P$-value time $=0.311$ & $P$-value interaction $=0.949$ \\
$P$-value groups $=0.439$ & $12.86 \pm 12.82$ & $12.13 \pm 7.08$ \\
Insulin $(\mu \mathrm{H} / \mathrm{ml})$ & $11.08 \pm 7.47$ & $13.08 \pm 7.25$ \\
Baseline & $11.53 \pm 7.84$ & $12.20 \pm 7.33$ \\
3 months & $P$-value time $=0.475$ & $P$-value interaction $=0.490$ \\
6 months & & \\
$P$-value groups $=0.859$ & $8.25 \pm 2.40$ & $8.26 \pm 1.92$ \\
A1C $(\%)$ & $8.32 \pm 2.17$ & $8.08 \pm 1.63$ \\
Baseline & $8.25 \pm 2.14$ & $8.05 \pm 1.80$ \\
3 months & $P$-value time $=0.417$ & $P$-value interaction $=0.329$ \\
6 months & & \\
$P$-value groups $=0.213$ & &
\end{tabular}

Data represented by mean \pm standard error. $*$ Represents significant differences from baseline. Level of significance is at $P<0.05$. 25(OH)D: serum vitamin D, FPG: fasting plasma glucose, A1C: glycated hemoglobin. Analysis was adjusted for age, gender, years with diabetes, smoking, BMI, vitamin D intake, sun exposure score, upper arm skin color, forearm skin color. 


\section{References}

1. Centers for Disease Control and Prevention. Vitamin D Status: United States, 2001-2006. Accessed April 29, 2013. Available http://www.cdc.gov/nchs/data/databriefs/db59.pdf

2. Holick MF. Vitamin D: a millennium perspective. J Cell Biochem. 2003;88:296307.

3. Mitri J, Dawson-Hughes B, Hu FB, Pittas AG. Effects of vitamin D and calcium supplementation on pancreatic $\beta$ cell function, insulin sensitivity, and glycemia in adults at high risk of diabetes: the Calcium and Vitamin D for Diabetes Mellitus (CaDDM) randomized controlled trial. Am J Clin Nutr. 2011;94:486-494.

4. Borissova AM, Tankova T, Kirilov G, Dakovska L, Kovacheva R. The effect of vitamin D3 on insulin secretion and peripheral insulin sensitivity in type 2 diabetic patients. Int J Clin Pract. 2003;57(4):258-261.

5. Inomata S, Kadowaki S, Yamatani T. Effect of $1 \alpha(\mathrm{OH})$-vitamin D3 on insulin secretion in diabetes mellitus. Bone and Mineral. 1986;1(3):187-192.

6. Orwoll E, Riddle M, Prince M. Effects of vitamin D on insulin and glucagon secretion in non-insulin-dependent diabetes mellitus. American Journal of Clinical Nutrition. 1994;59(5):1083-1087.

7. Jorde R, Figenschau Y. Supplementation with cholecalciferol does not improve glycaemic control in diabetic subjects with normal serum 25-hydroxyvitamin D levels. European Journal of Nutrition. 2009;48(6):349-354.

8. Fiscella K, Pranks P. Vitamin D, race, and cardiovascular mortality: Findings from a national US sample. Annuals of Family Medicine. 2010;8(1):11-18.

9. Yanoff LB, Parikh SH, Spitalnik A, Denkinger B, Sebring NG, Slaughter P, McHugh T, Remaley AT, Yanovski JA. The prevalence of hypovitaminosis D and secondary hyperparathyroidism in obese Black Americans. Clin Endocrinol. 2006;64(5):523-529.

10. Zadshir A, Tareen N, Pan D, Norris K, Martins D. The prevalence of hypovitaminosis D among US adults: data from the NHANEIII. Ethn Dis. 2005;15(Suppl 5):S5-97-1010. 
11. Centers for Disease Control and Prevention. National diabetes fact sheet: general information and national estimates on diabetes in the United States, 2007. Atlanta, GA: U.S. Department of Health and Human Services, Centers for Disease Control and Prevention, 2008. Accessed April 24, 2013. Available online: http://www.cdc.gov/diabetes/pubs/pdf/ndfs_2007.pdf

12. Hanwell HE, Vieth R, Cole DE, Scillitani A, Modoni S, Frusciante V, et al. Sun exposure questionnaire predicts circulating 25-hydroxyvitamin D concentrations in Caucasian hospital workers in southern Italy. J Steroid Biochem Mol Biol. 2010;121(1-2):334-337.

13. Willet WC, Sampson L, Stampfer MJ, Rosner B, Bain C, Witschi J, et al. Reproducibility and validity of a semiquantitative food frequency questionnaire. Am J Epidemiol. 1985;122(1):51-65.

14. Nath SD, Huffman FG. Validation of a semi quantitative food frequency questionnaire to assess energy and macronutrient intakes of Cuban Americans. International Journal of Food Science and Nutrition. 2005;56(5):309-314.

15. Norman AW, Frankel JB, Heldt AM, Grodsky GM. Vitamin D deficiency inhibits pancreatic secretion of insulin. Science. 1980;209:823-825.

16. Johnson JA, Grande JP, Roche PC, Kumar R. Immunoistochemical localization of the 1,25(OH)2D3 receptor and calbindin D28k in human and rat pancreas. Am J Physiol 1994;267:E356-360.

17. Sergeev IN, Rhoten WB. 1,25-Dihydroxyvitamin D3 evokes oscillations of intracellular calcium in a pancreatic beta-cell line. Endocrinology. 1995;136:2852-2861.

18. Pittas AG, Harris SS, Stark PC, Dawson-Hughes B. The effects of calcium and vitamin D supplementation on blood glucose and markers of inflammation in nondiabetic adults. Diabetes Care. 2007;30:980-986.

19. George PS, Pearson ER, Witham MD. Effect of vitamin D supplementation on glycemic control and insulin resistance: a systemic review and meta-analysis. Diabetic Medicine. 2012;29:e142-e150.

20. Alkharfy KM, Al-Daghri NM, Sabico SB, Al-Othman A, Moharram O, Alokail MS, et al. Vitamin D supplementation in patients with diabetes mellitus type 2 on different therapeutic regimens: a one-year prospective study. Cardiovascular Diabetology. 2013;12:113-122.

21. Al-Daghri NM, Alkharfy KM, El-Kholie E, Yousef M, Al-Othman A, Al-Saleh Y, et al. Vitamin D supplementation as an adjuvant therapy for Saudi patients 
with DMT2: an 18-month interventional study. Cardiovascular Diabetology. 2012;11:85-96.

22. Bischoff-Ferrari HA, Giovannucci E, Willett WC, Dietrich T, Dawson-Hughes B. Estimation of optimal serum concentrations of 25-hydroxyvitamin D for multiple health outcomes. Am J Clin Nutr. 2006;84:18-28.

23. Wortsman J, Matsuoka LY, Chen TC, Lu Z, Holick MF. Decreased bioavailability of vitamin D in obesity. Am J Clin Nutr. 2000;72:690-693. 


\section{CHAPTER IV: VITAMIN D REPLETION IN MINORITIES WITH TYPE 2 DIABETES AND COEXISTENT VITAMIN D INSUFFICIENCY}

\section{Introduction}

Low levels of vitamin D are prevalent in the US (1). According to data from the National Health and Nutrition Examination Surveys (NHANES) in 2001-2006, 33\% of the general US population had serum 25(OH)D below $50 \mathrm{nmol} / \mathrm{L}$. In addition, low vitamin D levels are especially common among minorities. For instance, $41 \%$ of African Americans and 33\% of Mexican Americans had serum 25(OH)D below 50 nmol/L compared to $18 \%$ of non-Hispanic Whites (1).

Poor vitamin D status has been found in participants at risk or with type 2 diabetes (T2D), however, the nature of this relationship is not clear (2, 3). Similarly, a negative association between vitamin $\mathrm{D}$ levels and insulin resistance has been reported in a large sample representative of the US adult population and in participants at risk for T2D (3, 4). According to these results, vitamin D levels are positively associated with insulin sensitivity and negatively associated with insulin resistance. The findings further suggest that vitamin D repletion would be of benefit to those with or at risk for diabetes.

Protocols for correction of vitamin D insufficiency in patients with cystic fibrosis, chronic kidney disease, hyperparathyroidism, osteoporosis and pregnancy have been published (5-9). However, there is no standard method developed for the repletion of vitamin D insufficiency in participants with T2D.

Some regimens to improve the vitamin D status in participants with T2D have been reported. For instance, Borissova et al (10) examined the effect of vitamin $\mathrm{D}_{3}$ 
supplementation on insulin resistance and insulin secretion in 10 patients with T2D. The intervention group received 1332 IU of cholecalciferol daily for 1 month. Inomata et al. (11) provided 2ug/d (80 IU/day) of alphacalcidiol versus placebo to 14 Japanese males with T2D for 3 weeks and evaluated improvements in insulin secretion. However, this study did not measure plasma vitamin D concentrations. Similarly, Orwoll et al. (12) provided 1 ug/d (40 IU/d) of 1,25(OH) 2 D versus placebo to 35 adults (mean age of 61 years old) with recently diagnosed T2D (within 3 years) for 14 days. A tendency for better insulin secretion was observed. Main limitations of this study were the short duration of the intervention and the lack of assessment of serum vitamin D postintervention. Persons with T2D and low serum 25(OH)D had improvements in glycemic control with $3000 \mathrm{IU}$ of vitamin $\mathrm{D}_{3}$ for 6 and 9 months (13). None of these studies have specifically evaluated the effectiveness of vitamin D supplementation regimens on vitamin D repletion.

Recently, the Endocrine Society announced new clinical practice guidelines of standard care for vitamin D supplementation for vitamin D insufficient populations (1500-2000 IU daily for ages 19-70) to achieve sufficiency (25(OH)D >30 ng/ml) and recommended an upper limit of 4000 IU/day as the threshold for safety in healthy individuals. In addition, all adults who are vitamin D deficient $(25(\mathrm{OH}) \mathrm{D}<20 \mathrm{ng} / \mathrm{ml})$ are recommended to supplement with 6000 IU/d of vitamin $\mathrm{D}_{3}$ until sufficiency is reached, followed by a maintenance therapy of 2000 IU/d. In obese patients, and patients taking medications that interfere with vitamin D metabolism, the suggested therapy is to supplement with 6000-10000 IU/d of vitamin $\mathrm{D}_{3}$ until sufficiency is reached, followed by a maintenance therapy of 3000-6000 IU/d (14). Optimal vitamin D supplementation 
required for participants with T2D, and individuals with dark skin color who are also insufficient in vitamin D has not been determined. Therefore, it is important to test the efficacy of the new standard of care in African Americans and Hispanics with T2D or if higher dosages are needed. However, there is concern that vitamin D repletion regimens may produce toxicity. Serum 25(OH)D levels $>150 \mathrm{ng} / \mathrm{ml}$ have been used as the threshold for toxicity (15).

The objective of the present study was to evaluate the efficacy and safety of two vitamin D repletion regimens: 4000 IU and 6000 IU of Cholecalciferol daily for 6 months in African Americans and Hispanics with T2D while monitoring serum vitamin D levels for toxicity.

\section{Methods}

\section{Participants}

An intervention study to assess the effects of vitamin D supplementation (4000 IU/day and 6000 IU/day) over six months on cardiovascular disease markers among a sample of African Americans and Hispanics with T2D was conducted. The present study analyzed the data collected at screening, 3 months, and 6 months.

The study consisted of two phases: phase one included the screening of

individuals, phase two included the recruitment of individuals who met inclusion criteria and beginning of the vitamin $\mathrm{D}$ intervention trial. The inclusion criteria were vitamin $\mathrm{D}$ insufficiency $(25(\mathrm{OH}) \mathrm{D}<30 \mathrm{ng} / \mathrm{ml}), 30-70$ years of age, African American or Hispanic with confirmed T2D. Exclusion criteria were taking vitamin D supplements other than 
standard daily multivitamin formula, pregnant or lactating, having thyroid, hepatic, renal dysfunction, cancer, HIV, and major psychiatric disorders.

Flyers explaining the purpose of the study, inclusion/exclusion criteria and containing investigators' emails and phone numbers were distributed in highly visited community areas such as churches, supermarkets, and clinics. Two clinics were visited every week for recruitment purposes: Borinquen Health Care Center and Clinical Care Medical Center. When participants called the investigators, purposes of the study were explained and specific questions were asked to assure compliance with inclusion criteria. All qualified participants were invited to participate in a morning session at Human Nutrition Laboratory at Florida International University (FIU) for fasting blood sampling to screen for vitamin D insufficiency. All participants were asked to sign an informed consent form previous to screening data collection and to provide contact number and address of their physician, as well as their own contact information. Only participants with T2D diagnosis confirmed by a physician were eligible to participate in the study. The study was approved by IRB at FIU.

Participants in both groups were required to take either $4000 \mathrm{IU}$ or $6000 \mathrm{IU}$ of vitamin D (Cholecalciferol) per day given in the form of a pill in a single daily dose. Compliance was determined by pill count. When less than $80 \%$ of the pills were taken, the subject was classified as non-compliant. Adverse events were recorded at each visit. Each participant was seen 4 times; at screening, baseline, 3 months, and 6 months. Parathyroid hormone (PTH) and serum 25(OH)D were measured at screening, 3 months, and 6 months. Total study lasted for 25 weeks for each participant from screening to final assessment. The study started in June 2011 and was completed on September 2013. 
Ninety two participants were screened. Seventy five qualified for the intervention ( $\mathrm{n}=50$ for $4000 \mathrm{IU} /$ day treatment and $\mathrm{n}=25$ for $6000 \mathrm{IU} /$ day treatment). Three participants qualified for the study based on their vitamin D status but did not attend the 3 month and 6 month follow ups (all in the 4000 IU group). Eight participants attended the 3 month but not the 6 month follow up (5 in the $4000 \mathrm{IU}$ and 3 in the 6000 IU group, respectively). Five participants completed the study but were non-compliant (3 in the $4000 \mathrm{IU}$ and 2 in the $6000 \mathrm{IU}$ treatment, respectively). Since an intent to treat approach was followed, all 75 participants were included in the present study.

\section{Blood Collection}

Venous blood (15 ml) was collected from each subject by a certified phlebotomist using standard laboratory methods at each study point. After coagulation, blood was centrifuged at 2500 RPM for 30 minutes. Glycated hemoglobin (A1C) was measured by the DCA2000+ system (Bayer Corporation, Diagnostics Division, N.Y., U.S.) using the monoclonal antibody method. Serum vitamin D concentrations were measured with an enzyme-immunoassay kit by absorbance (Immunodiagnostic Systems Scottsdale, A.Z., U.S.). Color intensity developed was inversely proportional to the concentration of 25(OH)D. Parathyroid hormone was determined by an electrochemiluminescence immunoassay (E170, Roche, Basel, Switzerland).

\section{Socio-demographic Questionnaire}

Participants were asked to fill out standard questionnaires on site. Trained interviewers bilingual in English and Spanish administered the questionnaires in the 
language of preference of the participants. Data were collected using a socio-

demographic questionnaire which included questions related to gender, age, years with diabetes, and smoking.

\section{Anthropometric Measurements}

Height and weight were measured using a SECA clinical balance scale (Seca Corp, Columbia, MD). Body mass index (BMI) was calculated as weight in $\mathrm{kg} / \mathrm{height}$ in $\mathrm{m}^{2}$.

\section{Statistical Analysis}

The descriptive statistics for continuous variables are presented as mean \pm SD and proportions for categorical variables. Baseline continues variables and categorical variables among participants in the $4000 \mathrm{IU}$ and $6000 \mathrm{IU}$ treatments were compared using independent samples $t$ test and Chi Square test, respectively. The Student's $t$ test for paired samples was used to test changes in serum 25(OH)D and PTH over 3 and 6 months. Results were confirmed running a standard mixed-models approach to repeated measures. A multiple linear regression model was run to test the association among serum 25(OH)D changes and PTH changes at 3 and 6 months for each treatment. Significant models were adjusted for age, gender, BMI, years with T2D, smoking, and A1C. The association between achieving sufficient vitamin D status and treatment was tested with a logistic regression model. Vitamin D status (sufficient/insufficient) was input as the dependent variable and treatment (4000 IU and $6000 \mathrm{IU}$ ) as the independent 
variables. All analyses were performed using SPSS version 19 (Chicago, IL, US). A pvalue of $<.05$ was considered significant.

\section{Results}

Both treatment groups were similar at baseline in serum 25(OH)D, PTH, age, gender distribution, years with T2D, smoking, and A1C levels. However, participants in the 4000 IU group showed a higher BMI compared to participants in the 6000 IU group at baseline (34.72 \pm 6.98 vs. $30.74 \pm 4.93 \mathrm{~kg} / \mathrm{m}^{2}, P=0.013$ ) (Table 1$)$.

Serum 25(OH)D increased significantly at 3 months in both treatments, from $22.25 \pm 7.19$ to $37.34 \pm 12.31 \mathrm{ng} / \mathrm{ml}$ and from $23.74 \pm 5.09$ to $43.20 \pm 15.94 \mathrm{ng} / \mathrm{ml}$ in the $4000 \mathrm{IU}(P=0.001)$ and $6000 \mathrm{IU}(P=0.001)$ groups, respectively (Table 2). The mean increase between treatments was not significantly different at 3 months.

Similarly, serum 25(OH)D increased significantly at 6 months in both treatments, from $22.25 \pm 7.19$ to $37.99 \pm 13.22 \mathrm{ng} / \mathrm{ml}$ and from $23.74 \pm 5.09$ to $40.62 \pm 19.39 \mathrm{ng} / \mathrm{ml}$ in the $4000 \mathrm{IU}(P=0.001)$ and $6000 \mathrm{IU}(P=0.001)$ groups, respectively (Table 2$)$. The mean increase between treatments at 6 months was not significant.

In addition, serum 25(OH)D levels at 3 months and at 6 months were not significantly different for both treatments, meaning that there was no additional benefit to extending the treatment for 6 months at any dosage in terms of increasing serum 25(OH)D levels.

Parathyroid hormone levels decreased at 3 months and 6 months compared to baseline. However, the change was not significant for any time period (Table 2). In addition, there was a non significant increase in PTH at 6 months compared to 3 months. 
The association between serum 25(OH)D change and PTH change was only significant at 3 and 6 months for the 4000 IU treatment $(\beta=-0.223, P=0.012$ and $\beta=-0.235, P=0.016$; respectively). This association held its significance even when the model was adjusted for covariates at 3 months and 6 months $(\beta=-0.176, P=0.045$ and $\beta=-0.209, P=0.039$; respectively). Keeping other covariates constant, an increase of 1 unit in serum 25(OH)D decreased PTH by 0.176 units at 3 months (Table 3). Similarly, keeping other covariates constant, an increase of 1 unit in serum 25(OH)D decreased PTH by 0.209 units at 6 months (Table 4). The fully adjusted model explained 29.3\% of the change in PTH at 3 months and $26.4 \%$ at 6 months.

The association between vitamin D status (insufficient/sufficient) and treatment (4000 IU and $6000 \mathrm{IU}$ ) was not significant. None of the participants with either dose had showed serum 25(OH)D > $150 \mathrm{ng} / \mathrm{ml}$ and no adverse events were reported during the study. Re-analysis of the data after excluding the participants that dropped out of the study after screening and at 3 months, did not alter the results.

\section{Discussion}

Treatments with $4000 \mathrm{IU} /$ day and $6000 \mathrm{IU} /$ day increased serum 25(OH)D levels significantly at 3 months and 6 months compared to baseline values. The proportion of participants achieving sufficient serum 25(OH)D levels was $68 \%$ at 3 months and $70 \%$ at 6 months for $4000 \mathrm{IU}$; and $72 \%$ at 3 months and $68 \%$ at 6 months for $6000 \mathrm{IU}$.

These results support the notion that $4000 \mathrm{IU} /$ day for 3 months is an adequate dosage to replenish vitamin D in Hispanics and African Americans with T2D. Additional treatment for 3 extra months or a higher dosage of $6000 \mathrm{IU} /$ day did not change serum 
25(OH)D levels significantly. According to these data, a physiological plateau is reached at 3 months with the use of the 4000 IU/day regimen. However, the sample size for the 6000 IU group was small ( $\mathrm{n}=25)$. In addition, the inclusion of the non-compliant participants ( $\mathrm{n}=2$ ) and the dropouts $(\mathrm{n}=3)$ in the intent to treat analysis for the $6000 \mathrm{IU}$ group may have pulled the $p$-value to the non-significant side. According to Pepper et al. (15), a much higher serum 25(OH) needs to be achieved to see changes in metabolic markers not related to bone turn over or calcium metabolism. Therefore, it remains to be seen if this serum 25(OH)D may have an effect on cardiovascular risk in this particular sample of Hispanics and African Americans with T2D.

The Endocrine Society recommends that vitamin D insufficient adults consume 1500-2000 IU/day with an upper limit of 4000 IU/day as the limit for safety (14). However, this recommendation is for healthy individuals. Since participants with T2D, African Americans, and Hispanics tend to have a higher incidence of vitamin D deficiency due to darker skin color and higher metabolic demands, it is assumed that a higher dosage is needed to achieve sufficiency in this particular population (1-3). However, no standard vitamin D repletion treatment has been developed for participants with T2D and darker skin color.

Our results support the regimens followed for other metabolic disorders. Malabanan et al. (16) showed that 50000 IU once a week per 8 weeks of ergocalciferol improved vitamin D status in participants with osteoporosis. Sixty percent of participants achieved sufficient status at the end of the study. This proportion achieving sufficiency is similar to the one achieved with the 4000 IU/day in the present study. Similarly, the National Kidney Foundation has released guidelines for the repletion of vitamin D in 
participants with chronic kidney disease based on the level of insufficiency ( $<5 \mathrm{ng} / \mathrm{ml}, 5$ to $15 \mathrm{ng} / \mathrm{ml}, 16$ to $30 \mathrm{ng} / \mathrm{ml})$. Participants in the category with the highest insufficiency should have supplements with 50000 IU weekly of ergocalciferol for 12 weeks followed by a monthly similar maintenance dose, 50000 IU weekly for 4 weeks and then monthly for participants in the middle category, and 50000 IU monthly for participants in the category with the lowest insufficiency (6).

These guidelines are based on ergocalciferol. However, in our study cholecalciferol was provided. Studies have shown that cholecalciferol may be more bioavailable than ergocalciferol (17-19). Therefore, plateau levels may be achieved faster and maintained for longer time. In a study providing equal molar quantities of cholecalciferol and ergocalciferol (4000 IU) for 14 days, participants in the cholecalciferol group achieved 1.7 times higher serum 25(OH)D compared to the ergocalciferol group (18). Similarly, Armas et al. (19), reported higher serum 25(OH)D levels in patients taking cholecalciferol compared to ergocalciferol. Variation in the binding of cholecalciferol and ergocalciferol to the vitamin D binding protein may explain these results (17).

Regarding the relationship between serum 25(OH)D and dosage provided, Pepper et al. (15) found a direct association. Participants receiving a total dose $<300000$ IU of ergocalciferol were 7 times more likely to remain vitamin D insufficient compared to participants taking > $600000 \mathrm{IU}$. Following the same trend, participants receiving between 300001 and 599999 IU of ergocalciferol were 3 times more likely to remain vitamin D insufficient compared to participants taking > 600000 IU. In our study, the relationship between dosage and insufficient status was not significant. This relation held 
even when participants who dropped out of the study were excluded from the analysis. Therefore, there is no advantage in increasing the dosage to $6000 \mathrm{IU} /$ day. It may be possible that the use of cholecalciferol saturated the vitamin D receptors faster compared to studies providing ergocalciferol.

Studies conducted in participants with T2D have assessed changes in metabolic outcomes (insulin resistance, and insulin production) after vitamin D supplementations. Comparing our results to those in the literature, however, is difficult because previous studies did not enroll vitamin D insufficient participants or assess serum 25(OH)D values before and after treatment (10-13).

Even though, changes in PTH were not significant, the relationship between change in serum 25(OH)D and change in PTH was correlated for the 4000 IU group. The fully adjusted model explained 29.3\% of the change in PTH at 3 months and $26.4 \%$ at 6 months. Still a large proportion of the change in PTH was not explained by the model. This finding suggests that to reduce bone turn over in this population other factors may be more important than vitamin $\mathrm{D}$ alone. In fact, age was a significant factor that affected PTH levels. These results support the notion that once vitamin D sufficiency is achieved, PTH levels do not continue decreasing (15). Studies have demonstrated that PTH levels achieve a plateau when serum 25(OH)D reaches a level of 30 to $32 \mathrm{ng} / \mathrm{ml}(20,21)$.

Regarding safety, studies have shown that dosages of 10000 IU/day of Cholecalciferol did not produce toxicity when provided to insufficient participants (22). In fact, none of the participants in our study reported any adverse events or achieved a serum 25(OH)D > $150 \mathrm{ng} / \mathrm{ml}$. Therefore, it seems that both treatments are safe to use 
among this particular population of Hispanics and African Americans with T2D for six months.

Limitations of our study include the small sample size in the 6000 IU group and the use of fixed time intervals. Therefore, the peak levels of serum 25(OH)D may have been missed. In addition, since participants with T2D are prone to developing renal disease, it may be possible that the conversion of Cholecalfierol to serum 25(OH)D may have been impaired in participants at early stages of renal disease. Further studies in participants that did not reach vitamin D sufficiency over the 6 months treatments are needed in order to explain the possible causes.

In conclusion, repletion of vitamin D among Hispanics and African Americans with T2D was successfully and safely achieved with a 4000 IU/day dose of cholecalciferol for 3 months in most participants. The increase in treatment time or dosage did not produce any significant difference in terms of achieving vitamin D sufficient status. The effect of the change in vitamin D status on metabolic markers should be evaluated in future studies to determine the optimal time of treatment for patients with T2D. 
Table 1. Baseline characteristics of participants prior to vitamin D repletion treatments

\begin{tabular}{lccc}
\hline Characteristic & \multicolumn{2}{c}{ Treatment } & \\
\cline { 2 - 3 } & $4000 \mathrm{IU}(\mathrm{n}=50)$ & $6000 \mathrm{IU}(\mathrm{n}=25)$ & \\
\hline & & & 0.302 \\
25(OH)D (ng/ml) & $22.25 \pm 7.19$ & $23.74 \pm 5.09$ & 0.523 \\
PTH (pg/ml) & $38.60 \pm 18.14$ & $41.42 \pm 17.77$ & 0.999 \\
Age (years) & $54.76 \pm 8.56$ & $54.17 \pm 10.99$ & 0.809 \\
Gender (Female \%) & $48 \%$ & $52 \%$ & 0.478 \\
Years with T2D & $6.48 \pm 5.18$ & $5.48 \pm 5.93$ & 0.091 \\
Smoking (yes \%) & $10 \%$ & $28 \%$ & 0.013 \\
BMI (kg/m ( $\left.^{2}\right)$ & $34.72 \pm 6.98$ & $30.74 \pm 4.93$ & 0.981 \\
A1C (\%) & $8.25 \pm 2.40$ & $8.26 \pm 1.92$ & \\
\hline
\end{tabular}

Continues variables are presented as mean \pm SD and categorical variables as \%. 25(OH)D: serum vitamin D, PTH: parathyroid hormone, T2D: type 2 diabetes, BMI: body mass index, A1C: glycated hemoglobin. 
Table 2. Effect of vitamin D repletion treatments on serum vitamin D and parathyroid hormone

\begin{tabular}{|c|c|c|}
\hline \multirow[t]{2}{*}{ Characteristic } & \multicolumn{2}{|c|}{ Treatment } \\
\hline & $\begin{array}{c}4000 \mathrm{IU} \\
(\mathrm{n}=50)\end{array}$ & $\begin{array}{c}6000 \mathrm{IU} \\
(\mathrm{n}=25)\end{array}$ \\
\hline \multicolumn{3}{|l|}{ 25(OH)D (ng/ml) } \\
\hline Baseline & $22.25 \pm 7.19$ & $23.74 \pm 5.09$ \\
\hline 3 months & $37.34 \pm 12.31$ & $43.20 \pm 15.94$ \\
\hline$P$-value (baseline vs. 3 months) & 0.001 & 0.001 \\
\hline 6 months & $37.99 \pm 13.22$ & $40.62 \pm 19.39$ \\
\hline$P$-value (baseline vs. 6 months) & 0.001 & 0.001 \\
\hline $\begin{array}{l}\text { Repletion of vitamin } D \\
\text { insufficiency } \geq 30 \mathrm{ng} / \mathrm{ml}(\%) \text { at } 3 \text { months }\end{array}$ & $68 \%$ & $72 \%$ \\
\hline $\begin{array}{l}\text { Repletion of vitamin D } \\
\text { insufficiency } \geq 30 \mathrm{ng} / \mathrm{ml}(\%) \text { at } 6 \text { months }\end{array}$ & $70 \%$ & $68 \%$ \\
\hline \multicolumn{3}{|l|}{ Parathyroid hormone (pg/ml) } \\
\hline Baseline & $38.60 \pm 18.14$ & $41.42 \pm 17.77$ \\
\hline 3 months & $32.21 \pm 20.59$ & $36.05 \pm 14.48$ \\
\hline$P$-value (baseline vs. 3 months) & 0.103 & 0.247 \\
\hline 6 months & $36.66 \pm 17.84$ & $36.11 \pm 18.78$ \\
\hline$P$-value (baseline vs. 6 months) & 0.592 & 0.309 \\
\hline
\end{tabular}


Table 3. Relationship between change in parathyroid hormone, change in serum 25(OH)D and covariates at 3 months for the 4000 IU treatment

\begin{tabular}{lcccc}
\hline Parameter* $^{*}$ & $B$ & $S E$ & $T$ & $P_{\text {-value }}^{\dagger}$ \\
\hline 25(OH)D (ng/ml) & -0.176 & 0.085 & -2.062 & 0.045 \\
Age (years) & -0.428 & 0.209 & -2.048 & 0.047 \\
& & & & \\
\hline
\end{tabular}

*Other covariates-in the multiple linear regression were gender, BMI, years with type 2 diabetes, smoking and A1C. $\dagger P<0.05$ is considered significant.

Table 4. Relationship between change in parathyroid hormone, change in serum 25(OH)D and covariates at 6 months for the $4000 \mathrm{IU}$ treatment

\begin{tabular}{lcccc}
\hline Parameter* $^{*}$ & $B$ & $S E$ & $T$ & $P_{\text {-value }}^{\dagger}$ \\
\hline 25(OH)D (ng/ml) & -0.209 & 0.098 & -2.134 & 0.039 \\
Age (years) & -0.449 & 0.206 & -2.180 & 0.035 \\
& & & & \\
\hline
\end{tabular}

*Other covariates-in the multiple linear regression were gender, BMI, years with type 2 diabetes, smoking and A1C. $† P<0.05$ is considered significant. 


\section{References}

1. Centers for Disease Control and Prevention. Vitamin D Status: United States, 2001-2006. Accessed April 29, 2013. Available http://www.cdc.gov/nchs/data/databriefs/db59.pdf

2. Baynes KCR, Boucher BJ, Feskens EJM, Kromhout D. Vitamin D, glucose tolerance and insulinaemia in elderly men. Diabetologia. 1997;40(3):344-347.

3. Scragg R, Sowers M, Bell C. Serun 25-hydroxyvitamin D, diabetes, and ethnicity in the Third National Health and Nutrition Examination Survey. Diabetes Care. 2004;27(12):2813-2818.

4. Kayaniyil S, Vieth R, Retnakaran R, Knight JA, Qi Y, Gerstein HC, et al. Association of vitamin $\mathrm{D}$ with insulin resistance and $\beta$-cell dysfunction in subjects at risk for type 2 diabetes. Diabetes Care. 2010;33(6):1379-1381.

5. Aris RM, Merkel PA, Bachrach LK, Borowitz DS, Boyle MP, Elkin SL, et al. Guide to bone health and disease in cystic fibrosis. J Clin Endocrinol Metab. 2005;90:1888-1896.

6. National Kidney Foundation. K/DOQI clinical practice guidelines for bone metabolism and disease in chronic kidney disease. Am J kidney Dis. 2003;42(4 suppl 3):S1-S201.

7. Grey A, Lucas J, Horne A, Gamble G, Davidson JS, Reid IR. Vitamin D repletion in patients with primary hyperparathyroidism and coexistent vitamin D insufficiency. J Clin Endocrinol Metab. 2005;90:2122-2126.

8. AACE Osteoporosis Task Force. American Association of Clinical Endocrinologist medical guidelines for clinical practice for the prevention and treatment of post-menopausal osteoporosis: 2001 edition, with selected updates for 2003. Endocr Pract. 2003;9:544-564.

9. Basile LA, Taylor SN, Wagner CL, Horst RL, Hollis BW. The effect of high-dose vitamin D supplementation on serum vitamin D levels and milk calcium concentration in lactating women and their infants. Breasfeed Med. 2006;1:27-35.

10. Borissova AM, Tankova T, Kirilov G, Dakovska L, Kovacheva R. The effect of vitamin D3 on insulin secretion and peripheral insulin sensitivity in type 2 diabetic patients. Int J Clin Pract. 2003;57(4):258-261.

11. Inomata S, Kadowaki S, Yamatani T. Effect of $1 \alpha(\mathrm{OH})$-vitamin D3 on insulin secretion in diabetes mellitus. Bone and Mineral. 1986;1(3):187-192. 
12. Orwoll E, Riddle M, Prince M. Effects of vitamin D on insulin and glucagon secretion in non-insulin-dependent diabetes mellitus. American Journal of Clinical Nutrition. 1994;59(5):1083-1087.

13. Schwalfenberg G. Vitamin D and diabetes: Improvement of glycemic control with vitamin D3 repletion. Canadian Family Physician. 2008;54:864-866.

14. Endocrine Society. Evaluation, treatment, and prevention of vitamin D deficiency: an Endocrine Society Clinical Practice Guideline. J Clin Endocrinol Metab. 2011;96:1911-1930.

15. Pepper KJ, Judd SE, Nanes MS, Tangpricha V. Evaluation of vitamin D repletion regimens to correct vitamin D status in adults. Endocr Pract. 2009;15(2):95-103.

16. Malabanan A, Veronikis IE, Holick MF. Redefining vitamin D insufficiency. Lancet. 1998;351:805-806.

17. Houghton LA, Vieth R. The case against ergocalciferol (vitamin D2) as a vitamin supplement. Am J Clin Nutr. 2006;84:694-697.

18. Trang HM, Cole DE, Rubin LA, Pierratos A, Siu S, Vieth R. Evidence that vitamin D3 increases serum 25-hydrovitamin D more efficiently than does vitamin D2. Am J Clin Nutr. 1998;68:854-858.

19. Armas LA, Hollis BW, Heaney RP. Vitamin D2 is much less effective than vitamin D3 in humans. J Clin Endocrinol Metab. 2004;89:5387-5391.

20. Brown SE. Vitamin D and fracture reduction: an evaluation of the existing research. Altern Med Rev. 2008;13:21-33.

21. Heaney RP. The vitamin D requirement in health and disease. J Steroid Biochem Mol Biol. 2005;97:13-19.

22. Vieth R. Vitamin D supplementation, 25-hydroxyvitamin D concentrations, and safety. Am J Clin Nutr. 1999;69:842-856. 


\section{CHAPTER V: VALIDATION OF A SUN EXPOSURE QUESTIONNAIRE IN PARTICIPANTS WITH TYPE 2 DIABETES RESIDING IN SOUTH FLORIDA}

\section{Introduction}

Low levels of vitamin D are prevalent in the US (1). According to data from the National Health and Nutrition Examination Surveys (NHANES) in 2001-2006, 33\% of the general US population had serum 25(OH)D below $50 \mathrm{nmol} / \mathrm{L}$. In addition, low vitamin D levels are especially common among minorities. For instance, $41 \%$ of African Americans and 33\% of Mexican Americans had serum 25(OH)D below $50 \mathrm{nmol} / \mathrm{L}$ compared to $18 \%$ of non-Hispanic Whites (1).

The sun is the main source of vitamin D. Ultraviolet B (UVB) radiation emitted by the sun converts cholesterol into vitamin $\mathrm{D}$ in the skin. The avoidance of sun exposure due to perceived skin cancer risk and the lack of outdoor physical activity due to a more sedentary life may explain in part the current vitamin D deficiency epidemic (2).

Research is still in progress to quantify vitamin D status in specific populations and its relation with several diseases. Therefore, the assessment of vitamin D status must take into consideration sun exposure behaviors through the use of validated tools.

Sun exposure questionnaires are commonly used to assess UVB exposure because they are easy to use and inexpensive. Observed sun exposure and dosimetry, an objective measure of UVB radiation, have been used for comparison (3-6), however, neither of them is considered a gold standard (7). The correlations among sun exposure questionnaires and observed exposure or dosimetry have been significant but relatively low, leaving a big percentage in the variation in UVB unexplained by sun exposure alone (3-6). 
Similarly, when sun exposure questionnaires have been used in models to predict 25(OH)D (the universally accepted biomarker to determine vitamin D status) a large percentage of the variation was not explained by sun exposure, which may lead to a misclassification of vitamin D status if based on sun exposure alone (8-10).

On the other hand, objective and reliable measures of change in skin color using scanners allow in vivo quantification and have shown significantly high correlations with laboratory induced UVB exposure $\left(r_{\mathrm{s}}=0.99\right)(11)$. In addition, these devices offer high inter/intra rater reliability (12). Therefore, they may be used as gold standard to validate sun exposure questionnaires.

Type 2 diabetes (T2D) has increased dramatically in the United States (US) among adults 20 years of age and older from 9\% in 1988 to $11 \%$ in 2010. The increase has been even more dramatic among African Americans from 16\% in 1988 to 20\% in 2010. In Mexican Americans the incidence has increased from 15\% to $17 \%$ in the same time period. Minorities, particularly African Americans and Hispanics, are disproportionately afflicted by T2D compared to non-Hispanics Whites (13).

In addition, poor vitamin D status has been found in participants at risk (with metabolic syndrome) and those with T2D. The nature of this relationship, however, is not clear $(14,15)$. Similarly, an inverse association between vitamin D levels and insulin resistance has been reported in a large sample representative of the US adult population and in participants at risk for T2D $(15,16)$. According to these results vitamin D levels are associated with insulin sensitivity and insulin resistance. Therefore, it is necessary to validate sun exposure tools in order to accurately assess vitamin D status in minorities with T2D. 
The objective of the present study was to validate a sun exposure questionnaire against objective measures of change in skin color and to assess its validity in predicting 25(OH)D status in a sample of African Americans and Hispanics with T2D.

\section{Methods}

\section{Participants}

An intervention study to assess the effects of vitamin D supplementation (4000 IU/day and $6000 \mathrm{IU} /$ day) over six months on cardiovascular markers among a sample of African Americans and Hispanics with T2D was conducted. The present study analyzed the data collected at screening.

The study consisted of two phases: phase one included the screening of individuals, phase two included the recruitment of individuals who met inclusion criteria and beginning of the vitamin $\mathrm{D}$ intervention trial. The inclusion criteria were vitamin $\mathrm{D}$ insufficiency (25(OH)D $<30 \mathrm{ng} / \mathrm{ml})$, 30-70 years of age, African American or Hispanic with confirmed T2D. Exclusion criteria were taking vitamin D supplements other than standard daily multivitamin formula, pregnant or lactating, having thyroid, hepatic, renal dysfunction, cancer, HIV, and major psychiatric disorders.

Flyers explaining the purpose of the study, inclusion/exclusion criteria and containing investigators' emails and phone numbers were distributed in highly visited community areas such as churches, supermarkets, and clinics. Two clinics were visited every week for recruitment purposes: Borinquen Health Care Center and Clinical Care Medical Center. When participants called the investigators, purposes of the study were explained and specific questions were asked to assure compliance with inclusion criteria. 
All qualified participants were invited to participate in a morning session at Human Nutrition Laboratory, AHC-1, room 430, Florida International University for fasting blood sampling to screen for vitamin D insufficiency. All participants were asked to sign an informed consent form previous to screening data collection and to provide contact number and address of their physician, as well as their own contact information. Only participants with T2D diagnosis confirmed by a physician were eligible to participate in the study. The study was approved by IRB at FIU.

Participants in both groups were required to take either $4000 \mathrm{IU}$ or $6000 \mathrm{IU}$ of vitamin D (Cholecalciferol) per day given in the form of a pill in a single daily dose. Each participant was seen 4 times; at screening, baseline, 3 months, and 6 months. The study lasted for 25 weeks for each participant from screening to final assessment. The study started in June 2011 and completed on September 2013. Ninety two participants were screened. Two subjects were excluded due to missing values for sun exposure scores. The present study analyzed the data collected only at screening. Total sample size was 90 participants.

\section{Blood Collection}

Venous blood ( $15 \mathrm{ml})$ was collected from each subject by a certified phlebotomist using standard laboratory methods at each study point. After coagulation, blood was centrifuged at 2500 RPM for 30 minutes. The plasma glucose concentration was measured by hexokinase enzymatic method. Glycated hemoglobin (A1c) was measured by the DCA2000+ system (Bayer Corporation, Diagnostics Division, N.Y.) using the monoclonal antibody method. Serum vitamin D concentrations were measured with an 
enzyme-immunoassay kit by absorbance (Immunodiagnostic Systems Scottsdale, AZ). Color intensity developed was inversely proportional to the concentration of serum 25(OH)D.

\section{Socio-demographic Questionnaire}

Participants were asked to fill out a standard questionnaire on site. Trained interviewers bilingual in English and Spanish administered the questionnaires in the language of preference of the participants. Data were collected using a sociodemographic questionnaire which includes questions related to gender, age, years living in the US, years with diabetes, smoking, and alcohol intake.

\section{Anthropometric Measurements}

Height and weight were measured using a SECA clinical balance scale (Seca Corp, Columbia, MD). Body mass index (BMI) was calculated as weight in $\mathrm{kg} / \mathrm{height}$ in $\mathrm{m}^{2}$.

\section{Sun Exposure Questionnaire}

The sun exposure questionnaire developed by Hanwell et al. (17) was used following the original rubric. Time spent outdoors during the previous week $(0 \leq 5$ minutes, $1=5-30$ minutes and 2=>30 min) was self-reported. Four options for skin exposed while outdoors were offered ( $1=$ face and hands, $2=$ face, hands and arms, $3=$ face, hands and legs and 4=bathing suit). The daily sun exposure score for each day was calculated by multiplying the time spent outdoors score times the skin exposed while 
outdoors score. The scale for each day ranged from 0 to 8 . The weekly sun exposure was calculated by adding the daily scores ( $\min =0, \max =56$ ).

\section{Skin Color}

In order to have an objective measure of sun exposure, skin color was determined by reflectance colorimetry using the SmartProbe 400 (IMS Inc. USA). This instrument uses the International Commission on Illumination Scale which ranges from 0 (black) to 100 (white) for skin color. Two readings at each measurement site (6 readings total) for each participant were taken: two on the dorsal aspect of the wrist of the right hand (area most exposed to sun), two on the inside of the right upper arm and the stomach (areas less exposed to the sun). The mean values of the two readings at each measurement site were used for analysis. The change in skin color due to sun exposure was calculated by finding the difference between the less exposed area (natural color) and the most exposed area.

\section{Statistical analysis}

Descriptive statistics for continuous variables were presented as mean \pm SD and proportions for categorical variables. Spearman's correlation among weekly sun exposure scores and delta of skin color, sun exposure scores, skin exposure score, forearm skin color, stomach skin color, and change in skin color with 25(OH)D were run. The relationship between serum 25(OH)D, skin exposure score and stomach skin color was evaluated by a multiple linear regression model. Serum 25(OH)D was the dependent variable. Skin exposure score and stomach skin color were independent variables. All of the three variables were continuous. A simple model was run using skin exposure score 
and stomach skin color as predictors of serum 25(OH)D. Confounding factors including age, gender, BMI, years living in US, years with type 2 diabetes, ethnicity, tobacco use and alcohol consumption were added to the adjusted model. Two-way and three-way interactions were tested between total skin exposure score, stomach skin color, and gender. All of the analyses were conducted using SPSS version 19 (Chicago, IL, US).

\section{Results}

Analysis for sun exposure questionnaire validation included 92 participants. Eighty four percent were vitamin D deficient. Two participants were excluded for missing sun exposure scores. Final sample considered for the analysis included 90 participants, males ( $n=44,49 \%)$, females ( $n=46,51 \%)$. Descriptive characteristics are provided in table I. The mean age was $54.8 \pm 9.7$ years. The mean BMI was $33.7 \pm 6.6$ $\mathrm{kg} / \mathrm{m}^{2}$. The mean serum 25(OH)D (22.6 $\left.\pm 6.6 \mathrm{ng} / \mathrm{ml}\right)$, forearm skin color (55.7 \pm 7.5$)$, stomach skin color (59.2 \pm 9.8$)$, change in skin color (3.5 \pm 5.4$)$, total sun exposure score (19.6 \pm 15.0$)$, time outdoors score (6.5 \pm 4.6$)$, skin exposure score (20.4 \pm 3.2$)$, and A1C (8.3 $\pm 2.2 \%)$ are presented in table 1 . The minimum and maximum scores for weekly sun exposure, time outdoors, and skin exposure scores were 0 and 52, 0 and 14, 8 and 28, respectively. About fourteen percent of the participants were African Americans and eighty six percent Hispanics.

Correlations between weekly sun exposure and change in skin color or serum 25(OH)D were not significant ( $P=0.487, r_{\mathrm{s}}=0.081$ and $P=0.864, r_{\mathrm{s}}=0.020$; respectively). Correlations between skin exposure score, stomach skin color, and change in skin color 
with serum 25(OH)D were significant $\left(P=0.047, r_{s}=0.230 ; P=0.024, r_{s}=0.260\right.$; and $P=0.015, r_{s}=0.280$; respectively) (Table 2).

The unadjusted model showed that skin exposure score $(P=0.037)$, and stomach skin color $(P=0.021)$ were good predictors of serum 25(OH)D. In this model, 22 percent of the variation in serum 25(OH)D was explained by skin exposure score and stomach skin color. This relationship remained significant for stomach skin color $(P=0.020)$, but not for skin exposure score $(P=0.149)$ after controlling for covariates, including age, gender, BMI, years living in US, years with T2D, ethnicity, tobacco use and alcohol consumption. The fully adjusted model explained 38.1 percent of the variation in serum 25(OH)D. A1C was also significantly associated with serum 25(OH)D. For every unit increase in stomach skin color, there was a 0.33 unit increase in serum 25(OH)D. In contrast, for every unit increase in A1C, there was a 1.274 unit decrease in serum 25(OH)D, keeping the other variables constant (Table 3). Two and three-way interactions between skin exposure scores, stomach skin color, and gender were not significant.

\section{Discussion}

Sun exposure questionnaires are commonly validated against observed records of sun exposure or dosimetry (3-6). However, none of them is considered a gold standard (7). Serum 25(OH)D levels are indicators of sun exposure in the last two months (18-20). Therefore, it has been used as gold standard in other studies. Similarly, colorimeters used to determine skin color have significantly correlated with induced UV exposure $(r=0.99)$ 
providing a more accurate gold standard tool to validate sun exposure questionnaires $(11,12)$.

The total weekly sun exposure score was not correlated with neither change in skin color nor serum 25(OH)D in our study. These results are explained by the very short time spent outdoors in this population of participants with T2D. In fact, 18 participants spent less than 5 minutes outdoors every day, making the whole sun exposure score equal to zero. When the skin exposure score alone is taken into consideration, it was significantly correlated with serum 25(OH)D. Therefore, the tool developed by Hanwell et al. (17) was not a good indicator of sun exposure in this population of participants with T2D due to the limited time they spent outdoors. The population used by Hanweel et al. (17) was active Caucasian hospital workers in Italy. However, the correlations between sun exposure scores and serum 25(OH)D were only significant for summer but not for winter, meaning that in times of limited sun exposure other tools should be used for screening. In addition, the strongest component of the total sun exposure score was the time spent outdoors. Time spent outdoors was significantly correlated with serum 25(OH)D despite the amount of skin exposed during summer (17). Therefore, the amount of skin exposed is not important during summer. The main determinant of UV exposure is the time spent outdoors.

Other studies have found significant but low correlations between self-reported sun exposure and dosimetry (21,22). A study conducted in Australia compared sun exposure behaviors from diaries to personal dosimetry in mothers $(r=0.32)$ and children $(r=0.34)$ (21). Another study conducted in the US found different correlation between self-reported sun exposure and dosimetry per body part ( $r=0.12$ for the arm and $r=0.49$ 
for the leg) (22). According to these data, the precision of UV exposure based on sun exposure questionnaires is poor. Therefore, measurement errors should be included in the models. To our knowledge, none of these instruments have been validated in older participants with T2D. In addition, self-reported questionnaires are prone to recall bias. In an older population, the bias may be even greater.

Regarding the use of sun exposure questionnaires to predict serum $25(\mathrm{OH}) \mathrm{D}$, a case-control study of multiple sclerosis found significant but low correlations for outdoor activities in the past 3 years and serum 25(OH)D levels $(r=0.39)(8)$. This means that about $85 \%$ of the variation in serum $25(\mathrm{OH}) \mathrm{D}$ is not explained by sun exposure behaviors. Another study found that the contribution of outdoor activities to serum 25(OH)D is important only in summer (10). According to these results, other variables such as age and skin color should be included in models to screen for vitamin D status.

The original tool was validated in white individuals (17). Since natural skin color have a profound impact on vitamin D synthesis and our population was Hispanics and African Americans, it may be possible that the color of the skin is a better predictor of serum 25(OH)D in this particular population than sun exposure behaviors.

In fact, unexposed skin color (stomach) and the difference between unexposed and exposed areas (stomach and forearm) were significantly correlated with serum 25(OH)D. This is in contrasts with Nessvi et al. (23) who suggested that both unexposed and exposed areas are good predictors of serum 25(OH)D. In our population, unexposed skin color was the biggest determinant of serum $25(\mathrm{OH}) \mathrm{D}$, meaning that the natural skin color of the individual can predict vitamin D status. However, correlation was low $\left(r_{\mathrm{s}}=0.26\right)$ leaving a large proportion of the variation in serum 25(OH)D unexplained by 
unexposed skin color alone. Other factors like vitamin D intake from food and supplements, type of clothing worn, and the months away from Florida may have been important in the assessment of vitamin D status.

The unadjusted model using skin exposure score and stomach skin color as independent variables was significant for both, but the model only explained 22\% of the variation in serum $25(\mathrm{OH}) \mathrm{D}$. When the model was adjusted for covariates, only stomach skin color remained significantly associated with serum 25(OH)D. The adjusted model explained 38.1\% of the variation in serum 25(OH)D, still leaving a big proportion unexplained. It is unlikely that tanning behaviors or sunscreen use may have played a role in serum 25(OH)D levels in this particular population.

Interestingly, A1C, a marker of the blood glucose control over the last 3 months, was strongly associated with serum 25(OH)D. This may imply that in participants with T2D with limited sun exposure, A1C levels may be an important marker to determine vitamin D status.

Even though, the correlation between change in skin color (unexposed minus exposed area) and serum 25(OH)D was significant, it was mainly driven by the unexposed area. In fact, since outdoors activities were limited, the differences in skin color between unexposed and exposed areas were minimal in many participants.

It is important to note that eighty four percent of our sample was vitamin D deficient at screening. It is paradoxical that in a tropical area like South Florida the incidence of vitamin D deficiency is still high among participants with T2D. Mean weekly sun exposure score was 19.6 out of a total of 56, reflecting very limited sun exposure. Alcohol intake and smoking can interfere with vitamin D absorption (7). 
However, the incidence for both of them (16\% and 28\%, respectively) was low. It seems that the limited outdoor activity may explain in part the high incidence of deficiency in our sample.

Limitations of our study include the small sample size, the high incidence of vitamin D deficiency, the lack of data regarding vitamin D intake from foods and supplements, and the limited outdoor activity of this particular sample.

The sun exposure questionnaire developed by Hanwell et al.(17) was not a valid tool to estimate change in skin color due to sun exposure or serum 25(OH)D levels in this sample of African Americans and Hispanics with T2D. Unexposed skin color and A1C levels were significantly associated with serum 25(OH)D. Unexposed skin color may be used as proxy measure to screen for vitamin D deficiency in this sample of participants with T2D. 
Table 1. Characteristics of the study participants at screening $(n=90)$

\begin{tabular}{lc}
\hline Variable & Mean \pm SD \\
\hline Age (years) & $54.8 \pm 9.7$ \\
BMI (kg/m²) & $33.7 \pm 6.6$ \\
Living in US (years) & $10.4 \pm 9.3$ \\
Serum 25(OH)D (ng/ml) & $22.6 \pm 6.6$ \\
Forearm skin color & $55.7 \pm 7.5$ \\
Stomach skin color & $59.2 \pm 9.8$ \\
Delta of skin color & $3.5 \pm 5.4$ \\
Sun exposure score & $19.6 \pm 15.0$ \\
Time outdoors score & $6.5 \pm 4.6$ \\
Skin exposure score & $20.4 \pm 3.2$ \\
A1C (\%) & $8.3 \pm 2.2$ \\
FPG (mg/dl) & $181.9 \pm 78.3$ \\
Years with T2D & $6.15 \pm 5.4$ \\
Tobacco use & \\
No & $84.0 \%$ \\
Yes & $16.0 \%$ \\
Alcohol consumption & \\
No & $72.0 \%$ \\
Yes & $28.0 \%$ \\
Gender & \\
females & \\
males & $51.1 \%$ \\
\hline Data are mean \pm standard deviation $(\mathrm{SD})$ or $\%$. \\
BMI = Body mass index, A1C= glycated \\
haemoglobin, FPG= fasting plasma glucose, \\
T2D= type 2 diabetes \\
$\begin{array}{l} \\
\end{array}$
\end{tabular}


Table 2. Correlation analysis $(n=90)$

\begin{tabular}{lcc}
\hline Variables compared & $r_{s}$ & $P$-value \\
\hline Sun exposure score vs. change in skin color & 0.081 & 0.487 \\
Sun exposure score vs. 25(OH)D & 0.020 & 0.864 \\
Skin exposure score vs. 25(OH)D & 0.230 & 0.047 \\
Forearm skin color vs. 25(OH)D & 0.197 & 0.090 \\
Stomach skin color vs. 25(OH)D & 0.260 & 0.024 \\
Change in skin color vs. 25(OH)D & 0.280 & 0.015 \\
\hline
\end{tabular}

Table 3. Relationship of serum 25(OH)D and covariates

\begin{tabular}{lcccc}
\hline Parameter* $^{*}$ & $B$ & $S E$ & $T$ & $P_{\text {-value }}^{\dagger}$ \\
\hline Stomach skin color & 0.330 & 0.139 & 2.378 & 0.020 \\
Skin exposure score & 0.356 & 0.244 & 1.462 & 0.149 \\
A1C (glycated hemoglobin) & -1.274 & 0.321 & -3.967 & 0.001 \\
\hline
\end{tabular}

*Other covariates-in the multiple linear regression were age, gender, BMI, years living in US, years with type 2 diabetes, ethnicity, tobacco use and alcohol consumption. $\uparrow P<0.05$ is considered significant. 


\section{References}

1. Centers for Disease Control and Prevention. Vitamin D Status: United States, 2001-2006. Accessed January 29, 2014. Available http://www.cdc.gov/nchs/data/databriefs/db59.pdf

2. Holick MF. Vitamin D deficiency. N Engl J Med 2007;357:266-281.

3. Vishvakarman D, Wong JCF, Boreham BW. Annual occupational exposure to ultraviolet radiation in central Queensland. Health Phys 2001;81:536-544.

4. O’Riodan DL, Lunde KB, Steffen AD, Maddock JE. Validity of beach-goers' self-report of their sun habits. Arch Dermatol 2006;142:1304-1311.

5. Diffey BL, Saunders PJ. Behavior outdoors and its effect on personal ultraviolet exposure rate measured using an ambulatory data logging dosimeter. Photochem Photobiol 1995;61:615-618.

6. Dwyer T, Blizzard L, Gies PH, Ashbolt R, Roy C. Assessment of habitual sun exposure in adolescents via questionnaire-a comparison with objective measurement using polysulphone badges. Melanoma Res 1996;6:231-239.

7. McCarty CA. Sunlight exposure assessment: can we accurately assess vitamin D exposure from sunlight questionnaires? Am J Clin Nutr 2008;87:1097S-1101S.

8. Van der Maei IAF, Blizzard L, Ponsonby AL, Dwyer T. Validity and reliability of adult recall of past sun exposure in a case-control study of multiple sclerosis. Cancer Epidemiol Biomarkers Prev 2006;15:1538-1544.

9. Brot C, Vestergaard P, Kolthoff N, Gram J, Hermann AP, Sorensen OH. Vitamin D status and its adequacy in healthy Danish perimenopausal women: relationships to dietary intake, sun exposure, and serum parathyroid hormone. Br J Nutr 2001;86:S97-S103.

10. Pasco JA, Henry MJ, Nicholson GC, Sanders KM, Kotowicz MA. Vitamin D status of women in the Geelong Osteoporosis Study: association with diet and casual exposure to sunlight. Med J Aust 2001;175:401-405.

11. Andersen PH, Bjerring P. Spectral reflectance of human skin in vivo. Photodermatol Photoimmunol Photomed 1990;7:5-12.

12. Glanz K, Mayer JA. Reducing ultraviolet radiation exposure to prevent skin cancer methodology and measurement. American Journal of Preventive Medicine 2005;29:131-142. 
13. Centers for Disease Control and Prevention. Health, United States, 2010. Accessed January 29, 2014. Available http://www.cdc.gov/nchs/data/hus/hus10.pdf\#050

14. Baynes KCR, Boucher BJ, Feskens EJM, Kromhout D. Vitamin D, glucose tolerance and insulinaemia in elderly men. Diabetologia. 1997;40(3):344-347.

15. Scragg R, Sowers M, Bell C. Serun 25-hydroxyvitamin D, diabetes, and ethnicity in the Third National Health and Nutrition Examination Survey. Diabetes Care. 2004;27(12):2813-2818.

16. Kayaniyil S, Vieth R, Retnakaran R, Knight JA, Qi Y, Gerstein HC, et al. Association of vitamin $\mathrm{D}$ with insulin resistance and $\beta$-cell dysfunction in subjects at risk for type 2 diabetes. Diabetes Care. 2010;33(6):1379-1381.

17. Hanwell HE, Vieth R, Cole DE, Scillitani A, Modoni S, Frusciante V, et al. Sun exposure questionnaire predicts circulating 25-hydroxyvitamin D concentrations in Caucasian hospital workers in southern Italy. J Steroid Biochem Mol Biol. 2010;121(1-2):334-337.

18. Vieth R. The pharmacology of vitamin D, including fortification strategies. In: Feldman D, Pike JW, Glorieux FH, editors. Vitamin D. Vol. 2. 2nd ed. New York: Elsevier; 2005. p. 995-1015.

19. Standing Committee on the Scientific Evaluation of Dietary Reference Intakes. Dietary reference intakes: calcium, phosphorus, magnesium, vitamin D, fluoride. National Academy Press; 1997.

20. Hollis BW, Wagner CL, Drezner MK, Binkley NC. Circulating vitamin D3 and 25-hydroxyvitamin D in humans: An important tool to define adequate nutritional vitamin D status. J Steroid Biochem Mol Biol. 2007;103(3-5):631-634.

21. O’Riordan DL, Stanton WR, Eyeson-Annam M, Gies P, Roy C. Correlations between reported and measured ultraviolet radioation exposure of mothers and young children. Photochem Photobiol 2000;71:60-64.

22. Yaroch AL, Reynolds KD, Buller DB, Maloy JA, Geno CR. Validity of a sun safety diary using UV monitors in middle school children. Health Educ Behav 2006;33:340-351.

23. Nessvi S, Johansson L, Jopson J, Stewart A, Reeder A, McKenzie R, et al. Association of 25-hydroxyvitamin D3 levels in adult New Zealanders with ethnicity, skin color and self-reported skin sensitivity to sun exposure. Photochem Photobiol. 2011;87(5):1173-1178. 


\section{CHAPTER VI: VALIDATION OF A SHORT FOOD FREQUENCY QUESTIONNAIRE FOR THE ASSESSMENT OF VITAMIN D INTAKE IN MINORITIES WITH TYPE 2 DIABETES}

\section{Introduction}

Low levels of vitamin D are prevalent in the US (1). According to data from the National Health and Nutrition Examination Surveys (NHANES) in 2001-2006, 33\% of the general US population had serum 25(OH)D below $50 \mathrm{nmol} / \mathrm{L}$. In addition, studies have shown that persons with darker skin color have lower vitamin D levels $(2,3)$. In

fact, low vitamin D levels are especially common among minorities. For instance, $41 \%$ of African Americans and 33\% of Mexican Americans had serum 25(OH)D below 50 nmol/L compared to $18 \%$ of non-Hispanic Whites (1).

Poor vitamin D status has been found in participants at risk or with type 2 diabetes (T2D), however, the nature of this relationship is not clear $(4,5)$. Similarly, a negative association between vitamin $\mathrm{D}$ levels and insulin resistance has been reported in a large sample representative of the US adult population and in participants at risk for T2D $(5,6)$. According to these results, vitamin D levels are positively associated with insulin sensitivity and negatively associated with insulin resistance.

Vitamin D level depends on several modifiable and non-modifiable factors. Skin color is the major non-modifiable factor and modifiable factors include sun exposure and vitamin D intake (7). However, there are no validated tools to assess vitamin D intake in participants with type 2 diabetes.

Nutrient intake can be estimated by multiple methods, each of them presenting their own advantages and disadvantages. Food records are usually considered the gold 
standard. They are administered over several days in order to represent usual intake. However, due to the burden of writing down every food and portion size, the period is limited (8). If the subject change his/her usual diet during this period, the data may be misleading. In addition, a tendency to underreport food intake by obese and overweight individuals have been reported (9). In contrast, food frequency questionnaires (FFQ) can assess food intake over a longer period of time (usually over a 1 year), can be administered by dietitians in situ or self-administered in a short period of time putting less burden on participants and may expose habits not evident on food records (10). However, FFQ should include ethnic specific foods and validated in the specific population under study (10).

Several vitamin D FFQs have been validated in different populations, however, to our knowledge; none have been validated in Hispanic and African American participants with type 2 diabetes. Marshall et al. (8) validated the Iowa Study Targeted Nutrient SemiQuantitative Questionnaire and the Block Kids Food Questionnaire for estimating calcium and vitamin D intake among children using a 3-day food diary as reference. Correlations between the questionnaires and food diary for vitamin D were modest ( $r=0.487$ and $r=0.512$, respectively). Pritchard et al. (11) validated a calcium, vitamin D, and vitamin K FFQ that also included assessment of supplement intake in overweight and obese post-menopausal women against a 5-day diet record. A strong correlation between the FFQ and the diet record for vitamin D was reported (r=0.89). Taylor et al. (10) validated a FFQ for assessing calcium and vitamin D intake in adolescent girls with anorexia nervosa against a 4-day food record. Strong correlations among the two diet 
collection methods for vitamin $\mathrm{D}$ was observed $(\mathrm{r}=0.78)$. The analysis was adjusted for energy intake.

Nucci et al. (7) evaluated the effectiveness of a short FFQ in determining vitamin D intake against a previously validated long FFQ in a population of 6 to 14 year old children. Correlations among the questionnaires was modest at baseline and follow up $(\mathrm{r}=0.35$ and $\mathrm{r}=0.37$, respectively). The study took into consideration the sun exposure habits of the population. Blalock et al. (12) assessed the validity of a short calcium and vitamin D FFQ among 27 university employees against a 7 day food diary and a previously validated long FFQ. Vitamin D intakes from the food diary and short FFQ were significantly correlated $(\mathrm{r}=0.72)$. The positive predictive value for identifying participants with low vitamin D intake using a cutoff point of 200 IU/day was $100 \%$.

It has been suggested that validation of nutrient intake should be conducted against a previously validated diet record but also against a biomarker of nutrient status (13). Vitamin D status is determined by serum 25(OH)D levels. However, since UVB light is the major contributor of vitamin $\mathrm{D}$, validation studies should be conducted during winter where 25(OH)D will be mainly affected by intake and not sun exposure. Otherwise, sun exposure should be taken into consideration in the analysis of vitamin D intake and 25(OH)D.

In this regard, Wu et al. (13) validated a 37-item vitamin D FFQ among a multiethnic sample of Canadian adults during late winter against a 7-day food diary and 25(OH)D levels. Intakes were modestly correlated among dietary collection methods and 25(OH)D ( $r=0.529$ and $r=0.481$, respectively). After redefining the serving sizes and 
excluding fortified orange juice from the FFQ, the correlations improved ( $r=0.602$ and $\mathrm{r}=0.520$, respectively).

Since studies suggested that vitamin D deficiency may have a role on insulin resistance and type 2 diabetes progression, it is imperative to validate diet collection tools in this particular population. The objective of the present study was to expand the short FFQ developed by Blalock et al (12). to include specific ethnic foods consumed by Hispanics and African Americans in South Florida and to examine the criterion validity of the short FFQ by comparing intakes with a previously validated long FFQ and serum $25(\mathrm{OH})$ levels.

\section{Methods}

\section{Participants}

An intervention study to assess the effects of vitamin D supplementation (4000 IU/day and 6000 IU/day) over six months on cardiovascular disease markers among a sample of African Americans and Hispanics with T2D was conducted. The present study analyzed the data collected at screening (short FFQ, 25(OH)D, sun exposure, and skin color) and baseline (long FFQ).

The study consisted of two phases: phase one included the screening of individuals, phase two included the recruitment of individuals who met inclusion criteria and beginning of the vitamin $\mathrm{D}$ intervention trial. The inclusion criteria were vitamin $\mathrm{D}$ insufficiency $(25(\mathrm{OH}) \mathrm{D}<30 \mathrm{ng} / \mathrm{ml}), 30-70$ years of age, African American or Hispanic with confirmed T2D. Exclusion criteria were taking vitamin D supplements other than 
standard daily multivitamin formula, pregnant or lactating, having thyroid, hepatic, renal dysfunction, cancer, HIV, and major psychiatric disorders.

Flyers explaining the purpose of the study, inclusion/exclusion criteria and containing investigators' emails and phone numbers were distributed in highly visited community areas such as churches, supermarkets, and clinics. Two clinics were visited every week for recruitment purposes: Borinquen Health Care Center and Clinical Care Medical Center. When participants called the investigators, purposes of the study were explained and specific questions were asked to assure compliance with inclusion criteria. All qualified participants were invited to participate in a morning session at Human Nutrition Laboratory at FIU for fasting blood sampling to screen for vitamin D insufficiency. All participants were asked to sign an informed consent form previous to screening data collection and to provide contact number and address of their physician, as well as their own contact information. Only participants with T2D diagnosis confirmed by a physician were eligible to participate in the study. The study was approved by IRB at FIU.

Participants in both groups were required to take either 4000 IU or $6000 \mathrm{IU}$ of vitamin D (Cholecalciferol) per day given in the form of a pill in a single daily dose. Each participant was seen 4 times; at screening, baseline, 3 months, and 6 months. Serum 25(OH)D were measured at screening, 3 months, and 6 months. The study lasted for 25 weeks for each participant from screening to final assessment. The study started in June 2011 and was completed on September 2013. Ninety two participants were screened. Seventy five qualified for the intervention ( $n=50$ for 4000 IU/day treatment and $n=25$ for $6000 \mathrm{IU} /$ day treatment). The time frame between dietary data collection was one week 
(short FFQ at screening and long FFQ at baseline). Serum 25(OH)D, skin color and sun exposure data collected at screening (before any treatment took place) was used for this analysis. Even though data from the short FFQ, skin color, sun exposure, and serum 25(OH)D was available for the ninety two initial participants at screening, only the data from the seventy five who qualified for the study and also completed the long FFQ at baseline were included in the analysis.

\section{Blood Collection}

Venous blood (15 ml) was collected from each subject by a certified phlebotomist using standard laboratory methods at each study point. After coagulation, blood was centrifuged at 2500 RPM for 30 minutes. The plasma glucose concentration was measured by hexokinase enzymatic method. Glycated hemoglobin (A1C) was measured by the DCA2000+ system (Bayer Corporation, Diagnostics Division, N.Y., U.S.) using the monoclonal antibody method. Serum vitamin D concentrations were measured with an enzyme-immunoassay kit by absorbance (Immunodiagnostic Systems Scottsdale, A.Z., U.S.). Color intensity developed was inversely proportional to the concentration of serum 25(OH)D.

\section{Socio-demographic Questionnaire}

Participants were asked to complete a standard questionnaire on site. Trained interviewers bilingual in English and Spanish administered the questionnaires in the language of preference of the participant. Data were collected using a socio-demographic 
questionnaire which included questions related to gender, age, years with T2D, smoking, alcohol intake, and years living in the US.

\section{Anthropometric Measurements}

Height (m) and weight (kg) were measured using a SECA clinical balance scale (Seca Corp, Columbia, MD). Body mass index (BMI) was calculated as weight in $\mathrm{kg} /$ height in $\mathrm{m}^{2}$.

\section{Sun Exposure Questionnaire}

The sun exposure questionnaire developed by Hanwell et al. (14) was used following the original rubric. Time spent outdoors during the previous week $(0 \leq 5$ minutes, 1=5-30 minutes and 2=>30 min) was self-reported. Four options for skin exposed while outdoors were offered (1=face and hands, 2=face, hands and arms, 3=face, hands and legs and 4=bathing suit). The daily sun exposure score for each day was calculated by multiplying the time spent outdoors score times the skin exposed while outdoors score. The scale for each day ranged from 0 to 8 . The weekly sun exposure was calculated by adding the daily scores ( $\min =0, \max =56$ ).

\section{Skin Color}

In order to have an objective measure of sun exposure, skin color was determined by reflectance colorimetry using the SmartProbe 400 (IMS Inc. USA). This instrument uses the International Commission on Illumination Scale which ranges from 0 (black) to 100 (white) for skin color. Two readings at each measurement site (6 readings total) for 
each participant were taken: two on the dorsal aspect of the wrist of the right hand (area most exposed to sun), two on the inside of the right upper arm and two on the stomach (areas less exposed to the sun). The mean values of the two readings at each measurement sites were used for analysis. The change in skin color due to sun exposure was calculated by finding the difference between the less exposed area (natural color) and the most exposed area.

\section{Assessment of Dietary Intake}

Dietary intake was determined using the long FFQ developed by Walter Willett (15). This FFQ has been validated in different ethnical groups and, also, specifically in Cuban-Americans in South Florida (16). Participants self-reported the average consumption of specific amount of foods over the past 12 months. Frequencies ranged from "never" to "six or more servings per day". The FFQ also assessed the frequency use of multivitamin/mineral supplements, salt, sugar, alcohol and vitamin D intake. A short FFQ containing 24 foods and beverages designed to assess vitamin D and calcium intake was administered during the screening phase. The original questionnaire contained only 22 foods (12). Pizza and sardines were added as common foods consumed by this population based on our previous studies $(16,17)$. The questionnaire asked participants how frequently they consume each food and the serving size. Total vitamin D intake was calculated following the original rubric (12). 


\section{Statistical Analysis}

The descriptive statistics for continuous variables were presented as mean $\pm \mathrm{SD}$ and proportions for categorical variables. The Student's $t$ test for paired samples was used to compare the vitamin D intake between both questionnaires. Pearson correlations among the long FFQ and short FFQ and the short FFQ and serum 25(OH)D was conducted to test the validity of the questionnaire. A cross classification analysis was run to determine the agreement between the questionnaires or if they misclassify participants into categories based on vitamin D intake levels. For this purpose vitamin D intakes were divided into quartiles. The proportion of participants who were classified into the same quartile, same \pm 1 quartile, or who were entirely misclassified when comparing both tools was calculated. The positive predictive value of the short FFQ to identify participants with vitamin D intake below the RDA (600 IU for people 1 to 70 years old) (18) was determined comparing the number of individuals below the cutoff for each dietary collection method. A multiple linear regression model was run to determine the association between serum 25(OH)D, vitamin D intake from the short FFQ, and sun exposure score. Serum 25(OH)D was the dependent variable. Later the model was adjusted for age, gender, BMI, forearm skin color, A1C, years with T2D, years living in

the US, ethnicity, alcohol intake, and smoking status. All analyses were performed using SPSS version 19 (Chicago, IL, US).A p-value of <.05 was considered significant.

\section{Results}

Participants $(n=75)$ had a mean \pm SD for age of $54.8 \pm 9.7$ years, BMI of $33.7 \pm$ $6.6 \mathrm{~kg} / \mathrm{m}^{2}$, serum $25(\mathrm{OH}) \mathrm{D}$ of $22.6 \pm 6.6 \mathrm{ng} / \mathrm{ml}$, forearm skin color of $55.7 \pm 7.5$, sun 
exposure score of $19.6 \pm 15$, A1C of $8.3 \pm 2.2 \%$, and fasting plasma glucose of $181.9 \pm$ $78.3 \mathrm{mg} / \mathrm{dl}$. They had been living in the US for $10.4 \pm 9.3$ years and have been diagnosed with T2D for $6.1 \pm 5.4$ years (Table 1). Sixteen percent were smokers, 28\% consumed alcohol, 48.9\% were males, and 86.7\% were Hispanics. Dietary vitamin D intake according to the long FFQ and short FFQ were $311.8 \pm 241.8$ and $323.7 \pm 290.9$ IU/day, respectively (Table 1).

There were no significant differences between dietary vitamin D intake derived from the long FFQ and the short FFQ $(P=0.637)$. The mean difference between intakes was $11.9 \mathrm{IU} /$ day. The correlation between dietary methods was $0.683(\mathrm{P}<0.001)$. The correlation between vitamin D intake according to the short FFQ and serum 25(OH)D was not significant $(r=0.010, P=0.934)$. The long FFQ was not correlated to serum 25(OH)D either ( $r=0.164, P=0.161)$ (Table 2).

The cross-classification analysis showed that $79 \%$ of the participants were classified into the same quartile by both collection methods and a 100\% were classified into the same \pm 1 quartile. None of the participants was misclassified (Table 3).

The positive predictive value of the short FFQ to identify participants with vitamin D intake below the RDA (600 IU/day) as compared to the long FFQ was 95.2\%.

The unadjusted multilinear regression showed that short FFQ was not associated with serum 25(OH)D ( $P=0.065)$. In contrast, sun exposure score was significantly associated with serum 25(OH)D ( $P=0.020)$. The unadjusted model explained 9.7\% of the variation in serum $25(\mathrm{OH}) \mathrm{D}$. When the model was adjusted for covariates, only A1C and years with T2D were significantly associated with serum $25(\mathrm{OH}) \mathrm{D}(P<0.001$ and 
$P=0.028$, respectively). The adjusted model explained $41 \%$ of the variation in serum 25(OH)D (Table 4).

\section{Discussion}

Food frequency questionnaires are used in clinical settings to record dietary patterns over a long period of time. They can show patterns that are not detected with food records and put less burden on the subject.

The FFQ developed by Willet et al. (15) has been commonly used in research settings and validated in several populations. This questionnaire has 126 food items and takes 45 minutes to be completed which is not practical in clinical settings. In contrast, the short FFQ used in the present study has only 24 food items and takes 5 minutes to be completed (12).

In fact, the short FFQ was valid when compared to the long FFQ. The correlation obtained between questionnaires ( $r=0.683$ ) was higher than the one obtained by Nucci et al. $(\mathrm{r}=0.35)(7)$ when validating a 21-item short FFQ against a 152-item long FFQ among 14 year old children. The reason for this low correlation may be that the information was provided by the parents and that supplement intake was assumed to be $400 \mathrm{IU}$ when it was not specified (7). Studies that used food records as the gold standard to validate short FFQ have obtained higher correlations. Pritchard et al. (11) validated a calcium, vitamin $\mathrm{D}$, and vitamin K FFQ in overweight and obese post-menopausal women against a 5-day diet record. A strong correlation between the FFQ and the diet record for vitamin D was reported ( $\mathrm{r}=0.89$ ). Taylor et al. (10) validated a FFQ for assessing calcium and vitamin D intake in adolescent girls with anorexia nervosa against a 4-day food record. Strong 
correlations among the two diet collection methods for vitamin $\mathrm{D}$ was observed $(\mathrm{r}=0.78)$. Blalock et al. (12), who developed the questionnaire that was used in the current study, validated the tool against a 7 day food diary. Vitamin D intakes from the food dairy and short FFQ were significantly correlated $(\mathrm{r}=0.72)$.

It may be possible that the use of a gold standard collection method like food records increased the correlation with the short FFQ in the previous studies compared to this study due to less variability. However, the food records are only collected during a short period of time and it is assumed that they represent real intake. Therefore, all errors in intake are assigned to the short FFQ when compared to food records. If some unusual foods are consumed during these days, then the food records no longer represent a real intake and a systemic bias is added to the analysis which does not happen when a short FFQ is validated against a long FFQ.

In addition, none of the participants was grossly misclassified when the sample was divided in quartiles for both questionnaires. Therefore, the short FFQ can accurately classify participants according to their vitamin D intake.

Even though the mean difference in vitamin D intake reported by both tools was not significant, the short FFQ over reported vitamin D by 12 IU/day compared to the long FFQ. This was expected since the short FFQ only focuses on foods containing vitamin D while the long FFQ assesses all foods eaten over one year.

Blalock et al. (12), reported a positive predictive value of $100 \%$ when using a cutoff point of $200 \mathrm{IU} /$ day. In our study the positive predictive value to detect participants with intakes below 600 IU/day was 95.2\% which was expected because the cut off was higher than the one used in the previous study. In addition, only $12 \%$ of our 
sample had intakes above $600 \mathrm{IU} / \mathrm{day}$. This was also expected because our study only enrolled participants with vitamin D insufficiency which makes our results not generalizable to the entire population of patients with T2D. However, since vitamin D insufficiency is prevalent among patients with T2D (5), this tool may be applicable to a vast majority of this population.

The mean BMI of our sample was $33.7 \pm 6.6 \mathrm{~kg} / \mathrm{m}^{2}$, which may have affected our results. It has been shown that obese participants underreport food intake despite the collection method used (9). The majority of participants in our sample were overweight and obese. Therefore, it is possible that actual vitamin D intake is higher and a correction factor may be needed to approximate this value. Regarding ethnicity, only 10 African Americans were enrolled in the study. Therefore, it was not possible to detect ethnic differences due to the small sample size.

Diffey et al. (19), proposed a model to estimate serum 25(OH)D based on vitamin D intake and sun exposure scores in Caucasian British adults. Even though, the model was significant, it has been criticized for not including other important factors that affects serum vitamin D levels. In fact, as we age vitamin D synthesis decreases and vitamin D is sequestered in fat tissue (7). Therefore, age and BMI should be added to the model in order to better represent the relationship with serum 25(OH)D.

In this regard, the correlation between the short FFQ vitamin D intake and serum 25(OH)D was not significant in our sample. We hypothesised that adding the sun exposure questionnaire was going to improve the relationship. A more careful view of the sun exposure scores revealed that a considerable proportion of the participants in our sample spend no time at all outdoors. Therefore, this was not a sample with enough 
variability in sun exposure habits. When age and BMI were added to the model, they did not contribute significantly to the association either. Interestingly, time with T2D and A1C were strongly associated with serum 25(OH)D. To our knowledge, there was no study validating a short vitamin D food frequency questionnaire in participants with T2D in the literature, thus, we were unable to compare our results. It may be possible that in participants with T2D, vitamin D levels are related to insulin sensitivity and to blood glucose. Therefore, supplementing vitamin D to participants with T2D may have a profound impact on glycemic control, despite sun exposure habits or intake.

We were not able to adjust for kcal intake because the short FFQ does not provide energy intake data. However, there was no correlation between energy intake and vitamin D intake in the long FFQ, which makes us think that energy intake is not a confounder in this particular sample.

Our study has additional limitations. The short FFQ did not include fortified foods like orange juice, meats, and soy milk. In addition, supplement intake was not recorded in the short FFQ. This short FFQ should be administered several times a year to track the vitamin D intake change between seasons.

Finally, this is the first short FFQ designed to asses vitamin D intake validated in a population of participants with T2D. This tool is easy to use in clinical settings due to its brevity and simplicity. In addition, it can help screen participants at high risk of vitamin D deficiency that can be confirmed later with biochemical analysis. Since glycemic control may be related to vitamin D status, screening for vitamin D deficiency using this short FFQ may help prevent diabetes complications in Hispanics and African Americans. 
Table 1. Characteristics of the study participants $(n=75)$

\begin{tabular}{lc}
\hline Variable & Mean \pm SD \\
\hline Age (years) & $54.8 \pm 9.7$ \\
BMI (kg/m ${ }^{2}$ ) & $33.7 \pm 6.6$ \\
Living in US (years) & $10.4 \pm 9.3$ \\
Serum 25(OH)D (ng/ml) & $22.6 \pm 6.6$ \\
Forearm skin color & $55.7 \pm 7.5$ \\
Stomach skin color & $59.2 \pm 9.8$ \\
Delta of skin color & $3.5 \pm 5.4$ \\
Sun exposure score & $19.6 \pm 15.0$ \\
Time outdoors score & $6.5 \pm 4.6$ \\
Skin exposure score & $20.4 \pm 3.2$ \\
A1C (\%) & $8.3 \pm 2.2$ \\
FPG (mg/dl) & $181.9 \pm 78.3$ \\
Years with T2D & $6.1 \pm 5.4$ \\
Dietary Vit D intake (long FFQ)(IU/day) & $311.8 \pm 241.8$ \\
Dietary Vit D intake (short FFQ)(IU/day) & $323.7 \pm 290.9$ \\
Tobacco use & \\
No & $84.0 \%$ \\
Yes & $16.0 \%$ \\
Alcohol consumption & \\
$\quad$ No & $72.0 \%$ \\
Yes & $28.0 \%$ \\
Gender & \\
Females & $51.1 \%$ \\
Males & $48.9 \%$ \\
Ethnicity & \\
African Americans & $13.3 \%$ \\
Hispanics & $86.7 \%$ \\
\hline Data are mean \pm standard deviation (SD) or \%. BMI = Body \\
mass index, A1C= glycated haemoglobin, FPG= fasting \\
plasma glucose, T2D= type 2 diabetes, FFQ = food frequency \\
questionnaire \\
\end{tabular}


Table 2. Dietary vitamin D intake derived from the long FFQ and short FFQ, and correlation between methods

\begin{tabular}{lllll}
\hline & $\begin{array}{l}\text { Long FFQ } \\
(\text { Mean } \pm \text { SD) }\end{array}$ & $\begin{array}{l}\text { Short FFQ } \\
(\text { Mean } \pm \text { SD) }\end{array}$ & $P$-value & Pearson $r$ \\
\hline $\begin{array}{l}\text { Dietary Vitamin D } \\
\text { intake (IU/day) }\end{array}$ & $311.8 \pm 241.8$ & $323.7 \pm 290.9$ & 0.637 & $0.683^{*}$ \\
\hline \multicolumn{2}{l}{$\begin{array}{l}\text { Significant differences between dietary sources determined by paired samples t- } \\
\text { test. *Indicates significant correlation between long FFQ and short FFQ, } P<0.05\end{array}$}
\end{tabular}

Table 3. Cross-classification analysis to determine proportion of participants classified into the same, or same \pm 1 quartile based on short FFQ and long FFQ intakes.

\begin{tabular}{lccc}
\hline & $\begin{array}{c}\text { \% classified into } \\
\text { same quartile }\end{array}$ & $\begin{array}{c}\text { \% classified into } \\
\text { same } \pm 1 \text { quartile }\end{array}$ & $\%$ misclassified \\
\hline Vitamin D intake & 79 & 100 & 0 \\
\hline Quartiles 1 to 4 for short FFQ were $<140,140-212,212-486,>486$ IU/day; quartiles 1 to \\
4 for long FFQ were $<133.4,133.4-245.3,245.3-443.7,>443.7$ IU/day. FFQ=short food \\
frequency questionnaire.
\end{tabular}


Table 4. Relationship of serum 25(OH)D, dietary vitamin D intake, and covariates

\begin{tabular}{lcccc}
\hline Parameter* $^{*}$ & $\beta$ & $S E$ & $T$ & $P$-value \\
\hline Vitamin D intake (short FFQ) & 0.004 & 0.003 & 1.48 & 0.144 \\
Sun exposure score & 0.370 & 0.224 & 1.65 & 0.104 \\
\hline
\end{tabular}

*Other covariates in the multiple linear regression were age, gender, BMI, forearm skin color, A1C, years living in US, years with type 2 diabetes, ethnicity, tobacco use and alcohol consumption. $\dagger P<0.05$ is considered significant. 


\section{References}

1. Centers for Disease Control and Prevention. Vitamin D Status: United States, 20012006. Accessed April 29, 2013. Available http://www.cdc.gov/nchs/data/databriefs/db59.pdf

2. Looker AC, Dawson-Hughes B, Calvo MS, Gunter EW, Sahyoun NR. Serum 25hydroxyvitamin D status of adolescents and adults in two seasonal subpopulations from NHANES III. Bone. 2002;30:771-777.

3. Nesby-O’Dell S, Scanlon KS, Cogswell ME, Gillespie C, Hollis BW, Looker AC, et al. Hypovitaminosis D prevalence and determinants among African American and white women of reproductive age: third National Health and Nutrition Examination Survey, 1988-1994. Am J ClinNutr. 2002;76:187-192.

4. Baynes KCR, Boucher BJ, Feskens EJM, Kromhout D. Vitamin D, glucose tolerance and insulinaemia in elderly men. Diabetologia. 1997;40(3):344-347.

5. Scragg R, Sowers M, Bell C. Serun 25-hydroxyvitamin D, diabetes, and ethnicity in the Third National Health and Nutrition Examination Survey. Diabetes Care. 2004;27(12):2813-2818.

6. Kayaniyil S, Vieth R, Retnakaran R, Knight JA, Qi Y, Gerstein HC, et al. Association of vitamin $D$ with insulin resistance and $\beta$-cell dysfunction in subjects at risk for type 2 diabetes. Diabetes Care. 2010;33(6):1379-1381.

7. Nucci AM, Russell CS, Luo R, Ganji V, Olabopo F, Hopkins B, et al. The effectiveness of a short food frequency questionnaire in determining vitamin $\mathrm{D}$ intake in children. Dermato-Endocrinology. 2013;5(1):205-210.

8. Marshall TA, Eichenberger Gilmore JM, Broffitt B, Stumbo PJ, Levy SM. Realtive validity of the Iowa Fluoride Study Targeted Nutrient Semi-Quantitative Questionnaire and the Block Kids’ Food Questionnaire for estimating beverage, calcium, and vitamin D intakes by children. J Am Diet Assoc. 2008;108:465-472.

9. Kaaks R, Ferrari P, Ciampi A, Plummer M, Riboli E, Part H. Uses and limitations of statistical accounting for random error correlations, in the validation of dietary questionnaire assessments. Public Health Nutr. 2002;5(6A):969-976.

10. Taylor C, Lamparello B, Kruczek K, Anderson E, Hubbard J, Misra M. Validation of a food frequency questionnaire for determining calcium and vitamin $\mathrm{D}$ intake by adolescents girls with anorexia nervosa. J Am Diet Assoc. 2009;109:479-485. 
11. Pritchard JM, Seechurn T, and Atkinson SA. A food frequency questionnaire for the assessment of calcium, vitamin D, and vitamin K: a pilot validation study. Nutrients. 2010,2:805-819.

12. Blalock SJ, Norton LL, Patel RA, Cabral K, Thomas CL. Development and assessment of a short instrument for assessing dietary intakes of calcium and vitamin D. J Am Pharm Assoc. 2003;43:685-693.

13. Wu H, Gozdzik A, Barta JL, Wagner D, Cole DE, Vieth R, et al. The development and evaluation of a food frequency questionnaire used in assessing vitamin D intake in a sample of healthy young Canadian adults of diverse ancestry. Nutrition Research. 2009;29:255-261.

14. Hanwell HE, Vieth R, Cole DE, Scillitani A, Modoni S, Frusciante V, et al. Sun exposure questionnaire predicts circulating 25-hydroxyvitamin D concentrations in Caucasian hospital workers in southern Italy. J Steroid BiochemMol Biol. 2010;121(1-2):334-337.

15. Willet WC, Sampson L, Stampfer MJ, Rosner B, Bain C, Witschi J, et al. Reproducibility and validity of a semiquantitative food frequency questionnaire. Am J Epidemiol. 1985;122(1): 51-65.

16. Nath SD, Huffman FG. Validation of a semi quantitative food frequency questionnaire to assess energy and macronutrient intakes of Cuban Americans. International Journal of Food Science and Nutrition. 2005;56(5):309-314.

17. Exebio JC, Zarini GG, Exebio C, Huffman FG. Healthy Eating Index scores associated with symptoms of depression in Cuban-Americans with and without type 2 diabetes: a cross sectional study. Nutr J. 2011;10:135.

18. Institute of Medicine, Food and Nutrition Board. Dietary Reference Intakes for Calcium and Vitamin D. Washington, DC: National Academy Press, 2010.

19. Diffey BL. Modeling vitamin D status due to oral intake and sun exposure in an adult British population. Br J Nutr. 2013;23:1-9. 


\section{CHAPTER VII: SUMMARY AND CONCLUSIONS}

\section{Effect of vitamin D supplementation on blood lipids}

In the current study, vitamin $\mathrm{D}_{3}$ supplementation at $6000 \mathrm{IU} /$ day significantly reduced total cholesterol, and triglycerides in a sample of Hispanics and African Americans with type 2 diabetes and vitamin D insufficiency. The significance was lost, however, after adjusting for confounders. Therefore, our results suggest that the association between vitamin D insufficiency and dyslipidemia may be mediated by other cardiovascular risk factors such as obesity.

In addition, the positive effect of vitamin D supplementation on total cholesterol and triglycerides was observed only in the 6000 IU group despite both groups reaching similar serum vitamin D levels. It might be that sufficient vitamin D status was achieved sooner in the 6000 IU/group and participants were exposed to sufficient vitamin D levels for a longer period of time.

\section{Effect of vitamin D supplementation on glucose homeostasis}

Our results did not support the hypothesis that vitamin D supplementation may improve glucose homeostasis in participants with established type 2 diabetes. Our participants had $6.48 \pm 5.18$ and $5.48 \pm 5.93$ years with type 2 diabetes for the $4000 \mathrm{IU}$ and $6000 \mathrm{IU}$ groups, respectively. This may indicate that vitamin D supplementation has no effect on glucose homeostasis once beta cell function has passed a certain point of deterioration. 
A trend for a decline in fasting plasma glucose was observed in the $4000 \mathrm{IU}$ group. Since no improvement was observed in A1C, a marker of long term glycemic control, changes in fasting plasma glucose may be of limited significance in this population with established type 2 diabetes.

\section{Vitamin D repletion}

Treatments with 4000 IU/day and 6000 IU/day increased serum 25(OH)D levels significantly at 3 months and 6 months compared to baseline values. These results support the notion that 4000 IU/day for 3 months is an adequate dosage to replenish vitamin D in Hispanics and African Americans with T2D. Additional treatment for 3 extra months or a higher dosage of $6000 \mathrm{IU} /$ day did not change serum 25(OH)D levels significantly. According to these data, a physiological plateau is reached at 3 months with the use of the $4000 \mathrm{IU} /$ day regimen.

Regarding safety, none of the participants in our study reported any adverse events or achieved a serum 25(OH)D $>150 \mathrm{ng} / \mathrm{ml}$. Therefore, it seems that both treatments are safe to use among this particular population of Hispanics and African Americans with T2D for six months.

\section{Validation of sun exposure questionnaire}

The total weekly sun exposure score was not correlated with either change in skin color or serum 25(OH)D in our study. These results are explained by the very short time spent outdoors in this population of participants with T2D. The sun exposure questionnaire was not a valid tool to estimate change in skin color due to sun exposure or 
serum 25(OH)D levels in this sample of African Americans and Hispanics with T2D. Unexposed skin color and A1C levels were significantly associated with serum 25(OH)D. Unexposed skin color may be used as proxy measure to screen for vitamin D deficiency in this sample of participants with T2D.

\section{Validation of a short food frequency questionnaire}

The short FFQ demonstrated to be valid when compared to the long FFQ. In addition, none of the participants was grossly misclassified when the sample was divided in quartiles for both questionnaires. Therefore, the short FFQ can accurately classify participants according to their vitamin D intake. The positive predictive value of the short FFQ to detect participants with intakes below 600 IU/day was 95.2\%. 


\section{CHAPTER VIII: STRENGTHS AND LIMITATIONS}

Our study had several strengths. First, to our knowledge this was the first study that analyzed vitamin D supplementation effects on cardiovascular risk factors in Hispanics and African Americans with T2D. Second, the dosages used were large enough to raise serum vitamin $\mathrm{D}$ to sufficient levels in a population that was insufficient at baseline. Third, analysis was adjusted for a wide range of covariates related to vitamin D metabolism. Fourth, our study had sufficient power to find changes in fasting plasma glucose, fasting insulin, A1C and lipid panel. Fifth, individuals did not change medication, vitamin D intake, BMI, smoking or sun exposure habits during the course of the study. Sixth, the short FFQ is the first validated tool to assess vitamin D intake in a population of participants with T2D. This tool is easy to use in clinical settings due to its brevity and simplicity. In addition, it can help screen participants at high risk of vitamin D deficiency that can be confirmed later with biochemical analysis. Lastly, compliance in our study was high with $94 \%$ for the 4000 IU group and 92\% for the 6000 IU group without any differences between groups. No adverse events were reported during the course of the study.

Limitations of our study included: first, the sample was not representative of the general population of people with T2D in the US and participants were not randomly distributed among groups. Thus, our results are not generalizable. Second, our sample was categorized as obese according to their BMI which may diminish the effect of vitamin D supplementation. In addition, obese participants are prone to underreport food intake. Third, the number of African American participants was not large enough to 
analyze data by ethnicity. Fourth, the use of fixed time intervals. Therefore, the peak levels of serum 25(OH)D may have been missed. Fifth, the limited outdoor activity of this particular sample. Sixth, the short FFQ did not include vitamin D fortified foods. Lastly, $64 \%$ and $68 \%$ of participants were taking lipid lowering medication in the 4000 IU and 6000 IU groups, respectively. Medication use may mask the effect of vitamin D supplementation. We tried to control for it by advising participants to keep their medication use constant during the study, however, this panorama reflects common clinical practice among patients with type 2 diabetes. 


\section{CHAPTER IX: FUTURE RESEARCH}

Our results suggest that the positive effect of vitamin D supplementation on lipid profile may be mediated by other cofactors related to vitamin D metabolism among Hispanic and African American participants with type 2 diabetes. The inclusion of obese/non obese participants is needed in order to assess the confounding effect of this variable. Longer, well designed randomized clinical trials are warranted.

The main objective of glycemic control in patients with type 2 diabetes is to prevent microvascular and macrovascular complications. The use of surrogate measures like fasting plasma glucose, insulin resistance, and A1C are of practical clinical significance but not ideal for research purposes. Longer and larger studies supplementing vitamin D to participants with type 2 diabetes that focus on microvascular and macrovascular complications, instead of surrogate measures, are needed to confirm our results.

It may be possible that maintenance of sufficient serum $25(\mathrm{OH})$ levels for a longer period of time are needed to see significant changes in metabolic markers not related to bone turn over or calcium metabolism. Therefore, it remains to be seen if supplementation periods longer than 6 months may have an effect on cardiovascular risk factors in this particular sample of Hispanics and African Americans with T2D.

Finally, the short FFQ is easy to use in clinical settings due to its brevity and simplicity. In addition, it can help screen participants at high risk of vitamin D deficiency that can be confirmed later with biochemical analysis. Therefore, studies testing the short FFQ in community and clinical settings are warranted. 
Appendix 1: Consent Forms 


\section{FIU}

\section{ADULT CONSENT TO PARTICIPATE IN A RESEARCH STUDY}

\section{"The Effect of Vitamin D Supplementation on Cardiovascular Risk Factors among Hispanics and African Americans with Type 2 diabetes"}

\section{PURPOSE OF THE STUDY}

You are being asked to participate in a research study. The purpose of this study is to determine the effect of supplemental vitamin D intake on cardiovascular risk factors in Hispanics and African Americans with type 2 diabetes.

\section{NUMBER OF STUDY PARTICIPANTS}

If you decide to be in this study, you will be one of 120 people in this research study.

\section{DURATION OF THE STUDY}

Your participation will require one (1) visit every 3 months and each visit may last up to 3 hours. You will be asked to participate in an initial blood collection screening. Depending on your vitamin D level, you will be contacted either to continue in the study or you will be told that you do not qualify after your first visit. If you qualify for the study, you will be required to make a total of 4 visits to the human nutrition lab, during the study period.

\section{PROCEDURES}

If you agree to be in the study, the following procedures will be done:

1. You will provide information on your gender, age, level of education, year of diagnosis of diabetes, medication use, and smoking.

2. You will answer questions about your mood, sun exposure habits and dietary intakes.

3. Your skin color will be measured by a hand-held device. This will be painless.

4. A certified phlebotomist will draw your blood (approximately four tablespoons of blood or $15 \mathrm{ml}$ ). Blood will be drawn from your arm. You will also provide a urine sample.

5. You will be required to take Vitamin D at a dose of $4000 \mathrm{IU} /$ day or $6000 \mathrm{IU} /$ day for 6 months.

6. You will take $4000 \mathrm{IU} /$ day if you are one of the first 60 participants and $6000 \mathrm{IU} /$ day if you are among the next 60 participants.

\section{RISKS AND/OR DISCOMFORTS}

The following risks may be associated with your participation in this study: First, soreness, redness or possible infection of the area in front of elbow joint from where blood will be drawn. A certified phlebotomist will be using sterile and standard procedures. Therefore, risks of soreness, redness or infection may be extremely rare. Second, you may experience very mild dizziness that is reversible within few minutes without any effects. Taking high doses of Vitamin D may cause signs of toxicity such as nausea, vomiting, excess thirst, excess urination, weakness and nervousness. You will be required to immediately report to the PI or the study team if you experience any of these issues. Study team will regularly monitor you at all visits for signs of toxicity. If you show signs of toxicity due to vitamin D, you will be withdrawn from the study. 


\section{PIII]}

\section{BENEFITS}

The following benefits may be associated with your participation in this study:

- You will receive your blood test, diet analysis results and be able to ask questions about Diabetes and the study.

- Vitamin D may improve your bone density.

\section{ALTERNATIVES}

You may choose not to participate in the study or withdraw from the study at anytime without any consequences.

\section{CONFIDENTIALITY}

The records of this study will be kept private and will be protected to the fullest extent provided by law. In any sort of report we might publish, we will not include any information that will make it possible to identify a subject. Research records will be stored securely and only the research team will have access to the records. The U.S. Department of Health and Human Services (DHHS) and/or the Food and Drug Administration (FDA) may request copies of your records to review them. Your records may also be reviewed for audit purposes by authorized University or other agents who will be bound by the same provisions of confidentiality. A description of this clinical trial will be available on http://www.ClinicalTrials.gov, as required by US Law. This web site will not include information that can identify you. At most, the web site will include a summary of the results. You can search this website at anytime.

\section{COMPENSATION \& COSTS}

You will receive a payment of twenty (\$20) dollars for your participation on the first visit. If you qualify for the study, you will receive a payment of twenty $(\$ 20)$ dollars on your second visit and forty $(\$ 40)$ dollars each on the third and fourth visit. You will not be responsible for any costs to participate in this study.

\section{MEDICAL TREATMENT}

Routinely, FIU, its agents, or its employees do not compensate for or provide free care for human subjects in the event that any injury results from participation in a research project. If you become ill or injured as a direct result of participating in this study, contact your regular medical provider. If you have insurance, your insurance company may or may not pay for these costs. If you do not have insurance, or if your insurance company refuses to pay, you will be billed. Funds to compensate for pain, expenses, lost wages and other damages caused by injury are not routinely available. If you show symptoms of physical or mental illness, you will be referred to your physician with your permission.

\section{RIGHT TO DECLINE OR WITHDRAW}

Your participation in this study is voluntary. You are free to participate in the study or withdraw your consent at any time during the study. Your withdrawal or lack of participation will not affect any benefits to which you are otherwise entitled. The investigator reserves the right to withdraw you from the study without your consent at such time that they feel is in the best interest of the study participant. 


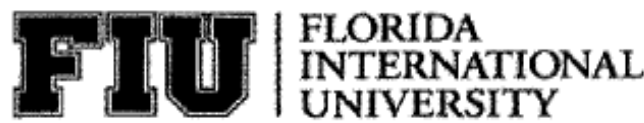

RESEARCHER CONTACT INFORMATION

If you have any questions about the purpose, procedures, or any other issues relating to this research study you may contact Dr. Fatma G. Huffman at HLS I room 435, (305) 348-3788, huffmanf@fiu.edu.

\section{IRB CONTACT INFORMATION}

If you would like to talk with someone about your rights of being a subject in this research study or about ethical issues with this research study you may contact Dr. Patricia Price, the Chairperson of the FIU Institutional Review Board (IRB) at 305-348-2618 or 305-348-2494.

\section{PARTICIPANT AGREEMENT}

I have read the information in this consent form and agree to participate in this study. I have had a chance to ask any questions I have about this study, and they have been answered for me. I understand that I am entitled to a copy of this form after it has been read and signed.

Signature of Participant

Printed Name of Participant

Signature of Person Obtaining Consent
Date

Date 


\section{FIU}

\section{CONSENTIMIENTO PARA PARTICIPAR EN UN ESTUDIO DE INVESTIGACION \\ "El Efecto de la Suplementación con Vitamina D en los Factores de Riesgo de Enfermedad Cardiovascular en Hispanos y Afro-Americanos con Diabetes Tipo 2"}

\section{PROPOSITO DEL ESTUDIO}

Usted ha sido invitado para participar en un estudio de investigación. El propósito del estudio es determinar el efecto de la suplementación con vitamina D en factores de riesgo cardiovasculares en Hispanos y AfroAmericanos con diabetes tipo 2.

\section{NUMERO DE PARTICIPANTES EN EL ESTUDIO}

Si usted participa en este estudio, será una de las 120 personas en este estudio de investigación.

\section{DURACION DEL ESTUDIO}

Su participación requerirá una (1) visita cada 3 meses y duraran alrededor de 3 horas cada una. Usted proveerá una muestra de sangre para selección. Dependiendo de sus niveles de vitamina D en sangre usted será contactado para continuar en el estudio o será retirado del mismo. Si usted califica para el estudio, usted tendrá que hacer un total de 4 visitas al laboratorio de nutrición humana.

\section{PROCEDIMIENTOS}

Si usted acepta participar en este estudio, los siguientes procedimientos serán realizados:

1. Usted proveerá información sobre su género, edad, nivel educacional, año de diagnostico de diabetes, medicación usada, y habito de fumar;

2. Usted responderá preguntas sobre sus sentimientos, hábitos de exposición al sol e ingesta de alimentos;

3. Su color de piel será medido por un instrumento manual. Esto será indoloro;

4. Un flebotomista certificado le sacara sangre (aproximadamente 4 cucharadas de sangre o $15 \mathrm{ml}$ ). La sangre será obtenida de su brazo. Usted proveerá una muestra de orina

5. Usted tendrá que tomar $4000 \mathrm{IU}$ o $6000 \mathrm{IU}$ de vitamina $\mathrm{D}$ al día por 6 meses.

6. Usted tomara $4000 \mathrm{UI} /$ dia si usted es uno de los 60 primeros participantes y $6000 \mathrm{UI} /$ dia is usted esta dentro de los siguientes 60 participantes.

\section{RIESGOS Y/O MOLESTIAS}

Los siguientes riesgos pueden ser asociados con su participación en el estudio: primero, dolor, enrojecimiento o posible infección del área enfrente del codo de donde la sangre fue obtenida. Un flebotomista certificado usara procedimientos estériles y estándares, por lo tanto, el riesgo de dolor, enrojecimiento o infección es muy raro. Segundo, usted puede experimentar un ligero mareo, el cual desaparecerá en unos pocos minutos sin ningún efecto. Tomar altas dosis de vitamina $\mathrm{D}$ puede causar síntomas de intoxicación como nausea, vomito, excesiva sed, excesiva micción, debilidad y nerviosismo. Usted tendrá que reportarse inmediatamente al PI o al equipo de investigación si usted sufriera de alguno de estos síntomas. El equipo de investigación estará constantemente monitoreando algún signo de intoxicación que usted presente. Si usted presenta signos de intoxicación causados por la vitamina $\mathrm{D}$, usted podría ser retirado del estudio.

\section{BENEFICIOS}

Los siguientes beneficios pueden ser asociados con su participación en este estudio:

- Usted recibirá los resultados de su análisis de sangre, dieta y podrá hacer preguntas referentes a la diabetes.

- La vitamina D puede mejorar su densidad ósea 


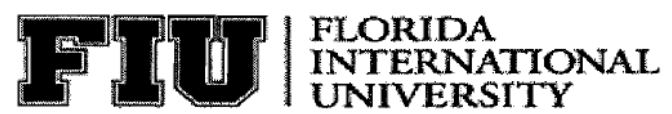

\begin{abstract}
ALTERNATIVAS
Usted puede escoger no participar en el estudio o retirarse del estudio en cualquier momento sin ninguna consecuencia.
\end{abstract}

\title{
CONFIDENCIALIDAD
}

Los archivos de este estudio serán privados y protegidos por la ley. En cualquier reporte que nosotros publiquemos, no incluiremos ninguna información que haga posible identificar a un sujeto. Los archivos serán guardados en forma asegura y solo el equipo de investigación tendrá acceso a ellos. El Departamento de Salud y Servicios Humanos de los Estados Unidos (DHHS) y/o la Administración de Alimentos y Drogas (FDA) pueden pedir copias de sus archivos para revisarlos. Sus archivos pueden ser también revisados para propósitos de auditoría por agentes autorizados de la Universidad u otros agentes que seguirán las mismas reglas de confidencialidad. Una descripción de este estudio clínico estará disponible en http://www.ClinicalTrials.gov, según lo requiere la ley. Esta página web no incluirá información que lo pueda identificar. A lo sumo, la página web incluirá un resumen de los resultados. Usted puede acceder a esta página web en cualquier momento.

\section{COMPENSACION Y COSTOS}

Usted recibirá un pago de veinte $(\$ 20)$ dólares por su participación en la primera visita. Si usted califica para el resto del estudio, recibirá un pago de veinte $(\$ 20)$ dólares en su segunda visita y cuarenta $(\$ 40)$ dólares por la tercera y cuarta visita. Usted no será responsable de ningún costo por participar en este estudio.

\section{TRATAMIENTO MEDICO}

Rutinariamente, FIU, sus agentes, o sus empleados no compensan o proveen cuidado gratis a sujetos en el evento de que una lesión resulte de su participación en el proyecto de investigación. Si usted resulta enfermo o lesionado como resultado directo de su participación en el estudio, contacte a su médico. Si usted tiene seguro, su compañía de seguros puede o no pagar por estos costos. Si usted no tiene seguro, o si su compañía de seguros se niega a pagar, usted será facturado. Fondos para compensar por dolor, gastos, pérdida de salario y otros daños causados por lesión no están disponibles habitualmente. Si usted muestra síntomas de enfermedad física o mental, será referido a su médico con su consentimiento.

\section{DERECHO DE DECLINAR O RETIRARSE}

$\mathrm{Su}$ participación en el estudio es voluntaria. Usted es libre de participar en el estudio o de retirar su consentimiento en cualquier momento durante el estudio. Su retiro o falta de participación no afectara ningún beneficio para los cuales tenga derecho. Los investigadores se reservan el derecho de removerlo del estudio sin su consentimiento en el momento que ellos lo crean necesario.

\section{INFORMACION DE CONTACTO DEL INVESTIGADOR}

Si tiene alguna pregunta acerca del propósito, procedimiento, u otro tema relacionado a esta investigación, puede contactar a Dr: Fatma G. Huffman en HLS I oficina 435, (305) 348-3788, huffmanf@fiu.edu.

\section{INFORMACION DE CONTACTO DEL IRB}

$\mathrm{Si}$ usted desea hablar con alguien acerca de sus derechos como participante en este estudio o acerca de temas éticos relacionados con el estudio, puede contactar a Dr. Patricia Price, Directora del Comité de Revisión Institucional de la FIU (IRB) al 305-348-261 8 o 305-348-2494. 


\section{FIU}

\section{ACUERDO DEL PARTICIPANTE}

Yo he leído la información en esta forma de consentimiento y estoy de acuerdo en participar en el estudio. Yo he tenido la opción de hacer preguntas acerca del estudio y han sido respondidas. Yo entiendo que tengo derecho a una copia de esta forma después de haberla leído y firmado.

Firma del Participante

Fecha

Nombre del Participante

Firma de la Persona que Obtiene el Consentimiento

Fecha 
Appendix 2: Sun Exposure Questionnaire 
Sun Exposure Questionnaire. Visit:_____ Date:_______ ID\#:

Please check the boxes that best describes your behavior

\begin{tabular}{|c|c|c|c|c|c|c|c|}
\hline & \multicolumn{3}{|c|}{ Time Outdoors } & \multicolumn{4}{|c|}{ Amount of Skin Exposed } \\
\hline & $<5 \min$ & $5-30 \mathrm{~min}$ & $>30 \mathrm{~min}$ & $\begin{array}{l}\text { Hands } \\
\text { and face }\end{array}$ & $\begin{array}{l}\text { Hands, } \\
\text { face, } \\
\text { and } \\
\text { arms }\end{array}$ & $\begin{array}{l}\text { Hands } \\
\text { face, and } \\
\text { legs }\end{array}$ & $\begin{array}{l}\text { Bathing } \\
\text { Suit }\end{array}$ \\
\hline Monday & & & & & & & \\
\hline Tuesday & & & & & & & \\
\hline Wednesc & & & & & & & \\
\hline Thursday & & & & & & & \\
\hline Friday & & & & & & & \\
\hline Saturday & & & & & & & \\
\hline Sunday & & & & & & & \\
\hline
\end{tabular}


Appendix 3: Short Food Frequency Questionnaire 
This form asks about your usual eating habits over the past year.

First: For each food listed, mark the column to show how often, on average, you ate the food during the past year. Please BE CAREFUL which column you put your answer in.

Second: Mark whether your usual serving size is small, medium, or large. Please DO NOT OMIT serving size.

Additional Comments:

Please DO NOT SKIP any foods, if you never eat a food, mark "Never or less that once per month."

A small serving is one-half the medium serving size shown or less.

A large serving is about one-and-a-half times the medium serving size shown or more.

Sample: This person ate a medium serving of rice about twice per month and never ate squash.

\begin{tabular}{|c|c|c|c|c|c|c|c|c|c|c|c|c|c|}
\hline \multirow[b]{3}{*}{ Type of food } & \multicolumn{8}{|c|}{ How Often } & \multicolumn{5}{|c|}{ How Much } \\
\hline & $\begin{array}{c}\text { Never or } \\
\text { Less than } \\
\text { Once }\end{array}$ & 1 per & $2.3 \mathrm{per}$ & $1 \mathrm{per}$ & 2 per & 34 per & $5.6 \mathrm{per}$ & $1 \mathrm{per}$ & $2+$ per & Medium & & $\begin{array}{l}\text { Your } \\
\text { ervin } \\
\text { Size }\end{array}$ & \\
\hline & per Month & Month & Month & Week & Week & Week & Week & Day & Day & Serving & $s$ & $M$ & L \\
\hline Rice & & & $x$ & & & & & & & $3 / 4$ cup & & $x$ & \\
\hline $\begin{array}{l}\text { Winter squash, } \\
\text { baked squash }\end{array}$ & $x$ & & & & & & & & & $1 / 2$ cup & & & \\
\hline
\end{tabular}

\begin{tabular}{|c|c|c|c|c|c|c|c|c|c|c|c|c|c|}
\hline \multirow[b]{2}{*}{ Type of Beverage } & $\begin{array}{l}\text { Never or } \\
\text { Less than } \\
\text { Once }\end{array}$ & 1 per & $2-3$ per & 1 per & 2 per & 34 per & $5-6$ per & 1 per & $2.3 \mathrm{per}$ & Medium & ow M & $\begin{array}{l}\text { h } \\
\text { Your } \\
\text { Serving } \\
\text { Size }\end{array}$ & \\
\hline & & Month & Month & Week & Week & Week & Week & Day & Day & Serving & $s$ & M & L \\
\hline $\begin{array}{l}\text { Whole milk and } \\
\text { beverages with } \\
\text { whole milk (not } \\
\text { including cereals) }\end{array}$ & & & & & & & & & & 802 glass & & & \\
\hline $\begin{array}{l}2 \% \text { milk and } \\
\text { beverage } \\
\text { With } 2 \% \text { milk (not } \\
\text { including cereal) }\end{array}$ & & & & & & & & & & 802 glass & & & \\
\hline $\begin{array}{l}\text { Skim milk, 1\% milk } \\
\text { or buttermilk (not } \\
\text { Including on cereal) }\end{array}$ & & & & & & & & & & $80 z$ glass & & & \\
\hline Milk in coffee or tea & & & & & & & & & & 1 tablespoon & & & \\
\hline
\end{tabular}




\begin{tabular}{|c|c|c|c|c|c|c|c|c|c|c|c|c|c|}
\hline Type of food & $\begin{array}{l}\text { Never or } \\
\text { Less than } \\
\text { Once } \\
\text { per Month }\end{array}$ & $\begin{array}{l}1 \text { per } \\
\text { Month }\end{array}$ & $\begin{array}{l}2-3 \text { per } \\
\text { Month }\end{array}$ & $\begin{array}{l}1 \text { per } \\
\text { Week }\end{array}$ & $\begin{array}{l}2 \text { per } \\
\text { Week }\end{array}$ & $\begin{array}{l}3-4 \text { per } \\
\text { Week }\end{array}$ & $\begin{array}{l}\text { 5-6 per } \\
\text { Week }\end{array}$ & $\begin{array}{l}1 \text { per } \\
\text { Day }\end{array}$ & $\begin{array}{c}2+\text { per } \\
\text { Day }\end{array}$ & $\begin{array}{l}\text { Medium } \\
\text { Serving }\end{array}$ & ow & $\begin{array}{l}\text { Your } \\
\text { Yorvin } \\
\text { Size } \\
\text { M }\end{array}$ & L \\
\hline Broccoli & & & & & & & & & & $1 / 2$ cup & & & \\
\hline $\begin{array}{l}\text { Mustard greens, } \\
\text { turnip greens, } \\
\text { collard greens }\end{array}$ & & & & & & & & & & $1 / 2$ cup & & & \\
\hline $\begin{array}{l}\text { Spaghetti, } \\
\text { lasagna, other } \\
\text { pasta with } \\
\text { tomato sauce }\end{array}$ & & & & & & & & & & 1 cup & & & \\
\hline $\begin{array}{l}\text { Mixed dishes with } \\
\text { cheese (such as } \\
\text { macaroni and } \\
\text { cheese) }\end{array}$ & & & & & & & & & & 1 cup & & & \\
\hline $\begin{array}{l}\text { Cheese and } \\
\text { cheese spreads } \\
\text { (including on } \\
\text { sandwiches, } \\
\text { burgers, tacos, } \\
\text { and nachos; } \\
\text { not including } \\
\text { cottage cheese) }\end{array}$ & & & & & & & & & & $\begin{array}{c}2 \text { slices } \\
\text { or } \\
2 \mathrm{oz}\end{array}$ & & & \\
\hline $\begin{array}{l}\text { White bread } \\
\text { (including } \\
\text { sandwiches, } \\
\text { bagels, burger } \\
\text { rolls, French or } \\
\text { Italian bread) }\end{array}$ & & & & & & & & & & 2 slices & & & \\
\hline $\begin{array}{l}\text { Dark bread, } \\
\text { such as wheat, } \\
\text { re, pumper- } \\
\text { nickel fincluding } \\
\text { sandwiches) }\end{array}$ & & & & & & & & & & 2 slices & & & \\
\hline $\begin{array}{l}\text { Biscuits or } \\
\text { muffins } \\
\text { (including } \\
\text { fast foods) }\end{array}$ & & & & & & & & & & $\begin{array}{c}1 \text { medium } \\
\text { piece }\end{array}$ & & & \\
\hline lce cream & & & & & & & & & & $\begin{array}{c}1 \text { scoop or } \\
1 / 2 \text { cup }\end{array}$ & & & \\
\hline $\begin{array}{l}\text { Yogurt, frozen } \\
\text { yogurt }\end{array}$ & & & & & & & & & & 1 cup & & & \\
\hline Milk on cereal & & & & & & & & & & 1/2 cup & & & \\
\hline
\end{tabular}




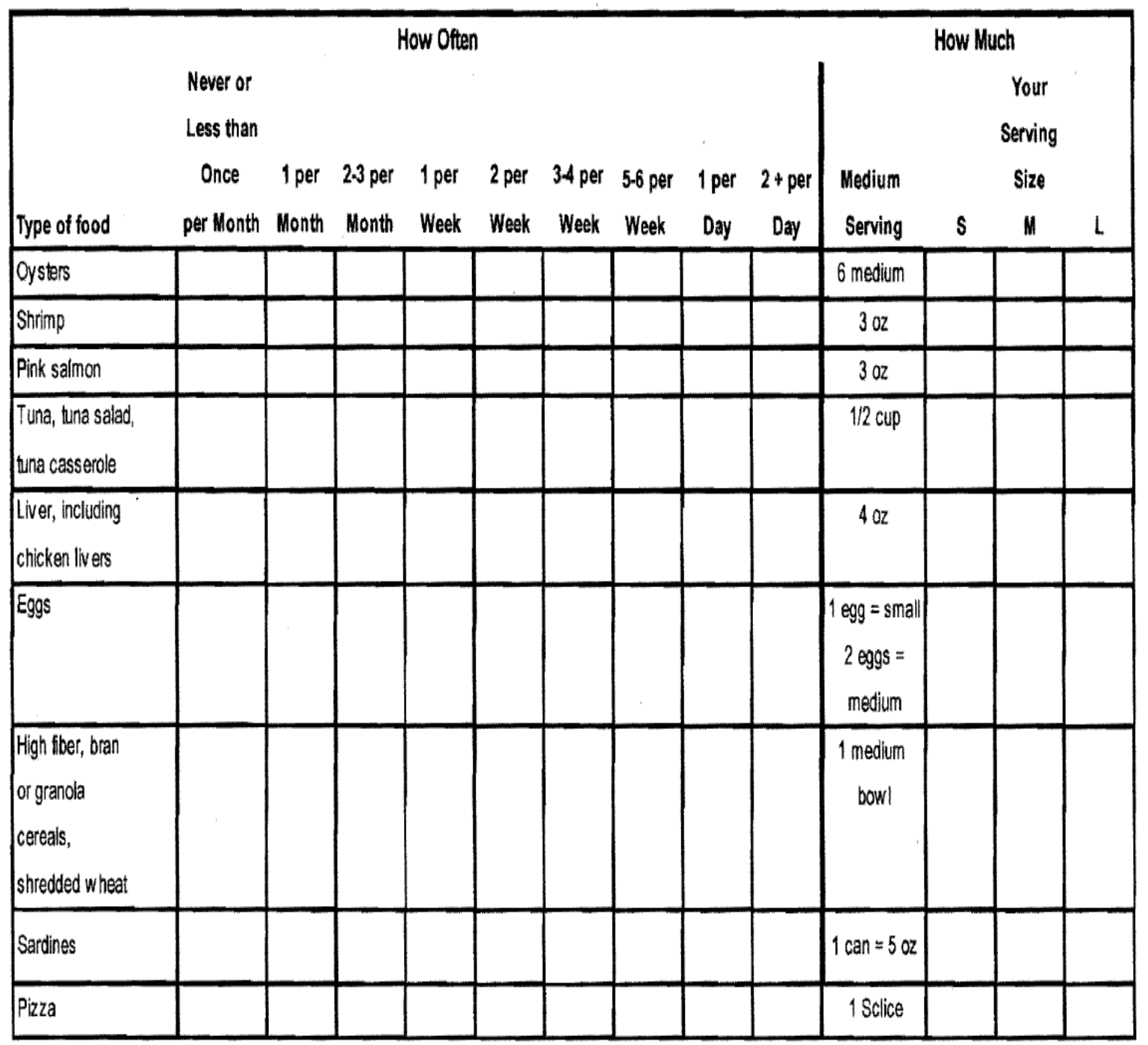


Appendix 4: Skin Color and Anthropometrics Control Form 
ID \#.

Date:

\section{Anthropometrics, Blood Pressure \& skin color (screening/baseline/3months/6months)}

Weight: ..............pounds

Height: inches

BMI:

Waist circumference 1 ...ms

Waist circumference 2 cms

Average Waist Circumference: .cms

Blood Pressure 1:

Systolic $\mathrm{mm} \mathrm{Hg}$

Diastolic. $\mathrm{mm} \mathrm{Hg}$

\section{Blood Pressure 2:}

Systolic $\mathrm{mm} \mathrm{Hg}$

Diastolic $\mathrm{mm} \mathrm{Hg}$

\section{Average Blood Pressures:}

Average Systolic: $\mathrm{mm} \mathrm{Hg}$

Average Diastolic: $\mathrm{mm} \mathrm{Hg}$

\section{$\underline{\text { Skin color 1: }}$}

Forearm:

Upper arm:

Stomach:.

Skin color 2:

Forearm:

Upper arm:

Stomach:

\section{Average Skin Color:}

Forearm:.......................

Upper arm:

Stomach:

Average difference: 
Appendix 5: Demographic Questionnaire 
Please answer each of the questions by filling in the blanks with the correct answer or by choosing the single best answer.

Q1. Please indicate your age in years

Q2. Male $\square_{1} \quad$ Female $\square_{2}$

Q3. How much schooling did you have?

$\square$ 1. $\quad 8^{\text {th }}$ grade or less

$\square$ 2. Some high school

$\square$ 3. High school diploma or GED

$\square$ 4. At least some college

Q4. Do you use tobacco? No $\square_{1} \quad$ Yes $\square_{2}$

Q4a. Please indicate your tobacco use

$\square$. Cigarettes $\quad \square$ Cigar $\square$ 3 Pipe $\square_{4}$ Chewing

Q4b. How many cigarettes do you smoke each day on average?

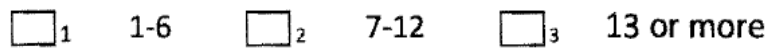

Q5. How many drinks of alcohol ( $12 \mathrm{oz}$ beer, $5 \mathrm{oz}$ wine, 1 oz hard liquor) do you drink each week on average?
$\square$ None
$\square 2 \quad 1-2$
$\square 3 \quad 3-7$
$\square_{4} \quad$ 8-14 $\quad \square_{5} \quad 15-21$
$\square 6 \quad 22$ or more

Q6. Please indicate any of the following types of medications that you take

$\square 1$ Cholesterol-lowering

$\square 2$ Blood-sugar regulating (not including insulin)

$\square 3$ Hypertensive medication

$\square 4$ Anti-depressants

$\square$ s Pain killers

$\square 6 \quad$ Aspirin

Q7. What year were you first diagnosed with diabetes? $19 \ldots . . . . . . . . . . .$.

Q8. What is your marital status? $\square 1$ Married $\square_{2}$ Single $\square_{3}$ Divorced $\square 4$ Widowed

Q9. Do you currently have a job? $\square_{1}$ No $\quad \square_{2}$ Yes $\square_{3}$ I am disabled

Q10. How many years have you been living in the US?

Q11. Do you currently have health insurance? $\square_{1}$ No $\square 2$ Yes 
Appendix 6: Compliance and Adverse Events Form 
3 months visit date:

Baseline visit date:

Type of visit: 3 months

No of days between visits (a):

PILL COUNT

Pills dispensed during last visit: $\quad$ Number of pills taken (b):

Adherence b/a:

On time $\square \quad$ Late $\square \quad$ Compliant: Yes/ No

Adverse Events Log

Date of event:

Date reported to IRB:

Notes about the event:

Remarks/ Comments about the visit

Hospitalization: Yes/No Surgery: Yes/ No

6TH MONTH VISIT

6 months visit date:

3 months visit date:

Type of visit: 6 months

No of days between visits (a):

PILL COUNT

Pills dispensed during last visit: $\quad$ Number of pills taken (b):

Adherence b/a:

On time $\square \quad$ Late $\square \quad$ Compliant: Yes/ No

Adverse Events Log

Date of event:

Date reported to IRB:

Notes about the event:

Remarks/ Comments about the visit

Hospitalization: Yes/No

Surgery: Yes/ No

Investigator's signature

Investigator's signature 
VITA

\section{JOEL EXEBIO}

Born, Trujillo, La Libertad, Peru

2000

B.A., Agro-Industrial Engineering

Universidad Nacional de Trujillo

Trujillo, Peru.

2004

Latin-American and Caribbean Scholarship

Florida International University

Miami, Florida.

2010

M.S., Dietetics and Nutrition

Florida International University

Miami, Florida.

2010-2012

Teaching Assistant

Florida International University

Miami, Florida.

2012

Nominated to the Best Novel Hispanic Scientist Award

Bimbo Pan-American Nutrition

Mexico City, Mexico.

2012

Editor of the Journal Scientia Agropecuaria

Universidad Nacional de Trujillo

Trujillo, Peru.

2013

Minority Opportunities in Biomedical Research Fellowship Florida International University

Miami, Florida

2013-2015

Doctoral Candidate

Florida International University

Miami, Florida

\section{PUBLICATIONS}

Ajabshir S, Exebio JC, Zarini GG, Nayer A, McLean M, Shaban L, et al.. Skin Color and Self-reported Sun Exposure Scores are Associated with Serum 25-Hydroxyvitamin D Concentrations in a Multi-ethnic Population Living in South Florida. Br J Med Med Res, 2014;4(34):5312-5323. 
Cheema AK, Zarini GG, Exebio J, Ajabshir S, Shaban L, Antwi J, et al. Ethnic Differences in Insulin Resistance, Adiponectin Levels and Abdominal Obesity: Haitian Americans and African Americans, with and without Type 2 Diabetes Mellitus. Br J Med Med Res, 2014;4(26):4455-4469.

Exebio JC, Ajabshir S, Zarini GG, Vaccaro J, Huffman FG. Use of Homeostatic Model Assessment Indexes for the Identification of Metabolic Syndrome and Insulin Resistance among Cuban-Americans: A Cross Sectional Study. Br J Med Med Res, 2014;4(29):4824-4833.

Exebio JC, Zarini GG, Ajabshir S, Antwi J, Huffman FG. Validation of a Sun Exposure Questionnaire among Subjects with Type 2 Diabetes Residing in South Florida. J Immigr Minor Health, 28 January, 2015. doi 10.1007/S10903-015-0163-7.

Exebio JC, Zarini GG, Vaccaro JA, Exebio C, Huffman FG. Use of hemoglobin A1C to detect Haitian-Americans with undiagnosed Type 2 diabetes. Arq Bras Endocrinol Metabol. 2012;56(7):449-55.

Exebio JC, Zarini GG, Exebio C, Huffman FG. Healthy Eating Index scores associated with symptoms of depression in Cuban-Americans with and without type 2 diabetes: a cross sectional study. Journal of Nutrition and Metabolism. 2011;398324.

doi:10.1155/2011/398324.

Huffman FG, Exebio JC, Vaccaro JA, Zarini GG, Dixon Z. Effect of Medical Advice for Diet on Diabetes Self-Management and Glycemic Control for Haitian and African Americans with Type 2 Diabetes. Food and Nutrition Sciences. 2013;4(11):1094-1101.

Huffman FG, Vallasciani M, Vaccaro JA, Exebio JC, Zarini GG, Nayer A, et al. The association of depression and perceived stress with beta cell function between African and Haitian Americans with and without type 2 diabetes. Journal of Diabetes Mellitus, 2013;3(4):236-243.

Huffman FG, Vaccaro JA, Ajabshir S, Zarini GG, Exebio J, Dixon Z. Perceived stress and self-rated health of Haitian and African Americans with and without Type 2 diabetes. J Res Med Sci. 2013;18(3):198-204.

Huffman FG, Vaccaro JA, Exebio JC, Abajshir S, Zarini GG, Shaban LH. Relationship of omega-3 fatty acids on C-reactive protein and homocysteine in Haitian and African Americans with and without type 2 diabetes. Journal of Nutrition and Food Sciences, 2013;3(179). doi:10.4172/255-9600.1000180.

Huffman FG, Vaccaro JA, Exebio JC, Zarini GG, Katz T, Dixon Z. Television watching, diet quality, and physical activity and diabetes among three ethnicities in the United States. J Environ Public Health. 2012:191465. doi: 10.1155/2012/191465. 